\title{
PharmacoEconomics \\ Utility decrements associated with adult overweight and obesity in Australia: a systematic review and meta-analysis \\ --Manuscript Draft--
}

\begin{tabular}{|c|c|c|}
\hline Manuscript Number: & \multicolumn{2}{|l|}{ PECA-D-20-00351R1 } \\
\hline Full Title: & \multicolumn{2}{|c|}{$\begin{array}{l}\text { Utility decrements associated with adult overweight and obesity in Australia: a } \\
\text { systematic review and meta-analysis }\end{array}$} \\
\hline Article Type: & \multicolumn{2}{|l|}{ Systematic Review } \\
\hline \multirow[t]{3}{*}{ Funding Information: } & $\begin{array}{l}\text { National Health and Medical Research } \\
\text { Council } \\
((\# 1169039)\end{array}$ & Miss Anagha Killedar \\
\hline & $\begin{array}{l}\text { National Health and Medical Research } \\
\text { Council } \\
\text { (APP1141392) }\end{array}$ & Dr Thomas Lung \\
\hline & $\begin{array}{l}\text { The Australian Prevention Partnership } \\
\text { Centre } \\
\text { (Post graduate Research scholarship) }\end{array}$ & Mr Joseph Carrello \\
\hline Abstract: & \multicolumn{2}{|c|}{$\begin{array}{l}\text { Purpose: To conduct a systematic review and meta-analysis of health state utility } \\
\text { decrements associated with overweight and obesity in adults } 18 \text { years and over, for } \\
\text { use in modelled economic evaluations in Australia. } \\
\text { Methods: A systematic review was conducted in nine databases to identify studies } \\
\text { that reported health state utility values by weight status. Random-effects meta-analysis } \\
\text { was used to synthesise average utility decrements (from healthy weight) associated } \\
\text { with overweight, all obesity and obesity classes } 1,2 \text { and } 3 \text {. Heterogeneity surrounding } \\
\text { utility decrements was assessed via sub-group analysis, random-effects meta- } \\
\text { regression and sensitivity analyses. } \\
\text { Results: Twelve studies were found for which data was used to synthesise utility } \\
\text { decrements, estimated as: overweight } 0.020(95 \% \mathrm{Cl}: 0.010,0.030) \text {, all obesity } 0.055 \\
(0.034,0.076) \text { and obesity class } 10.047(0.017,0.077) \text {, class } 20.072(0.028,0.116) \\
\text { and class } 30.084 \text { ( } 0.039,0.130) \text {. There was considerable heterogeneity in our results, } \\
\text { which could be accounted for by different ages and utility instruments used in the } \\
\text { contributing studies. } \\
\text { Conclusions: Our results demonstrate that elevated weight status is associated with } \\
\text { small but statistically significant reductions in utility compared with healthy weight, } \\
\text { which will result in reduced quality-adjusted life years when extrapolated across time } \\
\text { and used in economic evaluations. }\end{array}$} \\
\hline Corresponding Author: & \multicolumn{2}{|l|}{$\begin{array}{l}\text { Joseph Carrello, MPH, BSc(Physiotherapy) } \\
\text { University of Sydney } \\
\text { Camperdown, NSW AUSTRALIA }\end{array}$} \\
\hline \multicolumn{3}{|l|}{$\begin{array}{l}\text { Corresponding Author Secondary } \\
\text { Information: }\end{array}$} \\
\hline Corresponding Author's Institution: & \multicolumn{2}{|l|}{ University of Sydney } \\
\hline \multicolumn{3}{|l|}{$\begin{array}{l}\text { Corresponding Author's Secondary } \\
\text { Institution: }\end{array}$} \\
\hline First Author: & \multicolumn{2}{|l|}{ Joseph Carrello, MPH, BSc(Physiotherapy) } \\
\hline \multicolumn{3}{|l|}{ First Author Secondary Information: } \\
\hline \multirow[t]{6}{*}{ Order of Authors: } & \multicolumn{2}{|l|}{ Joseph Carrello, MPH, BSc(Physiotherapy) } \\
\hline & \multicolumn{2}{|l|}{ Alison Hayes } \\
\hline & \multicolumn{2}{|l|}{ Anagha Killedar } \\
\hline & \multicolumn{2}{|l|}{ Amy Von Huben } \\
\hline & \multicolumn{2}{|l|}{ Louise A Baur } \\
\hline & \multicolumn{2}{|l|}{ Stavros Petrou } \\
\hline
\end{tabular}


Order of Authors Secondary Information:

Author Comments:

Response to Reviewers:
NA

Comment

Reviewer \#2

2.1 The purpose of the manuscript was to identify utility decrements per BMI category that can be used in modelling. However, we know that interventions only have a limited impact on BMI. 2-4 BMI points. If we start with a BMI from 43-44 changes are big we stay in class 3 obesity also after treatment effect, so no gains that can be seen. So, what about intrapolation, to have a per BMI change in disutility? See Søltoft F, Hammer $\mathrm{M}$, Kragh $\mathrm{N}$. The association of body mass index and health-related quality of life in the general population: data from the 2003 Health Survey of England Qual Life Res (2009) 18:1293-1299

Response

We acknowledge the reviewer's comments on the benefits of disutility per BMI change, however we did not have sufficient data to complete a meta-analysis for this. Of the 12 studies found through our systematic review, only 2 studies presented utility values by BMI, $(1,2)$ with the remaining studies presenting values by weight categories only (reported on page 13 in the manuscript). We have added comments regarding this and the applicability of our results for economic modelling in the discussion (page 18). Changes to manuscript

Paragraph added to discussion page 18 "Another limitation relates to the practical applicability of our results for their intended use in economic modelling. Ideally our study results would present utility decrements per unit BMI, adjusted for age and sex and only using observations from MAUl's with Australian tariffs. However due to the relatively small number of studies found in our systematic review and because utility values were not presented uniformly across all studies, this was not possible.

Nevertheless, we believe our results still provide a valuable contribution to the literature and are an excellent source of health state utility values for overweight and obesity in an Australian population. We have explored the influence of age, sex and type of MAUI on our results within the limits of the available data as described above and would encourage those interested in using our findings to consider these supplementary results as part of their own sensitivity analysis."

\section{Comment}

2.2 What about differences in males and females? Other studies have shown clear differences.

Response

We would have liked to investigate the influence of sex on our results through metaregression, but this was not possible due to the small number of studies and the fact that this information was not available for each weight category in each study - see methods section, page 10. We have added further description of the studies found in our review by sex in the results (page 12) and have conducted sensitivity analyses, repeating the meta-analyses for each weight category but only including studies that present utility values by sex (see methods, page 11, results page 15 and supplementary figure 2 in appendix). Ultimately, it was difficult to draw any meaningful conclusions between our main results and those adjusted for sex given the difference in number of studies for each analysis (see discussion, page 17).

Changes to Manuscript

Description of studies added to results, page 12: “...the values reported in table 1 are for entire cohorts, with information on sex distribution for each weight category not reported. Six studies presented utility values by sex $(1,3-7)$, four studies presented utility values adjusting for sex (8-11), one study presented values from a female only cohort (12), while the remaining study did not present utility values by sex or adjust for $\operatorname{sex}(13)$ ".

Description of sensitivity analysis in methods, page 11: "Additionally, although there was insufficient data to include sex in our meta-regression as described above, we decided to explore its influence on utility values through sensitivity analysis, comparing meta-analysis results for each weight category using only observations from single sex cohorts."

Results of sensitivity analysis added on page 15: "Repeating the meta-analyses for each weight category using only studies that presented utility values by sex revealed 
no difference in utility decrements between sexes for overweight (Male $=-0.014(95 \%$ $\mathrm{Cl}-0.028,-0.001)$, Female $=-0.014(-0.021,-0.007))$, very minor differences for all obesity (Male $=-0.062(-0.119,-0.004)$, Female $=-0.060(-0.087,-0.033))$ and obesity class 2 (Male $=-0.045(-0.057,-0.032)$, Female $=-0.046(-0.055,-0.037))$, but increased decrements for females compared to males for obesity class 1 (Male $=-0.026(-0.038$, $0.015)$, Female $=-0.033(-0.041,-0.025))$ and class 3 (Male $=-0.053(-0.083,-0.022)$, Female $=-0.072(-0.084,-0.059)$ ) (See supplementary figure 2 in appendix)."

Difficulty in comparing sensitivity analysis to main results reported in the discussion, page 17: "Additional sensitivity analyses investigating only studies that presented utility values by sex were conducted (see supplementary figure 2 in appendix). Although we were unable to draw any meaningful conclusions on the influence of sex on our main results given the different numbers of studies used for each analysis, those using our results may consider using these supplementary findings if they require sex-adjusted utility values for economic modelling."

Comment

2.3 And what about the impact of CVD complications? Are we sure the disutilities are related $\mathrm{BMI}$ only, or can having more complications have led to differences between the groups?

Response

We excluded studies from our systematic review if 'the study sample was only from a specific clinical population with comorbid conditions (e.g. diabetes), as this would likely influence utility values (page 8). We agree with the reviewer that many subjects in our studies would likely have co-morbidities. However, the aim of this study was to capture the overall association between weight status and quality of life utilities, including the impact of co-morbidities related to higher weight status. Indeed, recommendations from ISPOR are that health state utility values should reflect both the condition of interest as well as comorbidities. (14)

Changes to manuscript Further description of studies that adjusted for co-morbidities in results, page 12: "Only six of our chosen studies presented utility values that adjusted for the presence of comorbidities. $(3,5,6,10,11,15) "$

Paragraph added to discussion pg 17: "There may be an argument that the presence of co-morbidities should be accounted for when investigating the disutility of increasing weight status. Indeed, six of our chosen studies presented utility values that adjusted for the presence of co-morbidities $(34,36,37,43-45)$. However, the aim of this study was to capture the overall association between weight status and quality of life utilities, including the impact of co-morbidities related to higher weight status. Our decision not to investigate the impact of co-morbidities on our results is further supported by ISPOR who recommend that health state utility values should reflect not only the condition of interest but co-morbidities as well. (6)"

\section{Comment}

2.4 And I spotted some errors:

Page 6 row 15: Professional Society for Health Economics and Outcomes Research (ISPOR) should be

International Society for Pharmaco Economics and Outcomes Research (ISPOR)

Response

Thanks to the reviewer for pointing out this error

Changes to Manuscript

Changes to the correct title have been made throughout the manuscript (pages 4, 6 , 19)

Comment

2.5 Page 13 row 43 please check whether all is correct (I think the - sign is missing for class 2and 3 ): The utility decrements ( $95 \%$ Confidence Intervals) were larger by 0.032 $(0.012,0.052)$ for overweight, $0.061(0.0088,0.11)$ for all obesity, $0.081(0.021,0.14)$ for obesity class $1,0.12(-0.21,-0.028)$ for obesity class 2 and $0.12(-0.21,-0.032)$ for obesity class 3 .

Response

Thanks to the reviewer for pointing out this error

Changes to manuscript

The edited text now reads as follows (pg 14):

"The utility decrements ( $95 \%$ Confidence Intervals) were larger by $0.032(0.012,0.052)$ 
for overweight, $0.061(0.0088,0.11)$ for all obesity, $0.081(0.021,0.14)$ for obesity class $1,0.12(0.028,0.21)$ for obesity class 2 and $0.12(0.032,0.21)$ for obesity class $3 . "$

\section{Reviewer \#3}

Comment

3.1 The main concern is that it is unclear whether the results from the meta-analysis are preferable to a robust single source for use in an economic evaluation due to study heterogeneity. For example, the authors acknowledge that age was an important factor but which was not accounted for in the meta-regression due to lack of data. Furthermore, it is unclear whether the utility decrements are only associated with weight status or whether there could be other variables influencing the utility decrements. Although the general population with overweight/obesity was the population of interest, people may have some comorbidities that are influencing their utility. Some further analysis or discussions around these issues would be helpful, i.e. on the robustness of these utility decrements for use in economic evaluations in obesity.

Response

Age- we would have liked to investigate the influence of age on the heterogeneity of our results, but this was not possible as studies presented mean age of the whole cohort (rather than mean ages for each weight category). See methods pg 10,11. On further investigation of the chosen studies, it was found 8 of the 12 studies presented utility values that adjusted for age. See results pg 12

Additionally, we investigated the influence of age through sensitivity analysis by exclusion of one study with a significantly older cohort- see methods pg 11, results pg 14.

Influence of comorbidities on results- Please see our response to Q2.3 above as we feel we adequately address the reviewer's questions there

Additionally, we have added justification for the robustness of our results in the discussion, page 16 .

Change to manuscript

Changes have been made to the manuscript as per Q2.1- Q2.3 above.

Sentence added to results pg 12: "The utility values reported in eight of the twelve studies adjusted for age $(33,34,36,38,40,41,43,44)$, while the remaining four studies did not. $(35,37,39,42)$."

Sentence added to discussion on page 16: "Our synthesised values are more robust than those used in these studies as they combine estimates from multiple sources, providing a more accurate assessment of the mean decrements and their associated uncertainties and are more generalisable in their use."

\section{Comment}

3.2 Page 12:

- The results from the meta-analysis are presented by type of utility measurement. It would be beneficial to see some explanation for why these numbers were not presented in the main text and abstract instead of the overall numbers?

Response

Our reasoning to present sub-group analysis by type of utility measurement in our forest plots is detailed in our methods, page 10. Our goal was to assess if there were any major differences by instrument, which we discuss on page 14 in the results section and the discussion on page 17 . Our decision to present the overall numbers as the main result of our meta-analysis, rather than the results from one particular instrument, are based on the small number of studies we found (12 in total) and the need for sufficient power to inform our results. Additionally, we have added to our discussion a suggestion for those considering using our results for economic modelling in Australia to use the sub-group analysis results for the AQoL only (Australian MAUI), as least for the purposes of a sensitivity analysis Changes to manuscript

Sentences added on page 17: "Additionally, most SF-6D studies use UK utility weights, which may account for some of the differences in utility values between instruments. Given the above, we would recommend those using our results for economic modelling in Australia consider at least using the sub-group analysis results for the AQoL as a sensitivity analysis." 
Comment

3.3 It is unclear whether the 22, 14 and 11 refer to number of observations: "Utility scores from varying samples within the 12 studies were used to arrive at these results, including 22 for an assessment of overweight status, 14 for an assessment of all obesity and 11 each for assessments of obesity classes 1/2/3." (page 12)

Response

We apologise for the lack of clarity. The values of 22, 14 and 11 refer to the number of observations from the 12 studies for each weight category.

Changes to manuscript

The text has been amended on page 13 to read as follows:

"Utility values from various samples within the 12 studies were used to arrive at these results, including 22 observations for overweight, 14 observations for all obesity and 11 observations for each of the obesity classes $1 / 2 / 3 . "$

\section{Comment}

3.4 Page 14, last paragraph, line 3: It would be helpful to see some discussion on why a meta-analysis has not been done before in this area.

Response

This is likely due to the field being an emerging area of research, with ISPOR's recommendations for such studies (as described in the introduction page 5/6) only released in 2014. A brief literature review of such studies for other conditions reveals the earliest publications dating from 2017. The literature review of health state utility values we reference did not conduct a meta-analysis but was from 2008 (before methods on how to conduct meta-analysis for health state utility values had been established),

\section{Changes to manuscript}

Sentence added to discussion page 15: "However, to our knowledge, no study yet has attempted a systematic review or meta-analysis, likely due to methods required to complete such studies being an emerging area of research."

\section{Comment}

3.5 Bottom of page 14: The text could benefit from a discussion on when your metaanalysis is appropriate to use and why it is stated that your meta-analysis is more robust. Are there any issues with using your meta-analysis results? Should the metaanalysis subgroups be considered instead of your overall results?

Response

Please see responses to Q2.1-Q2.3 and Q3.1 above as they address this question Changes to manuscript

Changes to manuscript as per Q2.1- Q2.3 above. Additionally, a sentence has been added to the discussion, page 16: "Our synthesised values are more robust than those used in these studies as they combine estimates from multiple sources, providing a more accurate assessment of the mean decrements and their associated uncertainties and are more generalisable in their use."

\section{Comment}

3.6 Discussion section:

- It would have been useful to see some discussion around the applicability in economic evaluations. To get a more accurate utility value for the model based economic evaluation the sourced utilities would ideally have to be age and sex adjusted to match the modelled cohort. This is especially important in this case because age and sex were not accounted for in the meta-regression.

Response

In response to the applicability of our results in economic evaluations, please see our response to $\mathrm{Q} 2.1$ above.

In response to utility values being age and sex adjusted, please see our responses to Q2.1 Q2.2 and Q 3.1 above

Changes to manuscript

Changes have been made to the manuscript as documented in the responses to $Q 2.1$, Q 2.2 and $Q 3.1$ above

\section{Comment}

3.7 Another area of uncertainty that is relevant for the discussion are the utility weights. Half of the included studies use UK tariffs instead of Australian tariffs. What are the implications of this in terms of the applicability of your meta-analysed utility decrements 
for decision models in Australia?

Response

We investigated the extent to which each type of instrument/tariff used influenced the heterogeneity of our meta-analysis results by conducting a random effects metaregression (pg10). This demonstrated that use of the AQoL (Australian tariffs) generated significantly greater decrements for all BMI categories when compared to the SF-6D (UK tariffs) (Table 2). We have added to our discussion by suggesting those using our results for economic modelling in Australia also use the utilities from the AQoL as a sensitivity analysis.

Changes to manuscript

Sentences added on page 17: "Additionally, most SF-6D studies use UK utility weights whereas the AQoL uses Australian utility weights, which may account for some of the differences in utility values between instruments. Given the above, we would recommend those using our results for economic modelling in Australia consider at least using the sub-group analysis results for the AQoL as a sensitivity analysis."

\section{Comment}

3.8 PRISMA diagram:

- Unclear what "Wrong comparator $(n=7)$ " means here.

- Is there a study missing? 99 full-texts and 86 excluded leaving 13 studies but there are 12 included studies.

Response

"Wrong comparator" is used to exclude studies that presented mean preference-based utility values for overweight or obesity but did not compare them to a baseline healthy weight value, hence we could not use them for the purposes of our meta-analysis.

Thanks to the reviewer for pointing out the error - correct number was 99 full-texts with 87 excluded.

Changes to manuscript

Updated inclusion/exclusion criteria in methods section, page 8:

"Studies were excluded if they used non-preference-based quality of life measures, if they presented mean utility values for overweight and/or obesity but did not compare them to healthy weight (hence we would not be able to calculate utility decrements for the purpose of our meta-analysis)..." In addition, changes have been made to the PRISMA diagram- "Wrong comparator" is now "No healthy weight comparator", number of excluded texts now 87 (additional study added to exclusion criteria "Not preference based utility measure" $n=64$ )

\section{Comment}

3.9 Figure 2: There are some positive utility differences between people with healthy weight and overweight. Is there a reason for this?

Response

The two values in question are from the same study, Kortt \& Dollery 2011 (5) (males $=0.0007 n=3703$, females $=0.0022 n=2807$ ). These values were derived from regression analysis adjusting for many variables, including co-morbidities and age; however, both were not significant $(p>0.05)$. The authors list some limitations in their study which may account for this, including self-reported height, weight and medical conditions and use of the SF-6D algorithm (validated for a UK cohort) in an Australian sample. However, these factors were not unique to this study alone. We believe this is a good example to demonstrate the benefits of using our results from a meta-analysis rather than taking values from a single study.

Changes to manuscript

No changes made.

Suggested Reviewers:

Richard Norman

Associate Professor, Curtin University of Technology

Richard.Norman@curtin.edu.au

Richard is a Health Economist with an ongoing interest in the economic evaluation of healthcare including the measurement and valuation of quality of life

Jonathan Karnon

Professor, Flinders University

jonathan.karnon@flinders.edu.au

Jonathan has particular expertise in the use of cost-effectiveness models to estimate costs and benefits over extended time horizons which is relevant to my paper 
Gang Chen

Associate Professor, Monash University

Gang.Chen@monash.edu

Expertise in Health Economics with interests in quality of life, has started to serve as an Associate Editor for the Quality of Life Research 


\section{SYDNEY}

Joseph Carrello BSc(Physiotherapy), MPH, current PhD student

School of Public Health, University of Sydney

Telephone: $\quad+61406484938$

Email: jcar6556@uni.sydney.edu.au

$20^{\text {th }}$ October 2020

Christopher I. Carswell

Timothy Wrightson

Editors-in-chief, PharmacoEconomics

Dear Mr Carswell and Mr Wrightson,

Please find attached our manuscript entitled: "Utility decrements associated with adult overweight and obesity in Australia: a systematic review and meta-analysis."

In this manuscript we conducted a systematic review in 9 databases (Scopus, PubMed, CINAHL, EMBASE, Web of Science, PsycINFO, EconLit, Cochrane Library of Reviews and Google Scholar) resulting in 12 studies in which data was extracted to synthesise health state utility decrements associated with overweight, all obesity and obesity class 1,2 and 3 weight categories. Heterogeneity of our results was explored thoroughly through sub-group analysis, random-effects meta-regression and sensitivity analysis using variables such as type of utility instrument used, mean age of included samples and year of data collection.

To our knowledge this is the first time that a systematic review and meta-analysis has provided utilities for weight status groups for any country. 'Best practice' advice from the Professional Society for Health Economics and Outcomes Research when selecting utility values for use in economic evaluations is that they should be sourced from systematic reviews and meta-analyses. Our results provide valuable information for economic evaluations of overweight and obesity prevention/interventions in Australia and should lead to greater consistency in modelled costeffectiveness studies. Additionally, we believe much can be learnt from our methodology in this paper and would encourage colleagues in other countries to apply the approach we have used to generate comparable figures in their settings. 
We confirm that the paper is original unpublished research, and that the authors have no conflicts of interest to declare.

We hope that you will be interested in reviewing the manuscript.

Yours sincerely,

Joseph Carrello 


\begin{tabular}{|c|c|c|}
\hline Comment & Response & Changes to manuscript \\
\hline \multicolumn{3}{|l|}{ Reviewer \#2 } \\
\hline $\begin{array}{l}\text { 2.1 The purpose of the } \\
\text { manuscript was to identify } \\
\text { utility decrements per BMI } \\
\text { category that can be used in } \\
\text { modelling. However, we know } \\
\text { that interventions only have a } \\
\text { limited impact on BMI. 2-4 BMI } \\
\text { points. If we start with a BMI } \\
\text { from } 43-44 \text { changes are big we } \\
\text { stay in class } 3 \text { obesity also after } \\
\text { treatment effect, so no gains } \\
\text { that can be seen. So, what } \\
\text { about intrapolation, to have a } \\
\text { per BMI change in disutility? } \\
\text { See Søltoft F, Hammer M, Kragh } \\
\text { N. The association of body mass } \\
\text { index and health-related quality } \\
\text { of life in the general population: } \\
\text { data from the } 2003 \text { Health } \\
\text { Survey of England Qual Life Res } \\
\text { (2009) } 18: 1293-1299\end{array}$ & $\begin{array}{l}\text { We acknowledge the } \\
\text { reviewer's comments on the } \\
\text { benefits of disutility per BMI } \\
\text { change, however we did not } \\
\text { have sufficient data to } \\
\text { complete a meta-analysis for } \\
\text { this. Of the } 12 \text { studies found } \\
\text { through our systematic review, } \\
\text { only } 2 \text { studies presented utility } \\
\text { values by BMI, (1,2) with the } \\
\text { remaining studies presenting } \\
\text { values by weight categories } \\
\text { only (reported on page } 13 \text { in } \\
\text { the manuscript). We have } \\
\text { added comments regarding } \\
\text { this and the applicability of our } \\
\text { results for economic modelling } \\
\text { in the discussion (page 18). }\end{array}$ & $\begin{array}{l}\text { Paragraph added to discussion } \\
\text { page } 18 \text { "Another limitation } \\
\text { relates to the practical } \\
\text { applicability of our results for } \\
\text { their intended use in economic } \\
\text { modelling. Ideally our study } \\
\text { results would present utility } \\
\text { decrements per unit BMI, } \\
\text { adjusted for age and sex and } \\
\text { only using observations from } \\
\text { MAUl's with Australian tariffs. } \\
\text { However due to the relatively } \\
\text { small number of studies found } \\
\text { in our systematic review and } \\
\text { because utility values were not } \\
\text { presented uniformly across all } \\
\text { studies, this was not possible. } \\
\text { Nevertheless, we believe our } \\
\text { results still provide a valuable } \\
\text { contribution to the literature } \\
\text { and are an excellent source of } \\
\text { health state utility values for } \\
\text { overweight and obesity in an } \\
\text { Australian population. We } \\
\text { have explored the influence of } \\
\text { age, sex and type of MAUl on } \\
\text { our results within the limits of } \\
\text { the available data as described } \\
\text { above and would encourage } \\
\text { those interested in using our } \\
\text { findings to consider these } \\
\text { supplementary results as part } \\
\text { of their own sensitivity } \\
\text { analysis." }\end{array}$ \\
\hline $\begin{array}{l}\text { 2.2 What about differences in } \\
\text { males and females? Other } \\
\text { studies have shown clear } \\
\text { differences. }\end{array}$ & $\begin{array}{l}\text { We would have liked to } \\
\text { investigate the influence of sex } \\
\text { on our results through meta- } \\
\text { regression, but this was not } \\
\text { possible due to the small } \\
\text { number of studies and the fact } \\
\text { that this information was not } \\
\text { available for each weight } \\
\text { category in each study - see } \\
\text { methods section, page } 10 \text {. We } \\
\text { have added further description } \\
\text { of the studies found in our } \\
\text { review by sex in the results } \\
\text { (page } 12 \text { ) and have conducted }\end{array}$ & $\begin{array}{l}\text { Description of studies added } \\
\text { to results, page } 12: \text { “...the } \\
\text { values reported in table } 1 \text { are } \\
\text { for entire cohorts, with } \\
\text { information on sex distribution } \\
\text { for each weight category not } \\
\text { reported. Six studies } \\
\text { presented utility values by sex } \\
\text { (1,3-7), four studies presented } \\
\text { utility values adjusting for sex } \\
\text { (8-11), one study presented } \\
\text { values from a female only } \\
\text { cohort (12), while the } \\
\text { remaining study did not }\end{array}$ \\
\hline
\end{tabular}




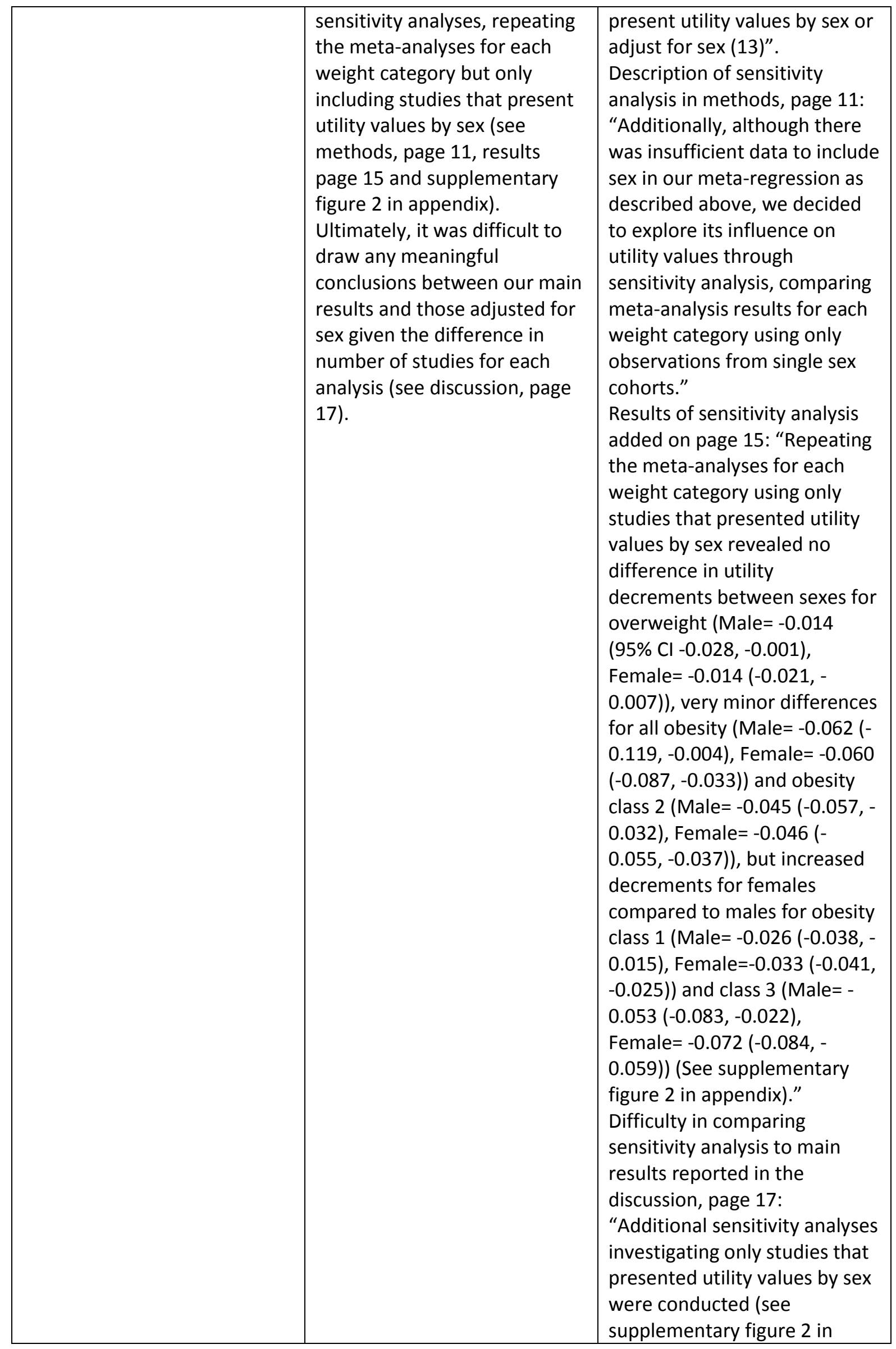




\begin{tabular}{|c|c|c|}
\hline & & $\begin{array}{l}\text { appendix). Although we were } \\
\text { unable to draw any meaningful } \\
\text { conclusions on the influence of } \\
\text { sex on our main results given } \\
\text { the different numbers of } \\
\text { studies used for each analysis, } \\
\text { those using our results may } \\
\text { consider using these } \\
\text { supplementary findings if they } \\
\text { require sex-adjusted utility } \\
\text { values for economic } \\
\text { modelling." }\end{array}$ \\
\hline $\begin{array}{l}\text { 2.3 And what about the impact } \\
\text { of CVD complications? Are we } \\
\text { sure the disutilities are related } \\
\text { BMI only, or can having more } \\
\text { complications have led to } \\
\text { differences between the groups? }\end{array}$ & $\begin{array}{l}\text { We excluded studies from our } \\
\text { systematic review if 'the study } \\
\text { sample was only from a } \\
\text { specific clinical population } \\
\text { with comorbid conditions (e.g. } \\
\text { diabetes), as this would likely } \\
\text { influence utility values (page } \\
\text { 8). We agree with the reviewer } \\
\text { that many subjects in our } \\
\text { studies would likely have co- } \\
\text { morbidities. However, the aim } \\
\text { of this study was to capture } \\
\text { the overall association } \\
\text { between weight status and } \\
\text { quality of life utilities, } \\
\text { including the impact of co- } \\
\text { morbidities related to higher } \\
\text { weight status. Indeed, } \\
\text { recommendations from ISPOR } \\
\text { are that health state utility } \\
\text { values should reflect both the } \\
\text { condition of interest as well as } \\
\text { comorbidities. (14) }\end{array}$ & $\begin{array}{l}\text { Further description of studies } \\
\text { that adjusted for co- } \\
\text { morbidities in results, page } 12 \text { : } \\
\text { "Only six of our chosen studies } \\
\text { presented utility values that } \\
\text { adjusted for the presence of } \\
\text { co-morbidities. } \\
\text { (3,5,6,10,11,15)" } \\
\text { Paragraph added to discussion } \\
\text { pg } 17: \text { "There may be an } \\
\text { argument that the presence of } \\
\text { co-morbidities should be } \\
\text { accounted for when } \\
\text { investigating the disutility of } \\
\text { increasing weight status. } \\
\text { Indeed, six of our chosen } \\
\text { studies presented utility values } \\
\text { that adjusted for the presence } \\
\text { of co-morbidities } \\
\text { (34,36,37,43-45). However, } \\
\text { the aim of this study was to } \\
\text { capture the overall association } \\
\text { between weight status and } \\
\text { quality of life utilities, } \\
\text { including the impact of co- } \\
\text { morbidities related to higher } \\
\text { weight status. Our decision not } \\
\text { to investigate the impact of co- } \\
\text { morbidities on our results is } \\
\text { further supported by ISPOR } \\
\text { who recommend that health } \\
\text { state utility values should } \\
\text { reflect not only the condition } \\
\text { of interest but co-morbidities } \\
\text { as well. (6)" }\end{array}$ \\
\hline $\begin{array}{l}\text { 2.4 And I spotted some errors: } \\
\text { Page } 6 \text { row 15: Professional } \\
\text { Society for Health Economics } \\
\text { and Outcomes Research } \\
\text { (ISPOR) should be } \\
\text { International Society for }\end{array}$ & $\begin{array}{l}\text { Thanks to the reviewer for } \\
\text { pointing out this error }\end{array}$ & $\begin{array}{l}\text { Changes to the correct title } \\
\text { have been made throughout } \\
\text { the manuscript (pages } 4,6,19 \text { ) }\end{array}$ \\
\hline
\end{tabular}




\begin{tabular}{|c|c|c|}
\hline $\begin{array}{l}\text { Pharmaco Economics and } \\
\text { Outcomes Research (ISPOR) }\end{array}$ & & \\
\hline $\begin{array}{l}2.5 \text { Page } 13 \text { row } 43 \text { please } \\
\text { check whether all is correct (I } \\
\text { think the }- \text { sign is missing for } \\
\text { class } 2 \text { and } 3) \text { : The utility } \\
\text { decrements }(95 \% \text { Confidence } \\
\text { Intervals) were larger by } 0.032 \\
\text { ( } 0.012,0.052) \text { for overweight, } \\
0.061(0.0088,0.11) \text { for all } \\
\text { obesity, } 0.081(0.021,0.14) \text { for } \\
\text { obesity class } 1,0.12(-0.21 \text { - } \\
0.028) \text { for obesity class } 2 \text { and } \\
0.12(-0.21,-0.032) \text { for obesity } \\
\text { class } 3 \text {. }\end{array}$ & $\begin{array}{l}\text { Thanks to the reviewer for } \\
\text { pointing out this error }\end{array}$ & $\begin{array}{l}\text { The edited text now reads as } \\
\text { follows (pg } 14) \text { : } \\
\text { "The utility decrements ( } 95 \% \\
\text { Confidence Intervals) were } \\
\text { larger by } 0.032(0.012,0.052) \\
\text { for overweight, } 0.061(0.0088 \text {, } \\
0.11) \text { for all obesity, } 0.081 \\
(0.021,0.14) \text { for obesity class } \\
1,0.12(0.028,0.21) \text { for } \\
\text { obesity class } 2 \text { and } 0.12(0.032 \text {, } \\
0.21) \text { for obesity class } 3 . "\end{array}$ \\
\hline Reviewer \#3 & & \\
\hline $\begin{array}{l}\text { 3.1 The main concern is that it } \\
\text { is unclear whether the results } \\
\text { from the meta-analysis are } \\
\text { preferable to a robust single } \\
\text { source for use in an economic } \\
\text { evaluation due to study } \\
\text { heterogeneity. For example, the } \\
\text { authors acknowledge that age } \\
\text { was an important factor but } \\
\text { which was not accounted for in } \\
\text { the meta-regression due to lack } \\
\text { of data. Furthermore, it is } \\
\text { unclear whether the utility } \\
\text { decrements are only associated } \\
\text { with weight status or whether } \\
\text { there could be other variables } \\
\text { influencing the utility } \\
\text { decrements. Although the } \\
\text { general population with } \\
\text { overweight/obesity was the } \\
\text { population of interest, people } \\
\text { may have some comorbidities } \\
\text { that are influencing their utility. } \\
\text { Some further analysis or } \\
\text { discussions around these issues } \\
\text { would be helpful, i.e. on the } \\
\text { robustness of these utility } \\
\text { decrements for use in economic } \\
\text { evaluations in obesity. }\end{array}$ & $\begin{array}{l}\text { Age- we would have liked to } \\
\text { investigate the influence of } \\
\text { age on the heterogeneity of } \\
\text { our results, but this was not } \\
\text { possible as studies presented } \\
\text { mean age of the whole cohort } \\
\text { (rather than mean ages for } \\
\text { each weight category). See } \\
\text { methods pg 10,11. On further } \\
\text { investigation of the chosen } \\
\text { studies, it was found } 8 \text { of the } \\
12 \text { studies presented utility } \\
\text { values that adjusted for age. } \\
\text { See results pg } 12 \\
\text { Additionally, we investigated } \\
\text { the influence of age through } \\
\text { sensitivity analysis by } \\
\text { exclusion of one study with a } \\
\text { significantly older cohort- see } \\
\text { methods pg } 11, \text { results pg } 14 . \\
\text { Influence of comorbidities on } \\
\text { results- Please see our } \\
\text { response to Q2.3 above as we } \\
\text { feel we adequately address } \\
\text { the reviewer's questions there } \\
\text { Additionally, we have added } \\
\text { justification for the robustness } \\
\text { of our results in the discussion, } \\
\text { page } 16 .\end{array}$ & $\begin{array}{l}\text { Changes have been made to } \\
\text { the manuscript as per Q2.1- } \\
\text { Q2.3 above. } \\
\text { Sentence added to results pg } \\
\text { 12: "The utility values reported } \\
\text { in eight of the twelve studies } \\
\text { adjusted for age } \\
(33,34,36,38,40,41,43,44) \text {, } \\
\text { while the remaining four } \\
\text { studies did not. (35,37,39,42)." } \\
\text { Sentence added to discussion } \\
\text { on page } 16: \text { "Our synthesised } \\
\text { values are more robust than } \\
\text { those used in these studies as } \\
\text { they combine estimates from } \\
\text { multiple sources, providing a } \\
\text { more accurate assessment of } \\
\text { the mean decrements and } \\
\text { their associated uncertainties } \\
\text { and are more generalisable in } \\
\text { their use." }\end{array}$ \\
\hline $\begin{array}{l}\text { 3.2 Page } 12 \text { : } \\
\text { - The results from the meta- } \\
\text { analysis are presented by type } \\
\text { of utility measurement. It would } \\
\text { be beneficial to see some } \\
\text { explanation for why these } \\
\text { numbers were not presented in } \\
\text { the main text and abstract }\end{array}$ & $\begin{array}{l}\text { Our reasoning to present sub- } \\
\text { group analysis by type of utility } \\
\text { measurement in our forest } \\
\text { plots is detailed in our } \\
\text { methods, page } 10 \text {. Our goal } \\
\text { was to assess if there were any }\end{array}$ & $\begin{array}{l}\text { Sentences added on page 17: } \\
\text { "Additionally, most SF-6D } \\
\text { studies use UK utility weights, } \\
\text { which may account for some } \\
\text { of the differences in utility } \\
\text { values between instruments. }\end{array}$ \\
\hline
\end{tabular}




\begin{tabular}{|c|c|c|}
\hline instead of the overall numbers? & $\begin{array}{l}\text { major differences by } \\
\text { instrument, which we discuss } \\
\text { on page } 14 \text { in the results } \\
\text { section and the discussion on } \\
\text { page } 17 . \text { Our decision to } \\
\text { present the overall numbers as } \\
\text { the main result of our meta- } \\
\text { analysis, rather than the } \\
\text { results from one particular } \\
\text { instrument, are based on the } \\
\text { small number of studies we } \\
\text { found (12 in total) and the } \\
\text { need for sufficient power to } \\
\text { inform our results. } \\
\text { Additionally, we have added to } \\
\text { our discussion a suggestion for } \\
\text { those considering using our } \\
\text { results for economic modelling } \\
\text { in Australia to use the sub- } \\
\text { group analysis results for the } \\
\text { AQoL only (Australian MAUI), } \\
\text { as least for the purposes of a } \\
\text { sensitivity analysis }\end{array}$ & $\begin{array}{l}\text { Given the above, we would } \\
\text { recommend those using our } \\
\text { results for economic modelling } \\
\text { in Australia consider at least } \\
\text { using the sub-group analysis } \\
\text { results for the AQoL as a } \\
\text { sensitivity analysis." }\end{array}$ \\
\hline $\begin{array}{l}3.3 \text { It is unclear whether the } \\
22,14 \text { and } 11 \text { refer to number } \\
\text { of observations: "Utility scores } \\
\text { from varying samples within the } \\
12 \text { studies were used to arrive } \\
\text { at these results, including } 22 \text { for } \\
\text { an assessment of overweight } \\
\text { status, } 14 \text { for an assessment of } \\
\text { all obesity and } 11 \text { each for } \\
\text { assessments of obesity classes } \\
1 / 2 / 3 . " \text { (page } 12 \text { ) }\end{array}$ & $\begin{array}{l}\text { We apologise for the lack of } \\
\text { clarity. The values of } 22,14 \\
\text { and } 11 \text { refer to the number of } \\
\text { observations from the } 12 \\
\text { studies for each weight } \\
\text { category. }\end{array}$ & $\begin{array}{l}\text { The text has been amended on } \\
\text { page } 13 \text { to read as follows: } \\
\text { "Utility values from various } \\
\text { samples within the } 12 \text { studies } \\
\text { were used to arrive at these } \\
\text { results, including } 22 \\
\text { observations for overweight, } \\
14 \text { observations for all obesity } \\
\text { and } 11 \text { observations for each } \\
\text { of the obesity classes } 1 / 2 / 3 . "\end{array}$ \\
\hline $\begin{array}{l}\text { 3.4 Page 14, last paragraph, } \\
\text { line 3: It would be helpful to } \\
\text { see some discussion on why a } \\
\text { meta-analysis has not been } \\
\text { done before in this area. }\end{array}$ & $\begin{array}{l}\text { This is likely due to the field } \\
\text { being an emerging area of } \\
\text { research, with ISPOR's } \\
\text { recommendations for such } \\
\text { studies (as described in the } \\
\text { introduction page 5/6) only } \\
\text { released in 2014. A brief } \\
\text { literature review of such } \\
\text { studies for other conditions } \\
\text { reveals the earliest } \\
\text { publications dating from } 2017 \text {. } \\
\text { The literature review of health } \\
\text { state utility values we } \\
\text { reference did not conduct a } \\
\text { meta-analysis but was from } \\
2008 \text { (before methods on how } \\
\text { to conduct meta-analysis for }\end{array}$ & $\begin{array}{l}\text { Sentence added to discussion } \\
\text { page 15: "However, to our } \\
\text { knowledge, no study yet has } \\
\text { attempted a systematic review } \\
\text { or meta-analysis, likely due to } \\
\text { methods required to complete } \\
\text { such studies being an } \\
\text { emerging area of research." }\end{array}$ \\
\hline
\end{tabular}




\begin{tabular}{|c|c|c|}
\hline & $\begin{array}{l}\text { health state utility values had } \\
\text { been established), }\end{array}$ & \\
\hline $\begin{array}{l}\text { 3.5 Bottom of page 14: The } \\
\text { text could benefit from a } \\
\text { discussion on when your meta- } \\
\text { analysis is appropriate to use } \\
\text { and why it is stated that your } \\
\text { meta-analysis is more robust. } \\
\text { Are there any issues with using } \\
\text { your meta-analysis results? } \\
\text { Should the meta-analysis } \\
\text { subgroups be considered } \\
\text { instead of your overall results? }\end{array}$ & $\begin{array}{l}\text { Please see responses to Q2.1- } \\
\text { Q2.3 and Q3.1 above as they } \\
\text { address this question }\end{array}$ & $\begin{array}{l}\text { Changes to manuscript as per } \\
\text { Q2.1- Q2.3 above. } \\
\text { Additionally, a sentence has } \\
\text { been added to the discussion, } \\
\text { page 16: "Our synthesised } \\
\text { values are more robust than } \\
\text { those used in these studies as } \\
\text { they combine estimates from } \\
\text { multiple sources, providing a } \\
\text { more accurate assessment of } \\
\text { the mean decrements and } \\
\text { their associated uncertainties } \\
\text { and are more generalisable in } \\
\text { their use." }\end{array}$ \\
\hline $\begin{array}{l}\text { 3.6 Discussion section: } \\
\text { - It would have been useful to } \\
\text { see some discussion around the } \\
\text { applicability in economic } \\
\text { evaluations. To get a more } \\
\text { accurate utility value for the } \\
\text { model based economic } \\
\text { evaluation the sourced utilities } \\
\text { would ideally have to be age } \\
\text { and sex adjusted to match the } \\
\text { modelled cohort. This is } \\
\text { especially important in this case } \\
\text { because age and sex were not } \\
\text { accounted for in the meta- } \\
\text { regression. }\end{array}$ & $\begin{array}{l}\text { In response to the applicability } \\
\text { of our results in economic } \\
\text { evaluations, please see our } \\
\text { response to Q } 2.1 \text { above. } \\
\text { In response to utility values } \\
\text { being age and sex adjusted, } \\
\text { please see our responses to } \\
\text { Q2.1 Q2.2 and Q } 3.1 \text { above }\end{array}$ & $\begin{array}{l}\text { Changes have been made to } \\
\text { the manuscript as documented } \\
\text { in the responses to Q } 2.1, Q \\
2.2 \text { and } Q 3.1 \text { above }\end{array}$ \\
\hline $\begin{array}{l}\text { 3.7 Another area of uncertainty } \\
\text { that is relevant for the } \\
\text { discussion are the utility } \\
\text { weights. Half of the included } \\
\text { studies use UK tariffs instead of } \\
\text { Australian tariffs. What are the } \\
\text { implications of this in terms of } \\
\text { the applicability of your meta- } \\
\text { analysed utility decrements for } \\
\text { decision models in Australia? }\end{array}$ & $\begin{array}{l}\text { We investigated the extent to } \\
\text { which each type of } \\
\text { instrument/tariff used } \\
\text { influenced the heterogeneity } \\
\text { of our meta-analysis results by } \\
\text { conducting a random effects } \\
\text { meta-regression (pg10). This } \\
\text { demonstrated that use of the } \\
\text { AQoL (Australian tariffs) } \\
\text { generated significantly greater } \\
\text { decrements for all BMI } \\
\text { categories when compared to } \\
\text { the SF-6D (UK tariffs) (Table 2). } \\
\text { We have added to our } \\
\text { discussion by suggesting those } \\
\text { using our results for economic } \\
\text { modelling in Australia also use } \\
\text { the utilities from the AQoL as a } \\
\text { sensitivity analysis. }\end{array}$ & $\begin{array}{l}\text { Sentences added on page } 17 \text { : } \\
\text { "Additionally, most SF-6D } \\
\text { studies use UK utility weights } \\
\text { whereas the AQoL uses } \\
\text { Australian utility weights, } \\
\text { which may account for some } \\
\text { of the differences in utility } \\
\text { values between instruments. } \\
\text { Given the above, we would } \\
\text { recommend those using our } \\
\text { results for economic modelling } \\
\text { in Australia consider at least } \\
\text { using the sub-group analysis } \\
\text { results for the AQoL as a } \\
\text { sensitivity analysis." }\end{array}$ \\
\hline $\begin{array}{l}\text { 3.8 PRISMA diagram: } \\
\text { - Unclear what "Wrong } \\
\text { comparator }(n=7) " \text { means here. } \\
\text { - Is there a study missing? } 99 \\
\text { full-texts and } 86 \text { excluded } \\
\text { leaving } 13 \text { studies but there are }\end{array}$ & $\begin{array}{l}\text { "Wrong comparator" is used } \\
\text { to exclude studies that } \\
\text { presented mean preference- } \\
\text { based utility values for } \\
\text { overweight or obesity but did }\end{array}$ & $\begin{array}{l}\text { Updated inclusion/exclusion } \\
\text { criteria in methods section, } \\
\text { page 8: } \\
\text { "Studies were excluded if they } \\
\text { used non-preference-based }\end{array}$ \\
\hline
\end{tabular}




\begin{tabular}{|c|c|c|}
\hline 12 included studies. & $\begin{array}{l}\text { not compare them to a } \\
\text { baseline healthy weight value, } \\
\text { hence we could not use them } \\
\text { for the purposes of our meta- } \\
\text { analysis. } \\
\text { Thanks to the reviewer for } \\
\text { pointing out the error - correct } \\
\text { number was } 99 \text { full-texts with } \\
87 \text { excluded. }\end{array}$ & $\begin{array}{l}\text { quality of life measures, if they } \\
\text { presented mean utility values } \\
\text { for overweight and/or obesity } \\
\text { but did not compare them to } \\
\text { healthy weight (hence we } \\
\text { would not be able to calculate } \\
\text { utility decrements for the } \\
\text { purpose of our meta- } \\
\text { analysis)..." In addition, } \\
\text { changes have been made to } \\
\text { the PRISMA diagram- "Wrong } \\
\text { comparator" is now "No } \\
\text { healthy weight comparator", } \\
\text { number of excluded texts now } \\
87 \text { (additional study added to } \\
\text { exclusion criteria "Not } \\
\text { preference based utility } \\
\text { measure" n=64) }\end{array}$ \\
\hline $\begin{array}{l}\text { 3.9 Figure 2: There are some } \\
\text { positive utility differences } \\
\text { between people with healthy } \\
\text { weight and overweight. Is there } \\
\text { a reason for this? }\end{array}$ & $\begin{array}{l}\text { The two values in question are } \\
\text { from the same study, Kortt \& } \\
\text { Dollery } 2011 \text { (5) (males } \\
=0.0007 n=3703 \text {, } \\
\text { females }=0.0022 \text { n=2807). } \\
\text { These values were derived } \\
\text { from regression analysis } \\
\text { adjusting for many variables, } \\
\text { including co-morbidities and } \\
\text { age; however, both were not } \\
\text { significant (p>0.05). The } \\
\text { authors list some limitations in } \\
\text { their study which may account } \\
\text { for this, including self-reported } \\
\text { height, weight and medical } \\
\text { conditions and use of the SF- } \\
6 D \text { algorithm (validated for a } \\
\text { UK cohort) in an Australian } \\
\text { sample. However, these } \\
\text { factors were not unique to this } \\
\text { study alone. We believe this is } \\
\text { a good example to } \\
\text { demonstrate the benefits of } \\
\text { using our results from a meta- } \\
\text { analysis rather than taking } \\
\text { values from a single study. }\end{array}$ & No changes made. \\
\hline
\end{tabular}




\section{References}

1. Kortt MA, Clarke PM. Estimating utility values for health states of overweight and obese individuals using the SF-36. Qual Life Res Int J Qual Life Asp Treat Care Rehabil.

2005;14(10):2177-85.

2. Wang L, Crawford JD, Reppermund S, Trollor J, Campbell L, Baune BT, et al. Body mass index and waist circumference predict health-related quality of life, but not satisfaction with life, in the elderly. Qual Life Res Int J Qual Life Asp Treat Care Rehabil. 2018;27(10):2653-65.

3. Baxter S, Sanderson K, Venn A, Otahal P, Palmer AJ. Construct validity of SF-6D health state utility values in an employed population. Qual Life Res. 2015 Apr;24(4):851-70.

4. Norman R, Church J, Berg B van den, Goodall S. Australian health-related quality of life population norms derived from the SF-6D. Aust N Z J Public Health. 2013;37(1):17-23.

5. Kortt MA, Dollery B. Association Between Body Mass Index and Health-Related Quality of Life Among an Australian Sample. Clin Ther. 2011 Oct 1;33(10):1466-74.

6. Heard C., Scuffham P.A., Ratcliffe J., Whitty J.A. The association between misperceptions around weight status and quality of life in adults in Australia. Health Qual Life Outcomes. 2017;15(1):53.

7. Hawthorne G, Korn S, Richardson J. Population norms for the AQoL derived from the 2007 Australian National Survey of Mental Health and Wellbeing. Aust N Z J Public Health. 2013 Feb;37(1):7-16.

8. Clemens S, Begum N, Harper C, Whitty JA, Scuffham PA. A comparison of EQ-5D-3L population norms in Queensland, Australia, estimated using utility value sets from Australia, the UK and USA. Qual Life Res. 2014 Oct;23(8):2375-81.

9. Le LK-D, Mihalopoulos C, Engel L, Touyz S, González-Chica DA, Stocks N, et al. Burden and health state utility values of eating disorders: results from a population-based survey. Psychol Med. 2019 Oct 31;1-8.

10. Khan MA, Richardson J, O'Brien P. The effect of obesity upon Health Related Quality of Life (HRQoL): A comparison of the AQoL-8D and SF-36 instruments. Farmeconomia Health Econ Ther Pathw. 2012 Jun 4;13(2):69-82.

11. Wang L, Crawford JD, Reppermund S, Trollor J, Campbell L, Baune BT, et al. Body mass index and waist circumference predict health-related quality of life, but not satisfaction with life, in the elderly. Qual Life Res. 2018 Oct 1;27(10):2653-65.

12. Kanesarajah J, Waller M, Whitty JA, Mishra GD. The relationship between SF-6D utility scores and lifestyle factors across three life stages: evidence from the Australian Longitudinal Study on Women's Health. Qual Life Res. 2017 Jun;26(6):1507-19.

13. Hawthorne G. Assessing Utility Where Short Measures Are Required: Development of the Short Assessment of Quality of Life-8 (AQoL-8) Instrument. Value Health. 2009 Sep 1;12(6):948-57.

14. Brazier J, Ara R, Azzabi I, Busschbach J, Chevrou-Séverac H, Crawford B, et al. Identification, Review, and Use of Health State Utilities in Cost-Effectiveness Models: An ISPOR Good Practices for Outcomes Research Task Force Report. Value Health. 2019 Mar;22(3):267-75. 
15. Kortt MA, Clarke PM. Estimating Utility Values for Health States of Overweight and Obese Individuals Using the SF-36. Qual Life Res. 2005 Dec 1;14(10):2177-85. 
Title: Utility decrements associated with adult overweight and obesity in Australia: a systematic review and meta-analysis

Running title: Utility decrements of adult overweight and obesity

Authors: Joseph Carrello ${ }^{1}$, Alison Hayes ${ }^{1}$, Anagha Killedar ${ }^{1}$, Amy Von Huben ${ }^{1}$, Louise A Baur $^{1,2}$, Stavros Petrou ${ }^{3}$, Thomas Lung ${ }^{1,4}$

\section{Affiliations:}

1. School of Public Health, Faculty of Medicine and Health, University of Sydney NSW, Australia

2. Children's Hospital Westmead Clinical School, Faculty of Medicine and Health, University of Sydney, NSW Australia

3. Nuffield Department of Primary Care Health Sciences, University of Oxford, Radcliffe Observatory Quarter, Oxford, United Kingdom

4. Health Economics and Process Evaluation, The George Institute for Global Health, University of New South Wales, Kensington, Australia

Corresponding author: Mr Joseph Carrello, School of Public Health, Edward Ford Building, University of Sydney, Camperdown, NSW, 2006

Email: jcar6556@uni.sydney.edu.au Phone: +61 406484938

Acknowledgements: We would like to thank Bernie Carr, Academic Liaison Librarian, Fisher Library, University of Sydney for her assistance with the literature search strategy.

Word Count: 4277 Number of pages: 20 Number of figures: 6 Number of tables: 3

Appendix: Pages: 5 Figures: 2 Tables: 0 


\section{Declarations}

Funding: Joseph Carrello is supported by a Postgraduate Research Scholarship from the Australian Prevention Partnership Centre (TAPPC); Anagha Killedar is supported by a NHMRC PhD scholarship (\#1169039); Amy Von Huben is supported by a Postgraduate scholarship in Health Economics-Patient Centred Care and Outcomes in Chronic Disease. Thomas Lung is supported by a NHMRC Early Career Fellowship (APP1141392) and the National Heart Foundation Postdoctoral Fellowship (award 101956).

Conflicts of interest: All authors declare they have no conflict of interest

Availability of data and material: The datasets analysed during the current study are available from the corresponding author on reasonable request.

Code availability: Not applicable

Authors contributions: JC, AH, LB, SP and TL were involved in concept and design of paper. JC, AH, AK, AvH and TL were involved in analysis and interpretation of data. JC, $\mathrm{AvH}$ and TL were involved in statistical analysis. JC, AH and AK were involved in drafting manuscript. All authors were involved in critical revision of paper. 


\begin{abstract}
Purpose: To conduct a systematic review and meta-analysis of health state utility decrements associated with overweight and obesity in adults 18 years and over, for use in modelled economic evaluations in Australia.

Methods: A systematic review was conducted in nine databases to identify studies that reported health state utility values by weight status. Random-effects meta-analysis was used to synthesise average utility decrements (from healthy weight) associated with overweight, all obesity and obesity classes 1,2 and 3. Heterogeneity surrounding utility decrements was assessed via sub-group analysis, random-effects meta-regression and sensitivity analyses.
\end{abstract}

Results: Twelve studies were found for which data was used to synthesise utility decrements, estimated as: overweight 0.020 (95\% CI: $0.010,0.030)$, all obesity $0.055(0.034,0.076)$ and obesity class $10.047(0.017,0.077)$, class $20.072(0.028,0.116)$ and class $30.084(0.039$, 0.130). There was considerable heterogeneity in our results, which could be accounted for by different ages and utility instruments used in the contributing studies.

Conclusions: Our results demonstrate that elevated weight status is associated with small but statistically significant reductions in utility compared with healthy weight, which will result in reduced quality-adjusted life years when extrapolated across time and used in economic evaluations. 


\section{Key points for decision makers}

I. Health state utility values of overweight and obesity are used to calculate quality adjusted life years (QALYs) for modelled economic evaluations of interventions for these conditions. To date, these values have been sourced in the literature from individual studies, which is problematic as use of different samples, valuation protocols and estimation techniques can result in different utility values for the same health state.

II. This study is, to our knowledge, the first systematic review and meta-analysis of health state utility decrements associated with overweight and obesity in Australian adults.

III. Based on recommendations from the International Society for Pharmacoeconomics and Outcomes Research (ISPOR), we suggest our results be used as 'best evidence' utility inputs by anyone undertaking modelled economic evaluations in this field in Australia, including researchers, analysts and reviewers amongst others. 


\section{Introduction}

Overweight and obesity are terms given to excess body weight, defined by a body mass index (BMI) between $25-29.9 \mathrm{~kg} / \mathrm{m}^{2}$ for overweight and $30 \mathrm{~kg} / \mathrm{m}^{2}$ or greater for obesity (1). They represent major public health concern with their prevalence doubling in more than 70 countries since 1980 (2), affecting 52\% of adults globally in 2016 (1). It is a risk factor for many health problems including cardiovascular disease, diabetes, musculoskeletal disorders and several cancers (3). High BMI contributes to the global burden of disease, linked to 4.72 million deaths around the world in 2017 (4) and accounting for 7\% of deaths from any cause in 2015 (2).

Despite the enormity of the problem, investment in prevention and treatment of overweight and obesity remains a challenge. With increasing demand for scarce healthcare resources, decisions around resource allocation for competing interventions should be informed by evidence of their impacts on both costs and health outcomes (5). The quality-adjusted life year (QALY) is an outcome measure that can capture the impact of an intervention on both an individual's morbidity and mortality (5). QALYs are calculated by adjusting years of life by health-related quality of life, where the latter is valued in terms of health state utilities (5). Health state utilities are valued using preference-based techniques and indexed onto a cardinal scale reflecting the value or desirability for health states, where 0 indicates death and 1 indicates full health (5). Utilities can be measured directly using techniques such as standard gamble (SG) or time trade off (TTO) or indirectly using multi-attribute utility instruments (MAUIs). With the latter, individuals complete a descriptive health status classification system and health states are valued using a preference-based scoring algorithm (or tariff) that reflects the preferences of the general population for health states (6). 
QALYs are often used by health economists for economic evaluations of interventions to inform policy decisions for healthcare resource allocation (6). Health state utilities can be expensive and challenging to directly estimate and are not always measured in clinical trials or observational studies, meaning researchers requiring them for economic models commonly resort to extracting values from the literature (6). However, this method has many problems as use of different samples, valuation protocols and estimation techniques can result in different utility values for the same health state (6). There is also the risk that researchers are accused of 'cherry picking' health utility values from single published studies that prejudice the cost-effectiveness outcome in a particular direction (6).

In 2014, the International Society for Pharmacoeconomics and Outcomes Research (ISPOR) established a Good Practices for Outcomes Research Taskforce to address this issue (6). The taskforce advocated the use of systematic reviews and meta-analysis of health utility values to generate data inputs for cost-effectiveness models. Additionally, it provided guidance for synthesising all available information from different studies, generating summary health state utility values for use in economic evaluation, generating ranges of values that can be used in sensitivity analysis, and weighting studies based on sample size (6).

Recently, Brown and colleagues conducted a systematic review and meta-analysis of health state utility values for overweight and obesity in children up to 18 years (7). To our knowledge, there has been only one systematic review of health state utility values related to overweight and obesity in adults; however, this was for adults with concurrent type 2 diabetes and a meta-analysis was not conducted (8). Additionally, there has been a literature review of the impact of body weight on patient utilities with and without type 2 diabetes (9).

The aim of this study was to conduct a systematic review and meta-analysis of health state utility decrements associated with overweight and obesity in adults aged 18 years and over, 
for use in economic evaluation in Australia. Utility decrements associated with differences in
weight status were chosen over mean utility values, as they are pertinent to economic
modelling by allowing analysts to calculate incremental changes in QALYs.

\section{Methods}

The systematic review was based on the Preferred Reporting Items for Systematic Reviews and Meta Analyses (PRISMA) guidelines (10) and registered with PROSPERO (\#CRD42020175538). The online software Covidence (11) was used for uploading search results, screening titles and abstracts and full text reports, completing data extraction, conducting quality assessments, resolving disagreements, and exporting data into Excel.

\section{Literature search}

A systematic search of the literature extending to April 2020 was conducted using the databases Scopus, PubMed, CINAHL, EMBASE, Web of Science, PsycINFO, EconLit, Cochrane Library of Reviews and Google Scholar. We used key terms developed in collaboration with a specialist librarian, based on recommendations from experts in health economics and obesity research (12) (see appendix supplementary figure 1). Bibliographies of articles that reported utility values were also examined for further literature that may have been missed in the initial searches.

Our search strategy captured all preference-based utility measurement approaches, which included multi-attribute instruments such as the EuroQol Five Dimensions (EQ-5D) (13), the Health Utilities Index (HUI2, 3) (14), the Short-Form Six-Dimension (SF-6D) (15), the Assessment of Quality of Life (AQoL- 4D -6D -8D) (16) and directly elicited utility values using techniques such as the TTO (17) or SG (18) approaches. Initially, we planned to consider studies for all industrialised nations. However, after our initial search it became apparent that this task would be too large to manage with our available resources (nearly 


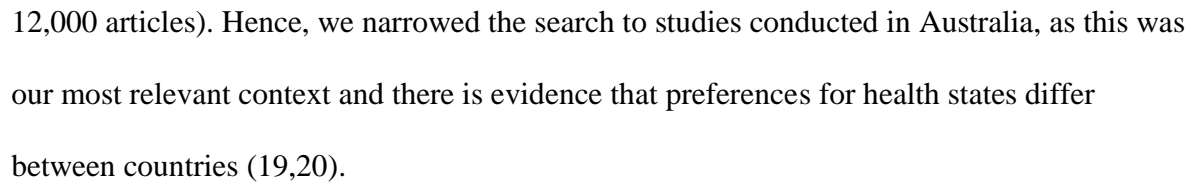

\section{Study eligibility}

Inclusion criteria were as follows:

- Studies published in English in peer reviewed journals

- Studies reporting primary data collection of utility values, with results reported by weight status

- Studies were conducted in an Australian population

- Study participants were 18 years or older

- Studies were published anytime until April 2020

Studies were excluded if they used non-preference-based quality of life measures, if they presented mean utility values for overweight and/or obesity but did not compare them to healthy weight (hence we would not be able to calculate utility decrements for the purpose of our meta-analysis), or if the study sample was a specifically targeted clinical population with comorbid conditions (e.g. diabetes) as this would likely influence utility values (21). For the latter point, it was inevitable that some participants in adult samples with overweight and obesity would have other co-morbidities, but our aim was to synthesise utility values for overweight and obesity in the general population, rather than specific clinical sub-groups.

Titles and abstracts and full texts of all articles were assessed against the inclusion criteria by two independent reviewers (JC and AK). Discrepancies around inclusion or exclusion were resolved by discussion and consensus between the reviewers, with two co-authors assisting this process for the full text screening (AH and TL). 


\section{Data extraction}

Where available, information on mean (standard error) utility decrements for weight status or body mass index (BMI) categories (compared to healthy weight) were extracted directly from each study by two independent reviewers (JC and AvH). Multiple observations from the same study were included if that study presented results stratified by sex, different cohorts, or different time-points. BMI is a person's weight in kilograms divided by the square of their height in meters (22). BMI categories presented in the studies included overweight (BMI 25$29.99 \mathrm{~kg} / \mathrm{m}^{2}$ ), all obesity (BMI $\geq 30 \mathrm{~kg} / \mathrm{m}^{2}$ ), and obesity class 1 (BMI $30-34.99 \mathrm{~kg} / \mathrm{m}^{2}$ ), class 2 (BMI $\left.35-39.99 \mathrm{~kg} / \mathrm{m}^{2}\right)$ and class $3\left(\mathrm{BMI} \geq 40 \mathrm{~kg} / \mathrm{m}^{2}\right)$ groups. Weight status information was not presented uniformly across all studies. For example, where studies reported utility decrements per unit of BMI, the values were converted into mean decrements from healthy weight for each weight category, using the number of BMI units from the midpoint of each weight category. Where studies reported mean utility values (not decrements) by weight category, we calculated decrements by subtracting the utility values for overweight or obesity categories from the utility value for healthy weight. Corresponding standard errors for each utility decrement were either extracted directly or calculated from standard deviations or $95 \%$ confidence intervals, following the recommendations of the Cochrane Handbook $(23,24)$. Study characteristics that could influence utility values such as mean age, sex, study type, setting/survey, calendar year of data collection, country source of preference indices and sample size were also extracted.

\section{Quality assessment}

For quality assessment of the selected articles, we used the ranking system for studies that derive health state utility values, proposed by Cooper and colleagues (25). This ranking system reflects the strength of evidence for health utility assessments on a scale from 1 (for 
direct utility assessment from the sample) to 6 (utility values developed from Delphi panels, expert opinion) (25). Two independent reviewers (JC and AvH) examined each article using the Cooper ranking system, then met and resolved any discrepancies.

\section{Data synthesis}

Random effects meta-analyses were conducted using the meta command in STATA (26), to combine the results for multiple studies into pooled estimates of utility decrements compared with healthy weight, for weight categories (overweight, all obesity and obesity classes 1,2 and 3). The Sidik-Jonkman estimation method was used due to the small number of identified studies (27). Results were presented as Forest plots, and tests for heterogeneity were performed using the I squared and Cochran's Q tests.

\section{Sub-group analysis}

There is evidence that health state utilities measured by MAUI's differ depending on which instrument is used, and hence could potentially be a source of heterogeneity in our results (28). To investigate this, we used subgroup analysis by MAUI to draw comparisons of the synthesised utility values elicited by each MAUI for each weight category (29).

\section{Meta-regression}

To investigate the extent to which type of MAUI used influenced heterogeneity of our metaanalysis results, we also conducted a random-effects meta-regression with MAUI as an explanatory variable using the metareg command in STATA $(26,30)$. Other covariates that could potentially influence heterogeneity of results included calendar year of data collection, proportion of males (based on evidence that males generally report higher mean health state utility values) (31) and mean age of participants (based on evidence that mean health state utility values decline with increasing age) (32). Although 11 of the 12 studies reported on all these variables (see Table 1), they did not present mean age and proportion of males by 
weight categories, hence there was insufficient data to include these covariates for analysis with meta-regression other than time of data collection.

\section{Sensitivity analyses}

Increasing age, with associated increased incidence of chronic diseases, is linked to worsening health-related quality of life (32). Although most studies used samples with similar mean ages (see table 1), one study included in the initial meta-analysis was based upon a significantly older cohort (Wang et al. 2018). Hence, additional meta-analyses were conducted to determine if there was any significant impact on synthesised utility decrements and heterogeneity when this study was removed. Additionally, although there was insufficient data to include sex in the meta-regression as described above, we explored its influence on utility values through sensitivity analysis, comparing meta-analysis results for each weight category using only observations from single sex cohorts.

\section{Results}

\section{Eligible studies and characteristics}

The literature searches identified 1239 articles of which 12 studies, published between 2005 and 2019, were included (see Figure 1). Methodological details of included studies can be seen in Table 1. Eleven studies involved cross-sectional analyses of health utility values in large samples across Australia, including the National Health survey (33), single waves of the Australian Household Income and Labour Dynamics (HILDA) surveys (34-36) and state health surveys in Queensland $(37,38)$ and South Australia $(37,39,40)$ amongst others. Kanesarajah et al 2017 (41) presented mean utility changes for different weight categories based on seven waves of longitudinal data for three separate cohorts of women (younger age (18-23 years), middle age (45-50 years) and older age (70-75 years) groups). Regarding utility elicitation methods, six studies used the SF-6D (33-36,40,41), five used the AQOL, 
AQOL-8D or AQOL-6D (37,39,42-44), and one study used the EQ-5D (with Australian population preference values) (38).

The mean age for participants in nine of the studies was between 41 and 49 years, the exceptions being the studies by Wang et al. 2018 (44) (two waves of data with average ages of 78.7 years and 80.1 years), Kanesarajah et al. 2017 (41) (three cohorts with average ages of 20.7 years, 47.6 years, and 72.6 years) and Clemens et al. 2014 (38) (no mean age reported). These mean ages were for the whole cohort, with information on the mean ages of subjects in each weight category not reported. The utility values reported in eight of the twelve studies adjusted for age $(33,34,36,38,40,41,43,44)$, while the remaining four studies did not. $(35,37,39,42)$.

Females were slightly more represented across the studies. However, the utility values reported in table 1 are for entire cohorts, with information on sex distribution for each weight category not reported. Six studies presented utility values by sex $(33-37,42)$, four studies presented utility values adjusting for sex $(38,40,43,44)$, one study presented utility values from a female only cohort (41), while the remaining study did not present utility values by sex or adjust for sex (39).

\section{Quality assessment}

Using the ranking system for quality of evidence of health state utility values proposed by Cooper and colleagues (on a scale of 1-6 ranging from strongest evidence to weakest) (25):

- Five studies scored a top ranking of 1 as they used indirect utility assessments from the patient sample, using a tool validated for the patient population (the studies using either the AQoL or the EQ-5D with Australian preference indices) $(37,38,42-44)$; 
- Six studies scored a ranking of 2 as they used indirect utility assessment from the patient sample, using a tool not validated for the patient population (the studies using the SF-6D with UK preference indices) $(33-36,40,41)$; and

- One study scored a ranking of 3 as it used values from an indirect utility assessment from a previous study, although the previous study had applied a tool validated for the patient population (39).

\section{Meta-analyses}

Figures 2-6 show the results of the random effects meta-analysis of health utility value decrements (from healthy weight) for overweight, all obesity, and obesity classes 1, 2 and 3. Synthesised values (95\% confidence intervals) for health utility decrements were as follows: overweight: $0.020(0.010,0.030)$ (Figure 2); all obesity: $0.055(0.034,0.076)$ (Figure 3); obesity class 1: $0.047(0.017,0.077)$ (Figure 4$)$; obesity class 2: $0.072(0.028,0.116)$ (Figure 5) and obesity class 3: $0.084(0.039,0.130)$ (Figure 6). Utility values were derived from a subset of the available 12 studies, including 22 observations for overweight, 14 observations for all obesity and 11 observations for each of the obesity classes 1-3. The different number of observations for each weight category was driven by differences in the presentation of utility decrements and numbers of multiple observations across included studies. For example, seven studies used a composite measure of obesity (36-42), whereas three studies divided the obesity group into different classes $(34,35,43)$ and two studies presented utility decrements per unit of BMI (allowing calculations for all weight categories including obesity classes) $(33,44)$. Also, nine studies analysed utility decrements by sex or using separate cohorts within the same study $(34-37,39,41,42,44,45)$. There was considerable betweenstudy heterogeneity in the utility values used for the meta-analysis, (overweight $Q=89.26 \mathrm{I}^{2}=$ 94.55, all obesity $\mathrm{Q}=213.48 \mathrm{I}^{2}=96.13$, obesity class $1 \mathrm{Q}=38.51 \mathrm{I}^{2}=97.86$, obesity class 2 $\mathrm{Q}=27.70 \mathrm{I}^{2}=97.49$, obesity class $\left.3 \mathrm{Q}=27.86 \mathrm{I}^{2}=94.80\right)(46)$. 


\section{Sub-group analyses}

The meta-analyses for each weight category were further analysed by type of MAUI used, as displayed in figures 2-6. As only one study used the EQ-5D (38), it was difficult to make comparisons; however, mean utility decrements were consistently lower for the SF-6D compared to the AQoL for all weight categories.

\section{Meta-regression}

Results of the random effects meta-regression for the covariates of MAUI and year of data collection can be seen in Table 2. This demonstrates that use of the AQoL utility instrument generated significantly greater decrements for all BMI categories when compared with the SF-6D. The utility decrements (95\% Confidence Intervals) were larger by $0.032(0.012$, $0.052)$ for overweight, $0.061(0.0088,0.11)$ for all obesity, $0.081(0.021,0.14)$ for obesity class $1,0.12(0.028,0.21)$ for obesity class 2 and $0.12(0.032,0.21)$ for obesity class 3. Between-study variance in utility decrements for these weight categories was reduced by half, suggesting that the type of MAUI used contributes a large part of the variance in utility decrements from our initial meta-analyses. There was no evidence that use of EQ-5D-3L compared to SF-6D or year of data collection significantly affected utility decrements.

\section{Sensitivity analyses}

Results from our sensitivity analyses exploring the impacts of age and sex on our utility decrements can be seen in Table 3. Following exclusion of observations from the considerably older cohorts used by Wang et al. 2018 (44), mean utility decrements were considerably reduced for all weight categories, whilst heterogeneity was also reduced. This indicates that the older age cohorts used in the study by Wang et al. 2018 (44) likely influenced health state utility values independent of weight status. 
Repeating the meta-analyses for each weight category using only studies that presented utility values by sex revealed very similar utility decrements by sex for overweight $($ Male $=-0.014$ $(95 \%$ CI $-0.028,-0.001)$, Female $=-0.014(-0.021,-0.007))$, all obesity $($ Male $=-0.062(-0.119$, $-0.004)$, Female $=-0.060(-0.087,-0.033))$ and obesity class $2($ Male $=-0.045(-0.057,-0.032)$, Female $=-0.046(-0.055,-0.037))$, but slightly larger decrements for females compared to males for obesity class $1($ Male $=-0.026(-0.038,-0.015)$, Female $=-0.033(-0.041,-0.025))$ and class $3($ Male $=-0.053(-0.083,-0.022)$, Female $=-0.072(-0.084,-0.059))($ See supplementary figure 2 in appendix).

\section{Discussion}

In this study, we carried out a systematic review and meta-analyses of health state utility decrements of overweight and obesity in Australian adults. The systematic review yielded 12 studies and the meta-analyses demonstrated that utility decrements increased with increasing weight status. The mean decrements $(95 \% \mathrm{CI})$, compared to adults at a healthy weight, were overweight: $0.020(0.010,0.030)$; all obesity: $0.055(0.034,0.076)$; obesity class 1 : $0.047(0.017,0.077)$; obesity class $2: 0.072(0.028,0.116)$ and obesity class $3: 0.084(0.039$, 0.130). Our meta-analysis results of increasing health state utility decrements associated with elevated weight status are consistent with decrements identified in a previous literature review (9). However, to our knowledge, no study yet has attempted a systematic review or meta-analysis, likely due to methods required to conduct such studies being an emerging area of research (6).

Several published economic evaluations of obesity preventive or treatment interventions in Australian adults have sourced utility values from various studies (47-51). However, these values were arbitrarily derived from various sources: one from a study included in our metaanalysis (45); AQoL measures from a single state health survey in South Australia (52); EQ- 


\begin{abstract}
5D measures from a single study in the UK (53) or within-trial measurements from international randomised controlled trials that included participants from Australia, Germany and the United Kingdom $(47,51)$. Our synthesised values are more robust than those used in these studies as they pool Australian-specific estimates from multiple sources, providing a more accurate assessment of the mean decrements and their associated uncertainties for Australian adults and are more generalisable in their use (6). Application of our estimates in these studies could have resulted in significant differences in QALYs when extrapolated over extended periods of time, potentially being the difference as to whether the proposed interventions were deemed to be 'cost-effective' or not and hence affected funding decisions.
\end{abstract} There was considerable heterogeneity in the studies used for the meta-analyses, which was investigated through meta-regression. This showed that use of the AQol produced significantly larger utility decrements than the SF-6D for all weight status groups, which is consistent with evidence from the literature suggesting that different MAUIs can produce different utility value estimates in the same population (54). This is because although MAUIs are constructed for the same purpose they cover different dimensions of health-related quality of life and differ in their valuation protocols (54). For example, the SF-6D is comprised of 6 dimensions with equal emphasis on physical and psychosocial health, whereas the AQoL has 35 items with a greater emphasis on psychosocial health (28). A study investigating differences in utility values between the AQoL and SF-6D found that $59 \%$ of the difference was attributable to the different descriptive systems of each instrument (the dimensions and response categories used to describe a person's health) (28). Additionally, most SF-6D studies used UK utility weights whereas the AQoL uses Australian utility weights, which may account for some of the differences in utility values between instruments found in our study. Given the above, we would recommend those using our results for economic 
modelling in Australia consider using the sub-group analysis results for the AQoL as a sensitivity analysis.

Exclusion of one study with significantly older cohorts (44) through a sensitivity analysis demonstrated that age was a highly influential factor. The differences between the mean utility decrements produced from our initial meta-analyses and those from the sensitivity analyses (Table 3) are large enough to result in significant differences in QALY estimates over extended time horizons and hence could have similar impacts to those described above. However, the confidence intervals from our initial meta-analyses encompass the confidence intervals from our sensitivity analysis. Hence, we recommend that anyone using our utility decrements for economic evaluation should consider uncertainty in their calculations of QALYs.

Additional sensitivity analyses investigating only studies that presented utility values by sex (see supplementary figure 2 in appendix) showed little evidence of different utilities for men and women. We were unable to draw any meaningful conclusions on the influence of sex on our main results as we could not include sex as a covariate in the meta regression, due to lack of studies reporting utilities by sex. Those using our results may consider using these supplementary findings if they require sex-adjusted utility values for economic modelling. There may be an argument that the presence of co-morbidities should be accounted for when investigating the disutility of increasing weight status. Indeed, six of our chosen studies presented utility values that adjusted for the presence of co-morbidities $(34,36,37,43-45)$. However, the aim of this study was to capture the overall association between weight status and quality of life utilities, including the impact of co-morbidities related to higher weight status. Our decision not to investigate the impact of co-morbidities on our results is further 
supported by ISPOR who recommend that health state utility values should reflect not only the condition of interest but co-morbidities as well. (6)

The strengths of our study are the comprehensive and systematic search strategy, meaning we are confident we have covered all the current literature on this topic. The included studies were of high quality (based on the quality ranking system used) and had large sample sizes covering both state and national levels, indicating that they reflected a representative sample of the Australian adult general population. Moreover, the exploration of heterogeneity using sub-group analysis, meta-regression and sensitivity analysis has allowed us to account for key factors that influence differences in observed values. Finally, our results were able to quantify utility decrements by obesity classes as opposed to obesity as a whole, which allows us to account for the growth in more severe obesity classes in Australia (55) and estimate its impact on QALYs and hence cost-effectiveness of interventions.

The main limitation of our study is its focus on evidence from Australian studies. Whilst consistent with our aim to derive utility decrements for use in economic evaluations of obesity prevention and interventions within an Australian context, it does limit their applicability more widely. Initially, we planned to include studies from several comparable nations, such as the US, UK, Canada and New Zealand. However, our searches returned an enormous number of articles (close to 12,000) that we were unable to manage given the resources for this project. Regardless, an argument could also be made that a review like ours should be limited to a single country, given evidence that health state utilities differ considerably from country to country, even when using the same MAUI $(19,20)$.

Another limitation relates to the practical applicability of our results for their intended use in economic modelling. Ideally our study results would present age and sex specific utility decrements per unit of BMI, only using observations from MAUI's with Australian tariffs. 
However due to the small number of studies found in our systematic review and the fact that utility values were not presented uniformly across all studies meant this was not possible. This is an important area for further research, as new studies measuring utility values in Australian adults are undertaken in the future. Nevertheless, we believe our results still provide a valuable contribution to the literature and are an excellent source of generalised health state utility values for overweight and obesity in Australian populations. We have explored the influence of age, sex, and type of MAUI on our results within the limits of the available data as described above and would encourage those interested in using our findings to consider these supplementary results as part of their own sensitivity analyses.

\section{Conclusion}

In conclusion, this study is, to our knowledge, the first systematic review and meta-analysis of health utility decrements associated with overweight and obesity in adults in Australia. Based on recommendations from International Society for Pharmacoeconomics and Outcomes Research (ISPOR), we suggest our results be used as 'best evidence' utility inputs by anyone undertaking economic evaluations in this field in Australia, including researchers, analysts and reviewers amongst others (6). Additionally, our methodology provides a foundation for researchers in other countries to generate appropriate utility values for their settings. 


\section{References}

1. WHO. Obesity and overweight [Internet]. [cited 2020 Jul 8]. Available from: https://www.who.int/news-room/fact-sheets/detail/obesity-and-overweight

2. Health Effects of Overweight and Obesity in 195 Countries over 25 Years. N Engl J Med. 2017 Jul 6;377(1):13-27.

3. World Health Organization, Commission on Ending Childhood Obesity. Report of the Commission on Ending Childhood Obesity. 2016.

4. Stanaway JD, Afshin A, Gakidou E, Lim SS, Abate D, Abate KH, et al. Global, regional, and national comparative risk assessment of 84 behavioural, environmental and occupational, and metabolic risks or clusters of risks for 195 countries and territories, 1990-2017: a systematic analysis for the Global Burden of Disease Study 2017. The Lancet. 2018 Nov;392(10159):1923-94.

5. Whitehead SJ, Ali S. Health outcomes in economic evaluation: the QALY and utilities. Br Med Bull. 2010;96:5-21.

6. Brazier J, Ara R, Azzabi I, Busschbach J, Chevrou-Séverac H, Crawford B, et al. Identification, Review, and Use of Health State Utilities in Cost-Effectiveness Models: An ISPOR Good Practices for Outcomes Research Task Force Report. Value Health. 2019 Mar;22(3):267-75.

7. Brown V, Tan EJ, Hayes AJ, Petrou S, Moodie ML. Utility values for childhood obesity interventions: a systematic review and meta-analysis of the evidence for use in economic evaluation. Obes Rev Off J Int Assoc Study Obes. 2018;19(7):905-16.

8. Doyle S, Lloyd A, Moore L, Ray J, Gray A. A Systematic Review and Critical Assessment of Health State Utilities: Weight Change and Type 2 Diabetes Mellitus. PharmacoEconomics. 2012 Dec;30(12):1133-43.

9. Dennett SL, Boye KS, Yurgin NR. The impact of body weight on patient utilities with or without type 2 diabetes: a review of the medical literature. Value Health J Int Soc Pharmacoeconomics Outcomes Res. 2008 Jun;11(3):478-86.

10. Liberati A, Altman DG, Tetzlaff J, Mulrow C, Gøtzsche PC, Ioannidis JPA, et al. The PRISMA Statement for Reporting Systematic Reviews and Meta-Analyses of Studies That Evaluate Health Care Interventions: Explanation and Elaboration. PLoS Med. 2009 Jul 21;6(7):e1000100.

11. Covidence - Better systematic review management [Internet]. [cited 2020 Jun 18]. Available from: https://www.covidence.org/home

12. Petrou S, Kwon J, Madan J. A Practical Guide to Conducting a Systematic Review and Meta-analysis of Health State Utility Values. PharmacoEconomics. 2018;36(9):104361.

13. EQ-5D [Internet]. [cited 2020 Jun 22]. Available from: https://euroqol.org/ 
14. Horsman J, Furlong W, Feeny D, Torrance G. The Health Utilities Index (HUI®): concepts, measurement properties and applications. Health Qual Life Outcomes. 2003 Oct 16;1(1):54.

15. Brazier J, Roberts J, Deverill M. The estimation of a preference-based measure of health from the SF-36. J Health Econ. 2002 Mar 1;21(2):271-92.

16. AQoL [Internet]. [cited 2020 Jun 22]. Available from: https://www.aqol.com.au/

17. Time Trade-Off [Internet]. YHEC - York Health Economics Consortium. [cited 2020 Jun 22]. Available from: https://yhec.co.uk/glossary/time-trade-off/

18. Standard Gamble [Internet]. YHEC - York Health Economics Consortium. [cited 2020 Jun 22]. Available from: https://yhec.co.uk/glossary/standard-gamble/

19. Mahlich J, Dilokthornsakul P, Sruamsiri R, Chaiyakunapruk N. Cultural beliefs, utility values, and health technology assessment. Cost Eff Resour Alloc. 2018 Jun 1;16(1):19.

20. Roudijk B, Donders ART, Stalmeier PFM. Cultural Values: Can They Explain Differences in Health Utilities between Countries? Med Decis Making. 2019 Jul 1;39(5):605-16.

21. Audureau Etienne, Pouchot Jacques, Coste Joël. Gender-Related Differential Effects of Obesity on Health-Related Quality of Life via Obesity-Related Comorbidities. Circ Cardiovasc Qual Outcomes. 2016 May 1;9(3):246-56.

22. Defining Adult Overweight and Obesity | Overweight \& Obesity | CDC [Internet]. 2020 [cited 2020 Jul 16]. Available from: https://www.cdc.gov/obesity/adult/defining.html

23. 7.7.7.2 Standard errors from confidence intervals and $P$ values: difference measures [Internet]. [cited 2020 May 4]. Available from: https://handbook-5-

1.cochrane.org/chapter_7/7_7_7_2_obtaining_standard_errors_from_confidence_interv als_and.htm

24. Sampling Distribution of Difference Between Means [Internet]. [cited 2020 May 4]. Available from: http://onlinestatbook.com/2/sampling_distributions/samplingdist_diff_means.html

25. Cooper N, Coyle D, Abrams K, Mugford M, Sutton A. Use of evidence in decision models: an appraisal of health technology assessments in the UK since 1997. J Health Serv Res Policy. 2005 Oct;10(4):245-50.

26. Stata: Software for Statistics and Data Science [Internet]. [cited 2020 Jun 22]. Available from: https://www.stata.com/

27. IntHout J, Ioannidis JP, Borm GF. The Hartung-Knapp-Sidik-Jonkman method for random effects meta-analysis is straightforward and considerably outperforms the standard DerSimonian-Laird method. BMC Med Res Methodol. 2014 Feb 18;14(1):25.

28. Richardson J, Iezzi A, Khan MA. Why do multi-attribute utility instruments produce different utilities: the relative importance of the descriptive systems, scale and 'microutility' effects. Qual Life Res. 2015;24(8):2045-53. 
29. 9.6.2 What are subgroup analyses? [Internet]. [cited $2020 \mathrm{Jul} 7$ ]. Available from: https://handbook-5-1.cochrane.org/chapter_9/9_6_2_what_are_subgroup_analyses.htm

30. 9.6.4 Meta-regression [Internet]. [cited $2020 \mathrm{Jul} 1$ 1]. Available from: https://handbook-51.cochrane.org/chapter_9/9_6_4_meta_regression.htm

31. Jayasinghe UW, Harris MF, Taggart J, Christl B, Black DA. Gender differences in health-related quality of life of Australian chronically-ill adults: patient and physician characteristics do matter. Health Qual Life Outcomes. 2013 Jun 21;11(1):102.

32. Hajian-Tilaki K, Heidari B, Hajian-Tilaki A. Solitary and combined negative influences of diabetes, obesity and hypertension on health-related quality of life of elderly individuals: A population-based cross-sectional study. Diabetes Metab Syndr Clin Res Rev. 2016 Apr 1;10(2, Supplement 1):S37-42.

33. Kortt MA, Clarke PM. Estimating utility values for health states of overweight and obese individuals using the SF-36. Booth B Brazier, Brown, Cawley, Chaing, Chou, Colditz, Diehr, Doll, Fanuele, Finkelstein, Fontaine, Franks, Fryback, Hakim, Hollingworth, Inoue, Jenkinson, Katz, Larsson, Lundberg, Marchesini, Nichol, O’Brien, Ohsawa, Peelers, Pi-Sunyer, Seidell, Sengupta, Spencer, Stevens, Walters, Ware, editor. Qual Life Res Int J Qual Life Asp Treat Care Rehabil. 2005;14(10):2177-85.

34. Baxter S, Sanderson K, Venn A, Otahal P, Palmer AJ. Construct validity of SF-6D health state utility values in an employed population. Qual Life Res. 2015 Apr;24(4):851-70.

35. Norman R, Church J, Berg B van den, Goodall S. Australian health-related quality of life population norms derived from the SF-6D. Aust N Z J Public Health. 2013;37(1):17-23.

36. Kortt MA, Dollery B. Association Between Body Mass Index and Health-Related Quality of Life Among an Australian Sample. Clin Ther. 2011 Oct 1;33(10):1466-74.

37. Heard C., Scuffham P.A., Ratcliffe J., Whitty J.A. The association between misperceptions around weight status and quality of life in adults in Australia. Health Qual Life Outcomes. 2017;15(1):53.

38. Clemens S, Begum N, Harper C, Whitty JA, Scuffham PA. A comparison of EQ-5D-3L population norms in Queensland, Australia, estimated using utility value sets from Australia, the UK and USA. Qual Life Res. 2014 Oct;23(8):2375-81.

39. Hawthorne G. Assessing Utility Where Short Measures Are Required: Development of the Short Assessment of Quality of Life-8 (AQoL-8) Instrument. Value Health. 2009 Sep 1;12(6):948-57.

40. Le LK-D, Mihalopoulos C, Engel L, Touyz S, González-Chica DA, Stocks N, et al. Burden and health state utility values of eating disorders: results from a populationbased survey. Psychol Med. 2019 Oct 31;1-8.

41. Kanesarajah J, Waller M, Whitty JA, Mishra GD. The relationship between SF-6D utility scores and lifestyle factors across three life stages: evidence from the Australian Longitudinal Study on Women's Health. Qual Life Res. 2017 Jun;26(6):1507-19. 
42. Hawthorne G, Korn S, Richardson J. Population norms for the AQoL derived from the 2007 Australian National Survey of Mental Health and Wellbeing. Aust N Z J Public Health. 2013 Feb;37(1):7-16.

43. Khan MA, Richardson J, O'Brien P. The effect of obesity upon Health Related Quality of Life (HRQoL): A comparison of the AQoL-8D and SF-36 instruments. Farmeconomia Health Econ Ther Pathw. 2012 Jun 4;13(2):69-82.

44. Wang L, Crawford JD, Reppermund S, Trollor J, Campbell L, Baune BT, et al. Body mass index and waist circumference predict health-related quality of life, but not satisfaction with life, in the elderly. Qual Life Res. 2018 Oct 1;27(10):2653-65.

45. Kortt MA, Clarke PM. Estimating Utility Values for Health States of Overweight and Obese Individuals Using the SF-36. Qual Life Res. 2005 Dec 1;14(10):2177-85.

46. 9.5.2 Identifying and measuring heterogeneity [Internet]. [cited 2020 Jun 8]. Available from: https://handbook-5-

1.cochrane.org/chapter_9/9_5_2_identifying_and_measuring_heterogeneity.htm

47. Fuller NR, Carter H, Schofield D, Hauner H, Jebb SA, Colagiuri S, et al. Costeffectiveness of primary care referral to a commercial provider for weight loss treatment, relative to standard care-a modelled lifetime analysis. Int J Obes 2005. 2014 Aug;38(8):1104-9.

48. Karnon J, Afzali HHA, Gray J, Holton C, Banham D, Beilby J. A risk adjusted costeffectiveness analysis of alternative models of nurse involvement in obesity management in primary care. Obesity. 2013;21(3):472-9.

49. Dalziel K, Segal L. Time to give nutrition interventions a higher profile: costeffectiveness of 10 nutrition interventions. Health Promot Int. 2007 Oct 17;22(4):27183.

50. James R, Salton RI, Byrnes JM, Scuffham PA. Cost-utility analysis for bariatric surgery compared with usual care for the treatment of obesity in Australia. Surg Obes Relat Dis. 2017 Dec;13(12):2012-20.

51. Fuller NR, Colagiuri S, Schofield D, Olson AD, Shrestha R, Holzapfel C, et al. A within-trial cost-effectiveness analysis of primary care referral to a commercial provider for weight loss treatment, relative to standard care - an international randomised controlled trial. Int J Obes. 2013 Jun;37(6):828-34.

52. McNeil H, Segal L. Research Report 17 Quality of Life and Obesity [Internet]. Centre for Health Program Evaluation; 1999 [cited 2020 Jul 31]. Available from: https://research.monash.edu/en/publications/research-report-17-quality-of-life-andobesity

53. Trueman P, Haynes SM, Felicity Lyons G, Louise McCombie E, McQuigg MSA, Mongia S, et al. Long-term cost-effectiveness of weight management in primary care. Int J Clin Pract. 2010 May;64(6):775-83. 
54. Pickles K, Lancsar E, Seymour J, Parkin D, Donaldson C, Carter SM. Accounts from developers of generic health state utility instruments explain why they produce different QALYs: A qualitative study. Soc Sci Med. 2019 Nov 1;240:112560.

55. Australian Institute of Health and Welfare. A picture of overweight and obesity in Australia. [Internet]. 2017 [cited 2020 Apr 22]. Available from: https://www.aihw.gov.au/reports/overweight-obesity/a-picture-of-overweight-andobesity-in-australia/contents/table-of-contents 
Fig 1 Flow chart of literature search, results, reasons for excluded studies and number of included articles in final meta-analysis

Fig 2 Forest plot of the meta-analysis (with sub-group analysis by MAUI) of 11 studies (22 observations) reporting utility decrements and confidence intervals of each study for people with overweight

Fig 3 Forest plot of the meta-analysis (with sub-group analysis by MAUI) of 7 studies (14 observations) reporting utility decrements and confidence intervals of each study for people with obesity

Fig 4 Forest plot of the meta-analysis (with sub-group analysis by MAUI) of 5 studies (11 observations) reporting utility decrements and confidence intervals of each study for people with class 1 obesity

Fig 5 Forest plot of the meta-analysis (with sub-group analysis by MAUI) of 5 studies (11 observations) reporting utility decrements and confidence intervals of each study for people with class 2 obesity

Fig 6 Forest plot of the meta-analysis (with sub-group analysis by MAUI) of 5 studies (11 observations) reporting utility decrements and confidence intervals of each study for people with class 3 obesity

Table 1 Details of studies included in meta-analyses

Table 2 Results of random effects meta-regression of factors potentially influencing utility decrements for each weight category

Table 3 Sensitivity analysis results- meta-analyses repeated with exclusion of Wang et al. 2018 study 
Title: Utility decrements associated with adult overweight and obesity in Australia: a

systematic review and meta-analysis

Running title: Utility decrements of adult overweight and obesity

Authors: Joseph Carrello ${ }^{1}$, Alison Hayes ${ }^{1}$, Anagha Killedar ${ }^{1}$, Amy Von Huben $^{1}$, Louise A Baur $^{1,2}$, Stavros Petrou ${ }^{3}$, Thomas Lung ${ }^{1,4}$

\section{Affiliations:}

1. School of Public Health, Faculty of Medicine and Health, University of Sydney NSW, Australia

2. Children's Hospital Westmead Clinical School, Faculty of Medicine and Health, University of Sydney, NSW Australia

3. Nuffield Department of Primary Care Health Sciences, University of Oxford, Radcliffe Observatory Quarter, Oxford, United Kingdom

4. Health Economics and Process Evaluation, The George Institute for Global Health, University of New South Wales, Kensington, Australia

Corresponding author: Mr Joseph Carrello, School of Public Health, Edward Ford Building, University of Sydney, Camperdown, NSW, 2006

Email: jcar6556@uni.sydney.edu.au Phone: +61 406484938

Acknowledgements: We would like to thank Bernie Carr, Academic Liaison Librarian, Fisher Library, University of Sydney for her assistance with the literature search strategy.

Word Count: 4277 Number of pages: 20 Number of figures: 6 Number of tables: 3

Appendix: Pages: 5 Figures: 2 Tables: 0 


\section{Declarations}

Funding: Joseph Carrello is supported by a Postgraduate Research Scholarship from the Australian Prevention Partnership Centre (TAPPC); Anagha Killedar is supported by a NHMRC PhD scholarship (\#1169039); Amy Von Huben is supported by a Postgraduate scholarship in Health Economics-Patient Centred Care and Outcomes in Chronic Disease. Thomas Lung is supported by a NHMRC Early Career Fellowship (APP1141392) and the National Heart Foundation Postdoctoral Fellowship (award 101956).

Conflicts of interest: All authors declare they have no conflict of interest

Availability of data and material: The datasets analysed during the current study are available from the corresponding author on reasonable request.

Code availability: Not applicable

Authors contributions: JC, AH, LB, SP and TL were involved in concept and design of paper. JC, AH, AK, AvH and TL were involved in analysis and interpretation of data. JC, $\mathrm{AvH}$ and TL were involved in statistical analysis. $\mathrm{JC}, \mathrm{AH}$ and $\mathrm{AK}$ were involved in drafting manuscript. All authors were involved in critical revision of paper. 


\begin{abstract}
Purpose: To conduct a systematic review and meta-analysis of health state utility decrements associated with overweight and obesity in adults 18 years and over, for use in modelled economic evaluations in Australia.

Methods: A systematic review was conducted in nine databases to identify studies that reported health state utility values by weight status. Random-effects meta-analysis was used to synthesise average utility decrements (from healthy weight) associated with overweight, all obesity and obesity classes 1,2 and 3. Heterogeneity surrounding utility decrements was assessed via sub-group analysis, random-effects meta-regression and sensitivity analyses.
\end{abstract}

Results: Twelve studies were found for which data was used to synthesise utility decrements, estimated as: overweight 0.020 (95\% CI: $0.010,0.030)$, all obesity $0.055(0.034,0.076)$ and obesity class $10.047(0.017,0.077)$, class $20.072(0.028,0.116)$ and class $30.084(0.039$, 0.130). There was considerable heterogeneity in our results, which could be accounted for by different ages and utility instruments used in the contributing studies.

Conclusions: Our results demonstrate that elevated weight status is associated with small but statistically significant reductions in utility compared with healthy weight, which will result in reduced quality-adjusted life years when extrapolated across time and used in economic evaluations. 


\section{Key points for decision makers}

I. Health state utility values of overweight and obesity are used to calculate quality adjusted life years (QALYs) for modelled economic evaluations of interventions for these conditions. To date, these values have been sourced in the literature from individual studies, which is problematic as use of different samples, valuation protocols and estimation techniques can result in different utility values for the same health state.

II. This study is, to our knowledge, the first systematic review and meta-analysis of health state utility decrements associated with overweight and obesity in Australian adults.

III. Based on recommendations from the International Society for Pharmacoeconomics and Outcomes Research (ISPOR), we suggest our results be used as 'best evidence' utility inputs by anyone undertaking modelled economic evaluations in this field in Australia, including researchers, analysts and reviewers amongst others. 


\section{Introduction}

Overweight and obesity are terms given to excess body weight, defined by a body mass index (BMI) between $25-29.9 \mathrm{~kg} / \mathrm{m}^{2}$ for overweight and $30 \mathrm{~kg} / \mathrm{m}^{2}$ or greater for obesity (1). They represent major public health concern with their prevalence doubling in more than 70 countries since 1980 (2), affecting 52\% of adults globally in 2016 (1). It is a risk factor for many health problems including cardiovascular disease, diabetes, musculoskeletal disorders and several cancers (3). High BMI contributes to the global burden of disease, linked to 4.72 million deaths around the world in 2017 (4) and accounting for 7\% of deaths from any cause in 2015 (2).

Despite the enormity of the problem, investment in prevention and treatment of overweight and obesity remains a challenge. With increasing demand for scarce healthcare resources, decisions around resource allocation for competing interventions should be informed by evidence of their impacts on both costs and health outcomes (5). The quality-adjusted life year (QALY) is an outcome measure that can capture the impact of an intervention on both an individual's morbidity and mortality (5). QALYs are calculated by adjusting years of life by health-related quality of life, where the latter is valued in terms of health state utilities (5). Health state utilities are valued using preference-based techniques and indexed onto a cardinal scale reflecting the value or desirability for health states, where 0 indicates death and 1 indicates full health (5). Utilities can be measured directly using techniques such as standard gamble (SG) or time trade off (TTO) or indirectly using multi-attribute utility instruments (MAUIs). With the latter, individuals complete a descriptive health status classification system and health states are valued using a preference-based scoring algorithm (or tariff) that reflects the preferences of the general population for health states (6). 
QALYs are often used by health economists for economic evaluations of interventions to inform policy decisions for healthcare resource allocation (6). Health state utilities can be expensive and challenging to directly estimate and are not always measured in clinical trials or observational studies, meaning researchers requiring them for economic models commonly resort to extracting values from the literature (6). However, this method has many problems as use of different samples, valuation protocols and estimation techniques can result in different utility values for the same health state (6). There is also the risk that researchers are accused of 'cherry picking' health utility values from single published studies that prejudice the cost-effectiveness outcome in a particular direction (6).

In 2014, the International Society for Pharmacoeconomics and Outcomes Research (ISPOR) established a Good Practices for Outcomes Research Taskforce to address this issue (6). The taskforce advocated the use of systematic reviews and meta-analysis of health utility values to generate data inputs for cost-effectiveness models. Additionally, it provided guidance for synthesising all available information from different studies, generating summary health state utility values for use in economic evaluation, generating ranges of values that can be used in sensitivity analysis, and weighting studies based on sample size (6).

Recently, Brown and colleagues conducted a systematic review and meta-analysis of health state utility values for overweight and obesity in children up to 18 years (7). To our knowledge, there has been only one systematic review of health state utility values related to overweight and obesity in adults; however, this was for adults with concurrent type 2 diabetes and a meta-analysis was not conducted (8). Additionally, there has been a literature review of the impact of body weight on patient utilities with and without type 2 diabetes (9).

The aim of this study was to conduct a systematic review and meta-analysis of health state utility decrements associated with overweight and obesity in adults aged 18 years and over, 
for use in economic evaluation in Australia. Utility decrements associated with differences in weight status were chosen over mean utility values, as they are pertinent to economic modelling by allowing analysts to calculate incremental changes in QALYs.

\section{Methods}

The systematic review was based on the Preferred Reporting Items for Systematic Reviews and Meta Analyses (PRISMA) guidelines (10) and registered with PROSPERO (\#CRD42020175538). The online software Covidence (11) was used for uploading search results, screening titles and abstracts and full text reports, completing data extraction, conducting quality assessments, resolving disagreements, and exporting data into Excel.

\section{Literature search}

A systematic search of the literature extending to April 2020 was conducted using the databases Scopus, PubMed, CINAHL, EMBASE, Web of Science, PsycINFO, EconLit, Cochrane Library of Reviews and Google Scholar. We used key terms developed in collaboration with a specialist librarian, based on recommendations from experts in health economics and obesity research (12) (see appendix supplementary figure 1). Bibliographies of articles that reported utility values were also examined for further literature that may have been missed in the initial searches.

Our search strategy captured all preference-based utility measurement approaches, which included multi-attribute instruments such as the EuroQol Five Dimensions (EQ-5D) (13), the Health Utilities Index (HUI2, 3) (14), the Short-Form Six-Dimension (SF-6D) (15), the Assessment of Quality of Life (AQoL- 4D -6D -8D) (16) and directly elicited utility values using techniques such as the TTO (17) or SG (18) approaches. Initially, we planned to consider studies for all industrialised nations. However, after our initial search it became apparent that this task would be too large to manage with our available resources (nearly 
12,000 articles). Hence, we narrowed the search to studies conducted in Australia, as this was our most relevant context and there is evidence that preferences for health states differ between countries $(19,20)$.

\section{Study eligibility}

Inclusion criteria were as follows:

- Studies published in English in peer reviewed journals

- Studies reporting primary data collection of utility values, with results reported by weight status

- Studies were conducted in an Australian population

- Study participants were 18 years or older

- Studies were published anytime until April 2020

Studies were excluded if they used non-preference-based quality of life measures, if they presented mean utility values for overweight and/or obesity but did not compare them to healthy weight (hence we would not be able to calculate utility decrements for the purpose of our meta-analysis), or if the study sample was a specifically targeted clinical population with comorbid conditions (e.g. diabetes) as this would likely influence utility values (21). For the latter point, it was inevitable that some participants in adult samples with overweight and obesity would have other co-morbidities, but our aim was to synthesise utility values for overweight and obesity in the general population, rather than specific clinical sub-groups.

Titles and abstracts and full texts of all articles were assessed against the inclusion criteria by two independent reviewers (JC and AK). Discrepancies around inclusion or exclusion were resolved by discussion and consensus between the reviewers, with two co-authors assisting this process for the full text screening (AH and TL). 


\section{Data extraction}

Where available, information on mean (standard error) utility decrements for weight status or body mass index (BMI) categories (compared to healthy weight) were extracted directly from each study by two independent reviewers ( $\mathrm{JC}$ and $\mathrm{AvH}$ ). Multiple observations from the same study were included if that study presented results stratified by sex, different cohorts, or different time-points. BMI is a person's weight in kilograms divided by the square of their height in meters (22). BMI categories presented in the studies included overweight (BMI 25$\left.29.99 \mathrm{~kg} / \mathrm{m}^{2}\right)$, all obesity $\left(\mathrm{BMI} \geq 30 \mathrm{~kg} / \mathrm{m}^{2}\right)$, and obesity class 1 (BMI $\left.30-34.99 \mathrm{~kg} / \mathrm{m}^{2}\right)$, class 2 (BMI $\left.35-39.99 \mathrm{~kg} / \mathrm{m}^{2}\right)$ and class $3\left(\mathrm{BMI} \geq 40 \mathrm{~kg} / \mathrm{m}^{2}\right)$ groups. Weight status information was not presented uniformly across all studies. For example, where studies reported utility decrements per unit of BMI, the values were converted into mean decrements from healthy weight for each weight category, using the number of BMI units from the midpoint of each weight category. Where studies reported mean utility values (not decrements) by weight category, we calculated decrements by subtracting the utility values for overweight or obesity categories from the utility value for healthy weight. Corresponding standard errors for each utility decrement were either extracted directly or calculated from standard deviations or 95\% confidence intervals, following the recommendations of the Cochrane Handbook $(23,24)$. Study characteristics that could influence utility values such as mean age, sex, study type, setting/survey, calendar year of data collection, country source of preference indices and sample size were also extracted.

\section{Quality assessment}

For quality assessment of the selected articles, we used the ranking system for studies that derive health state utility values, proposed by Cooper and colleagues (25). This ranking system reflects the strength of evidence for health utility assessments on a scale from 1 (for 
direct utility assessment from the sample) to 6 (utility values developed from Delphi panels, expert opinion) (25). Two independent reviewers (JC and AvH) examined each article using the Cooper ranking system, then met and resolved any discrepancies.

\section{Data synthesis}

Random effects meta-analyses were conducted using the meta command in STATA (26), to combine the results for multiple studies into pooled estimates of utility decrements compared with healthy weight, for weight categories (overweight, all obesity and obesity classes 1,2 and 3). The Sidik-Jonkman estimation method was used due to the small number of identified studies (27). Results were presented as Forest plots, and tests for heterogeneity were performed using the I squared and Cochran's Q tests.

\section{Sub-group analysis}

There is evidence that health state utilities measured by MAUI's differ depending on which instrument is used, and hence could potentially be a source of heterogeneity in our results (28). To investigate this, we used subgroup analysis by MAUI to draw comparisons of the synthesised utility values elicited by each MAUI for each weight category (29).

\section{Meta-regression}

To investigate the extent to which type of MAUI used influenced heterogeneity of our metaanalysis results, we also conducted a random-effects meta-regression with MAUI as an explanatory variable using the metareg command in STATA $(26,30)$. Other covariates that could potentially influence heterogeneity of results included calendar year of data collection, proportion of males (based on evidence that males generally report higher mean health state utility values) (31) and mean age of participants (based on evidence that mean health state utility values decline with increasing age) (32). Although 11 of the 12 studies reported on all these variables (see Table 1), they did not present mean age and proportion of males by 
weight categories, hence there was insufficient data to include these covariates for analysis with meta-regression other than time of data collection.

\section{Sensitivity analyses}

Increasing age, with associated increased incidence of chronic diseases, is linked to worsening health-related quality of life (32). Although most studies used samples with similar mean ages (see table 1), one study included in the initial meta-analysis was based upon a significantly older cohort (Wang et al. 2018). Hence, additional meta-analyses were conducted to determine if there was any significant impact on synthesised utility decrements and heterogeneity when this study was removed. Additionally, although there was insufficient data to include sex in the meta-regression as described above, we explored its influence on utility values through sensitivity analysis, comparing meta-analysis results for each weight category using only observations from single sex cohorts.

\section{Results}

\section{Eligible studies and characteristics}

The literature searches identified 1239 articles of which 12 studies, published between 2005 and 2019, were included (see Figure 1). Methodological details of included studies can be seen in Table 1. Eleven studies involved cross-sectional analyses of health utility values in large samples across Australia, including the National Health survey (33), single waves of the Australian Household Income and Labour Dynamics (HILDA) surveys (34-36) and state health surveys in Queensland $(37,38)$ and South Australia $(37,39,40)$ amongst others. Kanesarajah et al 2017 (41) presented mean utility changes for different weight categories based on seven waves of longitudinal data for three separate cohorts of women (younger age (18-23 years), middle age (45-50 years) and older age (70-75 years) groups). Regarding utility elicitation methods, six studies used the SF-6D (33-36,40,41), five used the AQOL, 
AQOL-8D or AQOL-6D (37,39,42-44), and one study used the EQ-5D (with Australian population preference values) (38).

The mean age for participants in nine of the studies was between 41 and 49 years, the exceptions being the studies by Wang et al. 2018 (44) (two waves of data with average ages of 78.7 years and 80.1 years), Kanesarajah et al. 2017 (41) (three cohorts with average ages of 20.7 years, 47.6 years, and 72.6 years) and Clemens et al. 2014 (38) (no mean age reported). These mean ages were for the whole cohort, with information on the mean ages of subjects in each weight category not reported. The utility values reported in eight of the twelve studies adjusted for age $(33,34,36,38,40,41,43,44)$, while the remaining four studies did not. $(35,37,39,42)$.

Females were slightly more represented across the studies. However, the utility values reported in table 1 are for entire cohorts, with information on sex distribution for each weight category not reported. Six studies presented utility values by sex $(33-37,42)$, four studies presented utility values adjusting for sex $(38,40,43,44)$, one study presented utility values from a female only cohort (41), while the remaining study did not present utility values by sex or adjust for sex (39).

\section{Quality assessment}

Using the ranking system for quality of evidence of health state utility values proposed by Cooper and colleagues (on a scale of 1-6 ranging from strongest evidence to weakest) (25):

- Five studies scored a top ranking of 1 as they used indirect utility assessments from the patient sample, using a tool validated for the patient population (the studies using either the AQoL or the EQ-5D with Australian preference indices) $(37,38,42-44)$; 
- Six studies scored a ranking of 2 as they used indirect utility assessment from the the SF-6D with UK preference indices) (33-36,40,41); and

- One study scored a ranking of 3 as it used values from an indirect utility assessment from a previous study, although the previous study had applied a tool validated for the patient population (39).

\section{Meta-analyses}

Figures 2-6 show the results of the random effects meta-analysis of health utility value decrements (from healthy weight) for overweight, all obesity, and obesity classes 1,2 and 3 . Synthesised values (95\% confidence intervals) for health utility decrements were as follows: overweight: $0.020(0.010,0.030)$ (Figure 2); all obesity: $0.055(0.034,0.076)$ (Figure 3); obesity class 1: $0.047(0.017,0.077)$ (Figure 4$)$; obesity class 2: $0.072(0.028,0.116)$ (Figure 5) and obesity class 3: $0.084(0.039,0.130)$ (Figure 6). Utility values were derived from a subset of the available 12 studies, including 22 observations for overweight, 14 observations for all obesity and 11 observations for each of the obesity classes $1-3$. The different number of observations for each weight category was driven by differences in the presentation of utility decrements and numbers of multiple observations across included studies. For example, seven studies used a composite measure of obesity (36-42), whereas three studies divided the obesity group into different classes $(34,35,43)$ and two studies presented utility decrements per unit of BMI (allowing calculations for all weight categories including obesity classes) $(33,44)$. Also, nine studies analysed utility decrements by sex or using separate cohorts within the same study $(34-37,39,41,42,44,45)$. There was considerable betweenstudy heterogeneity in the utility values used for the meta-analysis, (overweight $\mathrm{Q}=89.26 \mathrm{I}^{2}=$ 94.55, all obesity $\mathrm{Q}=213.48 \mathrm{I}^{2}=96.13$, obesity class $1 \mathrm{Q}=38.51 \mathrm{I}^{2}=97.86$, obesity class 2 $\mathrm{Q}=27.70 \mathrm{I}^{2}=97.49$, obesity class $\left.3 \mathrm{Q}=27.86 \mathrm{I}^{2}=94.80\right)(46)$. 


\section{Sub-group analyses}

The meta-analyses for each weight category were further analysed by type of MAUI used, as displayed in figures 2-6. As only one study used the EQ-5D (38), it was difficult to make comparisons; however, mean utility decrements were consistently lower for the SF-6D compared to the AQoL for all weight categories.

\section{Meta-regression}

Results of the random effects meta-regression for the covariates of MAUI and year of data collection can be seen in Table 2. This demonstrates that use of the AQoL utility instrument generated significantly greater decrements for all BMI categories when compared with the SF-6D. The utility decrements (95\% Confidence Intervals) were larger by $0.032(0.012$, $0.052)$ for overweight, $0.061(0.0088,0.11)$ for all obesity, $0.081(0.021,0.14)$ for obesity class $1,0.12(0.028,0.21)$ for obesity class 2 and $0.12(0.032,0.21)$ for obesity class 3. Between-study variance in utility decrements for these weight categories was reduced by half, suggesting that the type of MAUI used contributes a large part of the variance in utility decrements from our initial meta-analyses. There was no evidence that use of EQ-5D-3L compared to SF-6D or year of data collection significantly affected utility decrements.

\section{Sensitivity analyses}

Results from our sensitivity analyses exploring the impacts of age and sex on our utility decrements can be seen in Table 3. Following exclusion of observations from the considerably older cohorts used by Wang et al. 2018 (44), mean utility decrements were considerably reduced for all weight categories, whilst heterogeneity was also reduced. This indicates that the older age cohorts used in the study by Wang et al. 2018 (44) likely influenced health state utility values independent of weight status. 
Repeating the meta-analyses for each weight category using only studies that presented utility values by sex revealed very similar utility decrements by sex for overweight (Male $=-0.014$ $(95 \%$ CI $-0.028,-0.001)$, Female $=-0.014(-0.021,-0.007))$, all obesity $($ Male $=-0.062(-0.119$, $-0.004)$, Female $=-0.060(-0.087,-0.033))$ and obesity class $2($ Male $=-0.045(-0.057,-0.032)$, Female $=-0.046(-0.055,-0.037))$, but slightly larger decrements for females compared to males for obesity class $1($ Male $=-0.026(-0.038,-0.015)$, Female $=-0.033(-0.041,-0.025))$ and class $3($ Male $=-0.053(-0.083,-0.022)$, Female $=-0.072(-0.084,-0.059))($ See supplementary figure 2 in appendix).

\section{Discussion}

In this study, we carried out a systematic review and meta-analyses of health state utility decrements of overweight and obesity in Australian adults. The systematic review yielded 12 studies and the meta-analyses demonstrated that utility decrements increased with increasing weight status. The mean decrements $(95 \% \mathrm{CI})$, compared to adults at a healthy weight, were overweight: $0.020(0.010,0.030)$; all obesity: $0.055(0.034,0.076)$; obesity class 1 : $0.047(0.017,0.077)$; obesity class $2: 0.072(0.028,0.116)$ and obesity class $3: 0.084(0.039$, 0.130). Our meta-analysis results of increasing health state utility decrements associated with elevated weight status are consistent with decrements identified in a previous literature review (9). However, to our knowledge, no study yet has attempted a systematic review or meta-analysis, likely due to methods required to conduct such studies being an emerging area of research (6).

Several published economic evaluations of obesity preventive or treatment interventions in Australian adults have sourced utility values from various studies (47-51). However, these values were arbitrarily derived from various sources: one from a study included in our metaanalysis (45); AQoL measures from a single state health survey in South Australia (52); EQ- 
5D measures from a single study in the UK (53) or within-trial measurements from international randomised controlled trials that included participants from Australia, Germany and the United Kingdom (47,51). Our synthesised values are more robust than those used in these studies as they pool Australian-specific estimates from multiple sources, providing a more accurate assessment of the mean decrements and their associated uncertainties for Australian adults and are more generalisable in their use (6). Application of our estimates in these studies could have resulted in significant differences in QALYs when extrapolated over extended periods of time, potentially being the difference as to whether the proposed interventions were deemed to be 'cost-effective' or not and hence affected funding decisions. There was considerable heterogeneity in the studies used for the meta-analyses, which was investigated through meta-regression. This showed that use of the AQol produced significantly larger utility decrements than the SF-6D for all weight status groups, which is consistent with evidence from the literature suggesting that different MAUIs can produce different utility value estimates in the same population (54). This is because although MAUIs are constructed for the same purpose they cover different dimensions of health-related quality of life and differ in their valuation protocols (54). For example, the SF-6D is comprised of 6 dimensions with equal emphasis on physical and psychosocial health, whereas the AQoL has 35 items with a greater emphasis on psychosocial health (28). A study investigating differences in utility values between the AQoL and SF-6D found that 59\% of the difference was attributable to the different descriptive systems of each instrument (the dimensions and response categories used to describe a person's health) (28). Additionally, most SF-6D studies used UK utility weights whereas the AQoL uses Australian utility weights, which may account for some of the differences in utility values between instruments found in our study. Given the above, we would recommend those using our results for economic 
modelling in Australia consider using the sub-group analysis results for the AQoL as a sensitivity analysis.

Exclusion of one study with significantly older cohorts (44) through a sensitivity analysis demonstrated that age was a highly influential factor. The differences between the mean utility decrements produced from our initial meta-analyses and those from the sensitivity analyses (Table 3) are large enough to result in significant differences in QALY estimates over extended time horizons and hence could have similar impacts to those described above. However, the confidence intervals from our initial meta-analyses encompass the confidence intervals from our sensitivity analysis. Hence, we recommend that anyone using our utility decrements for economic evaluation should consider uncertainty in their calculations of QALYs.

Additional sensitivity analyses investigating only studies that presented utility values by sex (see supplementary figure 2 in appendix) showed little evidence of different utilities for men and women. We were unable to draw any meaningful conclusions on the influence of sex on our main results as we could not include sex as a covariate in the meta regression, due to lack of studies reporting utilities by sex. Those using our results may consider using these supplementary findings if they require sex-adjusted utility values for economic modelling.

There may be an argument that the presence of co-morbidities should be accounted for when investigating the disutility of increasing weight status. Indeed, six of our chosen studies presented utility values that adjusted for the presence of co-morbidities $(34,36,37,43-45)$. However, the aim of this study was to capture the overall association between weight status and quality of life utilities, including the impact of co-morbidities related to higher weight status. Our decision not to investigate the impact of co-morbidities on our results is further 
supported by ISPOR who recommend that health state utility values should reflect not only the condition of interest but co-morbidities as well. (6)

The strengths of our study are the comprehensive and systematic search strategy, meaning we are confident we have covered all the current literature on this topic. The included studies were of high quality (based on the quality ranking system used) and had large sample sizes covering both state and national levels, indicating that they reflected a representative sample of the Australian adult general population. Moreover, the exploration of heterogeneity using sub-group analysis, meta-regression and sensitivity analysis has allowed us to account for key factors that influence differences in observed values. Finally, our results were able to quantify utility decrements by obesity classes as opposed to obesity as a whole, which allows us to account for the growth in more severe obesity classes in Australia (55) and estimate its impact on QALYs and hence cost-effectiveness of interventions.

The main limitation of our study is its focus on evidence from Australian studies. Whilst consistent with our aim to derive utility decrements for use in economic evaluations of obesity prevention and interventions within an Australian context, it does limit their applicability more widely. Initially, we planned to include studies from several comparable nations, such as the US, UK, Canada and New Zealand. However, our searches returned an enormous number of articles (close to 12,000) that we were unable to manage given the resources for this project. Regardless, an argument could also be made that a review like ours should be limited to a single country, given evidence that health state utilities differ considerably from country to country, even when using the same MAUI $(19,20)$.

Another limitation relates to the practical applicability of our results for their intended use in economic modelling. Ideally our study results would present age and sex specific utility decrements per unit of BMI, only using observations from MAUI's with Australian tariffs. 
However due to the small number of studies found in our systematic review and the fact that utility values were not presented uniformly across all studies meant this was not possible. This is an important area for further research, as new studies measuring utility values in Australian adults are undertaken in the future. Nevertheless, we believe our results still provide a valuable contribution to the literature and are an excellent source of generalised health state utility values for overweight and obesity in Australian populations. We have explored the influence of age, sex, and type of MAUI on our results within the limits of the available data as described above and would encourage those interested in using our findings to consider these supplementary results as part of their own sensitivity analyses.

\section{Conclusion}

In conclusion, this study is, to our knowledge, the first systematic review and meta-analysis of health utility decrements associated with overweight and obesity in adults in Australia. Based on recommendations from International Society for Pharmacoeconomics and Outcomes Research (ISPOR), we suggest our results be used as 'best evidence' utility inputs by anyone undertaking economic evaluations in this field in Australia, including researchers, analysts and reviewers amongst others (6). Additionally, our methodology provides a foundation for researchers in other countries to generate appropriate utility values for their settings. 


\section{References}

1. WHO. Obesity and overweight [Internet]. [cited $2020 \mathrm{Jul}$ 8]. Available from: https://www.who.int/news-room/fact-sheets/detail/obesity-and-overweight

2. Health Effects of Overweight and Obesity in 195 Countries over 25 Years. N Engl J Med. 2017 Jul 6;377(1):13-27.

3. World Health Organization, Commission on Ending Childhood Obesity. Report of the Commission on Ending Childhood Obesity. 2016.

4. Stanaway JD, Afshin A, Gakidou E, Lim SS, Abate D, Abate KH, et al. Global, regional, and national comparative risk assessment of 84 behavioural, environmental and occupational, and metabolic risks or clusters of risks for 195 countries and territories, 1990-2017: a systematic analysis for the Global Burden of Disease Study 2017. The Lancet. 2018 Nov;392(10159):1923-94.

5. Whitehead SJ, Ali S. Health outcomes in economic evaluation: the QALY and utilities. Br Med Bull. 2010;96:5-21.

6. Brazier J, Ara R, Azzabi I, Busschbach J, Chevrou-Séverac H, Crawford B, et al. Identification, Review, and Use of Health State Utilities in Cost-Effectiveness Models: An ISPOR Good Practices for Outcomes Research Task Force Report. Value Health. 2019 Mar;22(3):267-75.

7. Brown V, Tan EJ, Hayes AJ, Petrou S, Moodie ML. Utility values for childhood obesity interventions: a systematic review and meta-analysis of the evidence for use in economic evaluation. Obes Rev Off J Int Assoc Study Obes. 2018;19(7):905-16.

8. Doyle S, Lloyd A, Moore L, Ray J, Gray A. A Systematic Review and Critical Assessment of Health State Utilities: Weight Change and Type 2 Diabetes Mellitus. PharmacoEconomics. 2012 Dec;30(12):1133-43.

9. Dennett SL, Boye KS, Yurgin NR. The impact of body weight on patient utilities with or without type 2 diabetes: a review of the medical literature. Value Health J Int Soc Pharmacoeconomics Outcomes Res. 2008 Jun;11(3):478-86.

10. Liberati A, Altman DG, Tetzlaff J, Mulrow C, Gøtzsche PC, Ioannidis JPA, et al. The PRISMA Statement for Reporting Systematic Reviews and Meta-Analyses of Studies That Evaluate Health Care Interventions: Explanation and Elaboration. PLoS Med. 2009 Jul 21;6(7):e1000100.

11. Covidence - Better systematic review management [Internet]. [cited 2020 Jun 18]. Available from: https://www.covidence.org/home

12. Petrou S, Kwon J, Madan J. A Practical Guide to Conducting a Systematic Review and Meta-analysis of Health State Utility Values. PharmacoEconomics. 2018;36(9):104361.

13. EQ-5D [Internet]. [cited 2020 Jun 22]. Available from: https://euroqol.org/ 
14. Horsman J, Furlong W, Feeny D, Torrance G. The Health Utilities Index (HUI@): concepts, measurement properties and applications. Health Qual Life Outcomes. 2003 Oct 16;1(1):54.

15. Brazier J, Roberts J, Deverill M. The estimation of a preference-based measure of health from the SF-36. J Health Econ. 2002 Mar 1;21(2):271-92.

16. AQoL [Internet]. [cited 2020 Jun 22]. Available from: https://www.aqol.com.au/

17. Time Trade-Off [Internet]. YHEC - York Health Economics Consortium. [cited 2020 Jun 22]. Available from: https://yhec.co.uk/glossary/time-trade-off/

18. Standard Gamble [Internet]. YHEC - York Health Economics Consortium. [cited 2020 Jun 22]. Available from: https://yhec.co.uk/glossary/standard-gamble/

19. Mahlich J, Dilokthornsakul P, Sruamsiri R, Chaiyakunapruk N. Cultural beliefs, utility values, and health technology assessment. Cost Eff Resour Alloc. 2018 Jun 1;16(1):19.

20. Roudijk B, Donders ART, Stalmeier PFM. Cultural Values: Can They Explain Differences in Health Utilities between Countries? Med Decis Making. 2019 Jul 1;39(5):605-16.

21. Audureau Etienne, Pouchot Jacques, Coste Joël. Gender-Related Differential Effects of Obesity on Health-Related Quality of Life via Obesity-Related Comorbidities. Circ Cardiovasc Qual Outcomes. 2016 May 1;9(3):246-56.

22. Defining Adult Overweight and Obesity | Overweight \& Obesity | CDC [Internet]. 2020 [cited $2020 \mathrm{Jul}$ 16]. Available from: https://www.cdc.gov/obesity/adult/defining.html

23. 7.7.7.2 Standard errors from confidence intervals and $P$ values: difference measures [Internet]. [cited 2020 May 4]. Available from: https://handbook-5-

1.cochrane.org/chapter_7/7_7_7_2_obtaining_standard_errors_from_confidence_interv als_and.htm

24. Sampling Distribution of Difference Between Means [Internet]. [cited 2020 May 4]. Available from: http://onlinestatbook.com/2/sampling_distributions/samplingdist_diff_means.html

25. Cooper N, Coyle D, Abrams K, Mugford M, Sutton A. Use of evidence in decision models: an appraisal of health technology assessments in the UK since 1997. J Health Serv Res Policy. 2005 Oct;10(4):245-50.

26. Stata: Software for Statistics and Data Science [Internet]. [cited 2020 Jun 22]. Available from: https://www.stata.com/

27. IntHout J, Ioannidis JP, Borm GF. The Hartung-Knapp-Sidik-Jonkman method for random effects meta-analysis is straightforward and considerably outperforms the standard DerSimonian-Laird method. BMC Med Res Methodol. 2014 Feb 18;14(1):25.

28. Richardson J, Iezzi A, Khan MA. Why do multi-attribute utility instruments produce different utilities: the relative importance of the descriptive systems, scale and 'microutility’ effects. Qual Life Res. 2015;24(8):2045-53. 
29. 9.6.2 What are subgroup analyses? [Internet]. [cited $2020 \mathrm{Jul}$ 7]. Available from: https://handbook-5-1.cochrane.org/chapter_9/9_6_2_what_are_subgroup_analyses.htm

30. 9.6.4 Meta-regression [Internet]. [cited $2020 \mathrm{Jul} 1$ 1]. Available from: https://handbook-51.cochrane.org/chapter_9/9_6_4_meta_regression.htm

31. Jayasinghe UW, Harris MF, Taggart J, Christl B, Black DA. Gender differences in health-related quality of life of Australian chronically-ill adults: patient and physician characteristics do matter. Health Qual Life Outcomes. 2013 Jun 21;11(1):102.

32. Hajian-Tilaki K, Heidari B, Hajian-Tilaki A. Solitary and combined negative influences of diabetes, obesity and hypertension on health-related quality of life of elderly individuals: A population-based cross-sectional study. Diabetes Metab Syndr Clin Res Rev. 2016 Apr 1;10(2, Supplement 1):S37-42.

33. Kortt MA, Clarke PM. Estimating utility values for health states of overweight and obese individuals using the SF-36. Booth B Brazier, Brown, Cawley, Chaing, Chou, Colditz, Diehr, Doll, Fanuele, Finkelstein, Fontaine, Franks, Fryback, Hakim, Hollingworth, Inoue, Jenkinson, Katz, Larsson, Lundberg, Marchesini, Nichol, O'Brien, Ohsawa, Peelers, Pi-Sunyer, Seidell, Sengupta, Spencer, Stevens, Walters, Ware, editor. Qual Life Res Int J Qual Life Asp Treat Care Rehabil. 2005;14(10):2177-85.

34. Baxter S, Sanderson K, Venn A, Otahal P, Palmer AJ. Construct validity of SF-6D health state utility values in an employed population. Qual Life Res. 2015 Apr;24(4):851-70.

35. Norman R, Church J, Berg B van den, Goodall S. Australian health-related quality of life population norms derived from the SF-6D. Aust N Z J Public Health. 2013;37(1):17-23.

36. Kortt MA, Dollery B. Association Between Body Mass Index and Health-Related Quality of Life Among an Australian Sample. Clin Ther. 2011 Oct 1;33(10):1466-74.

37. Heard C., Scuffham P.A., Ratcliffe J., Whitty J.A. The association between misperceptions around weight status and quality of life in adults in Australia. Health Qual Life Outcomes. 2017;15(1):53.

38. Clemens S, Begum N, Harper C, Whitty JA, Scuffham PA. A comparison of EQ-5D-3L population norms in Queensland, Australia, estimated using utility value sets from Australia, the UK and USA. Qual Life Res. 2014 Oct;23(8):2375-81.

39. Hawthorne G. Assessing Utility Where Short Measures Are Required: Development of the Short Assessment of Quality of Life-8 (AQoL-8) Instrument. Value Health. 2009 Sep 1;12(6):948-57.

40. Le LK-D, Mihalopoulos C, Engel L, Touyz S, González-Chica DA, Stocks N, et al. Burden and health state utility values of eating disorders: results from a populationbased survey. Psychol Med. 2019 Oct 31;1-8.

41. Kanesarajah J, Waller M, Whitty JA, Mishra GD. The relationship between SF-6D utility scores and lifestyle factors across three life stages: evidence from the Australian Longitudinal Study on Women's Health. Qual Life Res. 2017 Jun;26(6):1507-19. 
42. Hawthorne G, Korn S, Richardson J. Population norms for the AQoL derived from the 2007 Australian National Survey of Mental Health and Wellbeing. Aust N Z J Public Health. 2013 Feb;37(1):7-16.

43. Khan MA, Richardson J, O'Brien P. The effect of obesity upon Health Related Quality of Life (HRQoL): A comparison of the AQoL-8D and SF-36 instruments. Farmeconomia Health Econ Ther Pathw. 2012 Jun 4;13(2):69-82.

44. Wang L, Crawford JD, Reppermund S, Trollor J, Campbell L, Baune BT, et al. Body mass index and waist circumference predict health-related quality of life, but not satisfaction with life, in the elderly. Qual Life Res. 2018 Oct 1;27(10):2653-65.

45. Kortt MA, Clarke PM. Estimating Utility Values for Health States of Overweight and Obese Individuals Using the SF-36. Qual Life Res. 2005 Dec 1;14(10):2177-85.

46. 9.5.2 Identifying and measuring heterogeneity [Internet]. [cited 2020 Jun 8]. Available from: https://handbook-5-

1.cochrane.org/chapter_9/9_5_2_identifying_and_measuring_heterogeneity.htm

47. Fuller NR, Carter H, Schofield D, Hauner H, Jebb SA, Colagiuri S, et al. Costeffectiveness of primary care referral to a commercial provider for weight loss treatment, relative to standard care-a modelled lifetime analysis. Int J Obes 2005. 2014 Aug;38(8):1104-9.

48. Karnon J, Afzali HHA, Gray J, Holton C, Banham D, Beilby J. A risk adjusted costeffectiveness analysis of alternative models of nurse involvement in obesity management in primary care. Obesity. 2013;21(3):472-9.

49. Dalziel K, Segal L. Time to give nutrition interventions a higher profile: costeffectiveness of 10 nutrition interventions. Health Promot Int. 2007 Oct 17;22(4):27183.

50. James R, Salton RI, Byrnes JM, Scuffham PA. Cost-utility analysis for bariatric surgery compared with usual care for the treatment of obesity in Australia. Surg Obes Relat Dis. 2017 Dec;13(12):2012-20.

51. Fuller NR, Colagiuri S, Schofield D, Olson AD, Shrestha R, Holzapfel C, et al. A within-trial cost-effectiveness analysis of primary care referral to a commercial provider for weight loss treatment, relative to standard care - an international randomised controlled trial. Int J Obes. 2013 Jun;37(6):828-34.

52. McNeil H, Segal L. Research Report 17 Quality of Life and Obesity [Internet]. Centre for Health Program Evaluation; 1999 [cited 2020 Jul 31]. Available from: https://research.monash.edu/en/publications/research-report-17-quality-of-life-andobesity

53. Trueman P, Haynes SM, Felicity Lyons G, Louise McCombie E, McQuigg MSA, Mongia $S$, et al. Long-term cost-effectiveness of weight management in primary care. Int J Clin Pract. 2010 May;64(6):775-83. 
54. Pickles K, Lancsar E, Seymour J, Parkin D, Donaldson C, Carter SM. Accounts from developers of generic health state utility instruments explain why they produce different QALYs: A qualitative study. Soc Sci Med. 2019 Nov 1;240:112560.

55. Australian Institute of Health and Welfare. A picture of overweight and obesity in Australia. [Internet]. 2017 [cited 2020 Apr 22]. Available from:

https://www.aihw.gov.au/reports/overweight-obesity/a-picture-of-overweight-andobesity-in-australia/contents/table-of-contents 
Fig 1 Flow chart of literature search, results, reasons for excluded studies and number of included articles in final meta-analysis

Fig 2 Forest plot of the meta-analysis (with sub-group analysis by MAUI) of 11 studies (22 observations) reporting utility decrements and confidence intervals of each study for people with overweight

Fig 3 Forest plot of the meta-analysis (with sub-group analysis by MAUI) of 7 studies (14 observations) reporting utility decrements and confidence intervals of each study for people with obesity

Fig 4 Forest plot of the meta-analysis (with sub-group analysis by MAUI) of 5 studies (11 observations) reporting utility decrements and confidence intervals of each study for people with class 1 obesity

Fig 5 Forest plot of the meta-analysis (with sub-group analysis by MAUI) of 5 studies (11 observations) reporting utility decrements and confidence intervals of each study for people with class 2 obesity

Fig 6 Forest plot of the meta-analysis (with sub-group analysis by MAUI) of 5 studies (11 observations) reporting utility decrements and confidence intervals of each study for people with class 3 obesity

Table 1 Details of studies included in meta-analyses

Table 2 Results of random effects meta-regression of factors potentially influencing utility decrements for each weight category

Table 3 Sensitivity analysis results- meta-analyses repeated with exclusion of Wang et al. 2018 study 


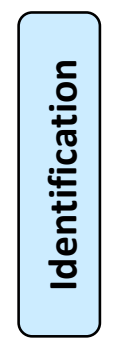

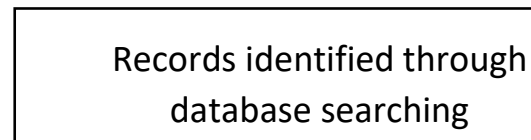

( $n=1957)$
Additional records identified through other sources

$(n=5)$

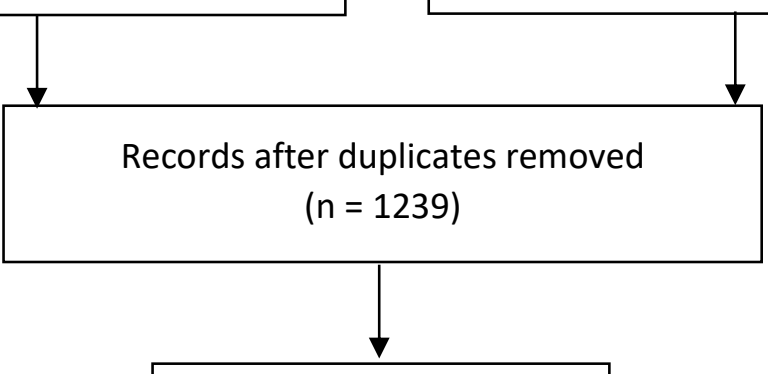

\begin{tabular}{|c|c|}
\hline $\begin{array}{l}\text { Records screened } \\
\qquad(n=1239)\end{array}$ & $\begin{array}{l}\text { Records excluded } \\
\qquad(n=1140)\end{array}$ \\
\hline$\downarrow$ & Full-text articles excluded \\
\hline $\begin{array}{l}\text { Full-text articles assessed } \\
\text { for eligibility } \\
\text { ( } n=99)\end{array}$ & $\begin{array}{l}\qquad(\mathrm{n}=87) \\
\text { Not preference-based } \\
\text { utility measure }(n=64)\end{array}$ \\
\hline$\downarrow$ & $\begin{array}{l}\text { Utility score not presented } \\
\text { by weight status }(n=8)\end{array}$ \\
\hline $\begin{array}{l}\text { Studies included in } \\
\text { qualitative synthesis } \\
\qquad(n=12)\end{array}$ & $\begin{array}{l}\text { Setting other than } \\
\text { Australia }(n=4)\end{array}$ \\
\hline$\downarrow$ & $\begin{array}{l}\text { Conference abstract only } \\
(n=4)\end{array}$ \\
\hline $\begin{array}{l}\text { Studies included in quantitative } \\
\text { synthesis (meta-analysis) }\end{array}$ & $\begin{array}{l}\text { No healthy weight } \\
\text { comparator }(n=7)\end{array}$ \\
\hline
\end{tabular}




\section{SF-6D}

Kortt \& Clarke 2005 (33) 30541995 20761995

Kortt \& Dollery 2011 (36) $\quad 3703 \quad 2007$ 28072007

20062009

15822009

Kanesarajah et al 2017 (41)

Norman et al $2013(35)$

\subsection{9}

Baxter et al 2015 (34)

4172010

6532010

20362010

11892010

Le et al 2019 (40) . 2015

Heterogeneity: $\tau^{2}=0.00, I^{2}=73.16 \%, H^{2}=3.73$

Test of $\theta_{i}=\theta_{j}: Q(13)=50.69, p=0.00$

\section{EQ-5D}

Clemens et al 2014 (38) 10062011

Heterogeneity: $\tau^{2}=0.00, \mathrm{I}^{2}=. \%, \mathrm{H}^{2}=$.

Test of $\theta_{\mathrm{i}}=\theta_{\mathrm{j}}: \mathrm{Q}(0)=-0.00, p=$.

\section{AQoL}

Hawthorne et al 2013 (42) 16982007 12702007

Heard et al 2017 (37)

. 2013

. 2013

Khan et al 2012 (43)

. 2009

Wang et al 2018 (44)

$402 \quad 2005$

3292007

Heterogeneity: $\tau^{2}=0.00, I^{2}=82.62 \%, H^{2}=5.75$

Test of $\theta_{i}=\theta_{j}: Q(6)=20.76, p=0.00$

\section{Overall}

Heterogeneity: $\tau^{2}=0.00, I^{2}=94.43 \%, H^{2}=17.97$

Test of $\theta_{\mathrm{i}}=\theta_{\mathrm{j}}: \mathrm{Q}(21)=89.26, p=0.00$

Test of group differences: $Q_{b}(2)=8.64, p=0.01$

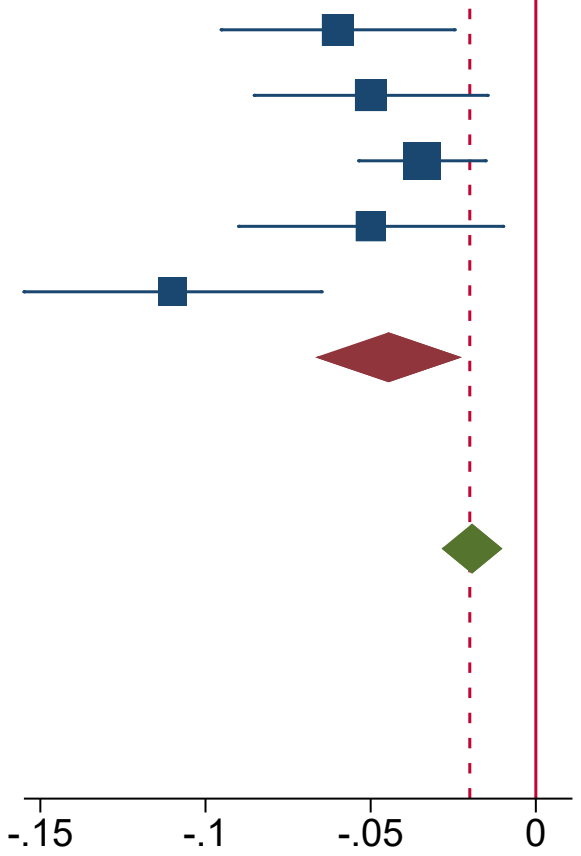

$-0.014[-0.019,-0.008] \quad 5.36$

$-0.020[-0.024,-0.015] \quad 5.40$

$0.001[-0.008,0.009] \quad 5.23$

$0.002[-0.005,0.009] \quad 5.29$

$-0.019[-0.035,-0.003] \quad 4.66$

$-0.016[-0.024,-0.008] \quad 5.27$

$-0.010[-0.016,-0.004] \quad 5.35$

$-0.020[-0.026,-0.014] \quad 5.35$

$-0.018[-0.028,-0.008] \quad 5.15$

$-0.014\left[\begin{array}{lll}-0.031, & 0.003] & 4.64\end{array}\right.$

$-0.006\left[\begin{array}{lll}-0.019, & 0.007] & 4.97\end{array}\right.$

$0.00\left[\begin{array}{lll}-0.011, & 0.011] & 5.07\end{array}\right.$

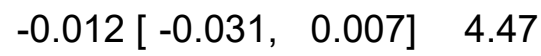

$-0.010[-0.018,-0.002] \quad 5.25$

$-0.011[-0.015,-0.007]$

$-0.020[-0.051,0.011]$

3.40

$-0.020[-0.051,0.011]$

$-0.020[-0.035,-0.005] \quad 4.77$

$-0.020[-0.035,-0.005] \quad 4.81$

$-0.060[-0.095,-0.025] 3.03$

$-0.050[-0.085,-0.015] \quad 3.03$

$-0.035[-0.054,-0.015] \quad 4.42$

$-0.050[-0.090,-0.010] 2.69$

$-0.110[-0.155,-0.065] \quad 2.37$

$-0.045[-0.067,-0.022]$

$-0.019[-0.029,-0.010]$

Random-effects Sidik-Jonkman model 


\section{SF-6D}

Kortt \& Clarke 2005 (33) 11861995

11441995

Kortt \& Dollery 2011 (36) 24692007

24772007

Kanesarajah et al 2017 (41)

Le et al 2019 (40)

Heterogeneity: $\tau^{2}=0.00, I^{2}=94.82 \%, H^{2}=19.29$

Test of $\theta_{\mathrm{i}}=\theta_{\mathrm{j}}: \mathrm{Q}(7)=130.23, \mathrm{p}=0.00$

\section{EQ-5D}

Clemens et al 2014 (38)

$528 \quad 2011$

Heterogeneity: $\tau^{2}=0.00, \mathrm{I}^{2}=. \%, \mathrm{H}^{2}=$.

Test of $\theta_{i}=\theta_{j}: Q(0)=0.00, p=$.

\section{AQoL}

Hawthorne 2009 (39)

Hawthorne et al 2013 (42)

2007

9642007

Heard et al 2017 (37)

. 2013

2013

Heterogeneity: $\tau^{2}=0.00, I^{2}=93.45 \%, H^{2}=15.26$

Test of $\theta_{i}=\theta_{j}: Q(4)=36.51, p=0.00$

\section{Overall}

Heterogeneity: $\tau^{2}=0.00, I^{2}=97.69 \%, H^{2}=43.33$

Test of $\theta_{i}=\theta_{j}: Q(13)=213.48, p=0.00$

Test of group differences: $Q_{b}(2)=6.34, p=0.04$

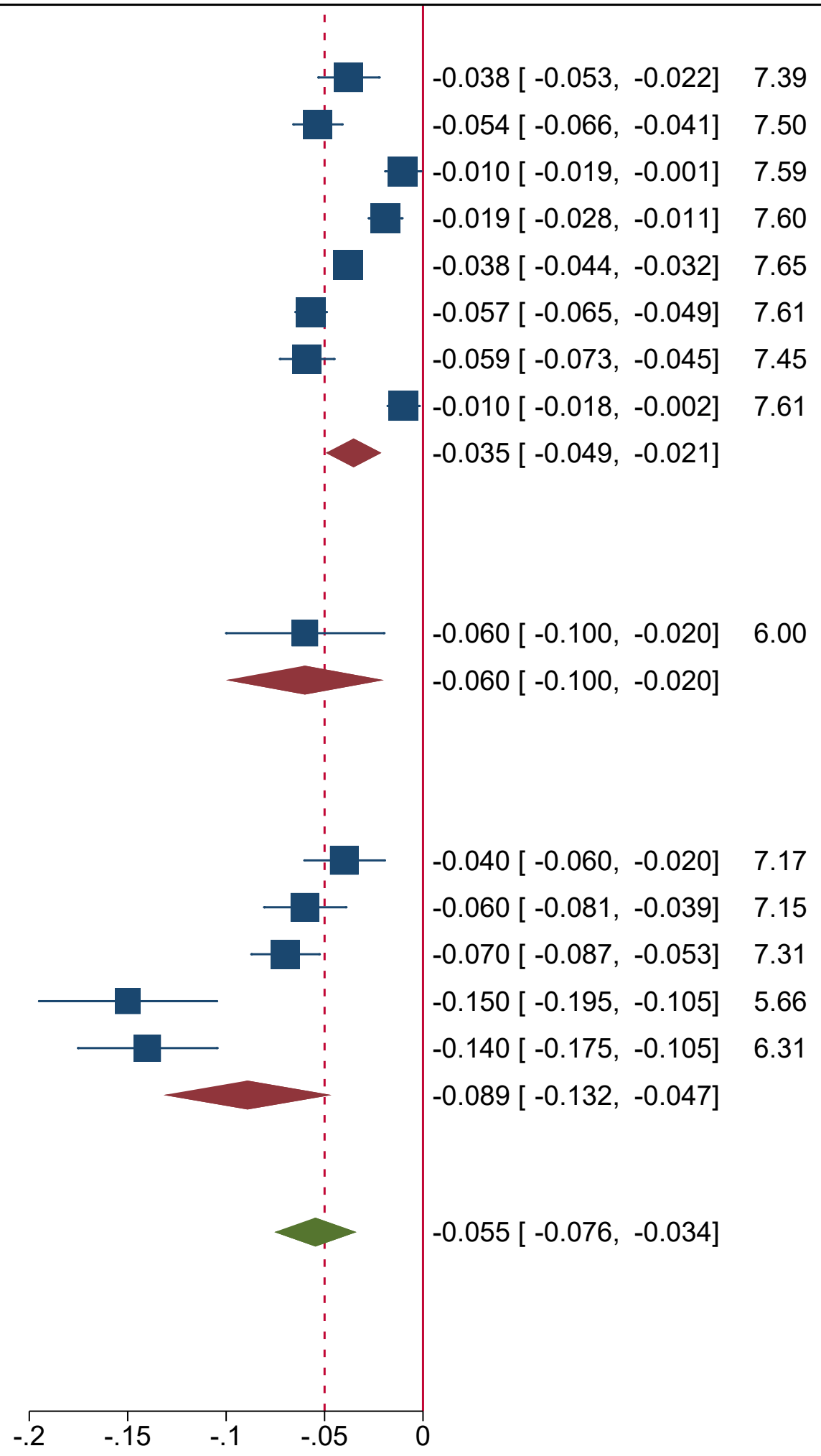




\begin{tabular}{lrr} 
Study & Sample size & Year \\
\hline 1. SF-6D & & \\
Kortt \& Clarke 2005 (33) & . & 1995 \\
& & 1995 \\
Norman et al 2013 (35) & 787 & 2009 \\
& 776 & 2009 \\
Baxter et al 2015 (34) & 127 & 2010 \\
& 323 & 2010 \\
& 788 & 2010 \\
& 579 & 2010
\end{tabular}

Heterogeneity: $\tau^{2}=0.00, \mathrm{I}^{2}=59.16 \%, \mathrm{H}^{2}=2.45$

Test of $\theta_{i}=\theta_{j}: Q(7)=15.50, p=0.03$

\section{AQoL}

Khan et al 2012 (43)

$22 \quad 2009$

Wang et al 2018 (44)

1652005

1332007

Heterogeneity: $\tau^{2}=0.00, \mathrm{I}^{2}=81.03 \%, \mathrm{H}^{2}=5.27$

Test of $\theta_{i}=\theta_{j}: Q(2)=10.00, p=0.01$

\section{Overall}

Heterogeneity: $\tau^{2}=0.00, I^{2}=97.86 \%, H^{2}=46.68$

Test of $\theta_{i}=\theta_{j}: Q(10)=38.51, p=0.00$

Test of group differences: $Q_{b}(1)=4.02, p=0.04$

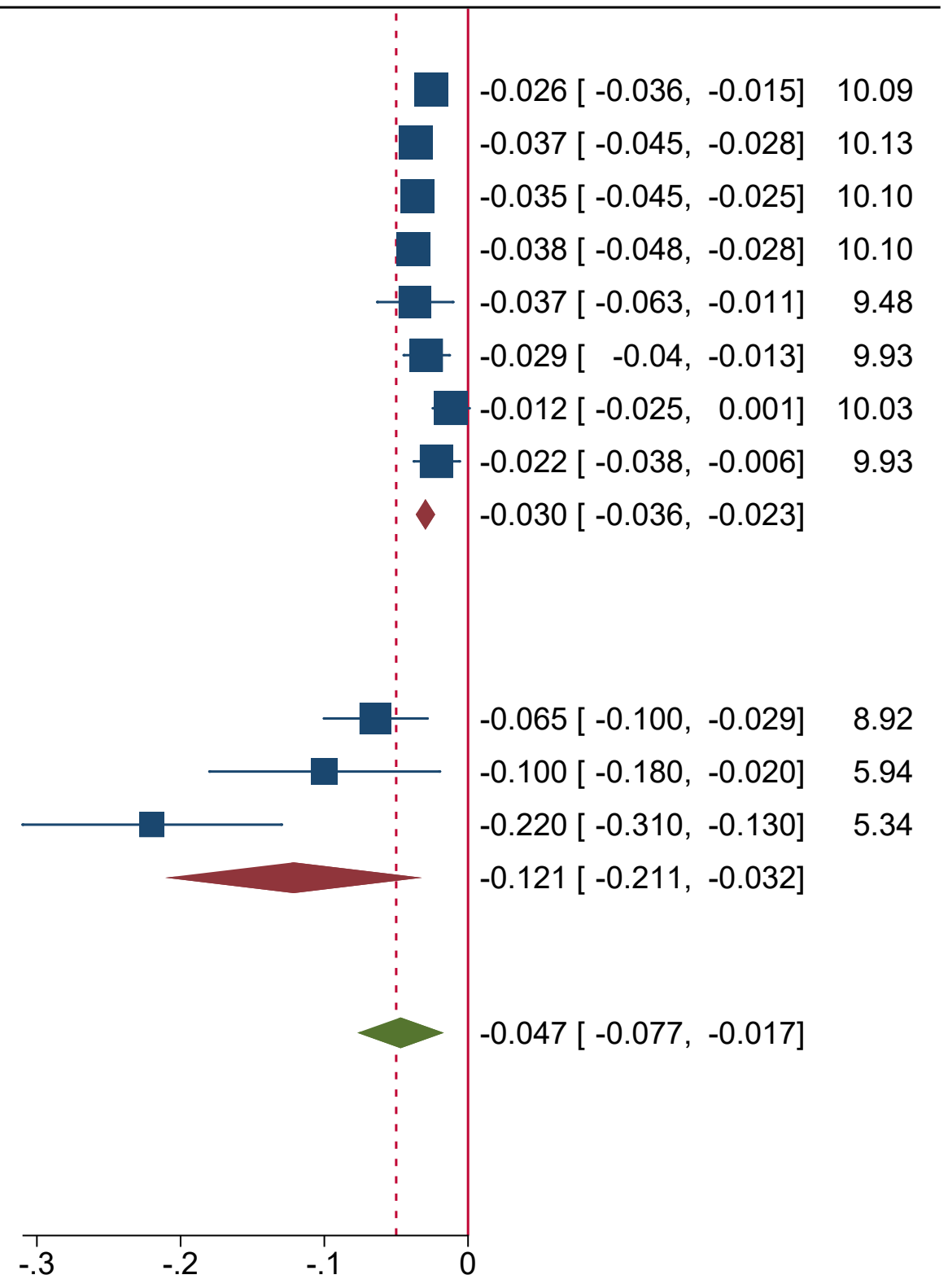




\begin{tabular}{lrl} 
Study & Sample size & Year \\
\hline 1. SF-6D & & \\
Kortt \& Clarke 2005 (33) & . & 1995 \\
&. & 1995 \\
Norman et al 2013 (35) & 194 & 2009 \\
& 305 & 2009 \\
Baxter et al 2015 (34) & 36 & 2010 \\
& 116 & 2010 \\
& 183 & 2010 \\
236 & 2010
\end{tabular}

Heterogeneity: $\tau^{2}=0.00, I^{2}=19.54 \%, H^{2}=1.24$

Test of $\theta_{i}=\theta_{j}: Q(7)=4.62, p=0.71$

\section{AQoL}

Khan et al 2012 (43)

552009

Wang et al 2018 (44)

512005

$38 \quad 2007$

Heterogeneity: $\tau^{2}=0.01, \mathrm{I}^{2}=81.47 \%, \mathrm{H}^{2}=5.40$

Test of $\theta_{i}=\theta_{j}: Q(2)=10.29, p=0.01$

\section{Overall}

Heterogeneity: $\tau^{2}=0.00, I^{2}=97.49 \%, H^{2}=39.91$

Test of $\theta_{i}=\theta_{j}: Q(10)=27.70, p=0.00$

Test of group differences: $Q_{b}(1)=3.87, p=0.05$

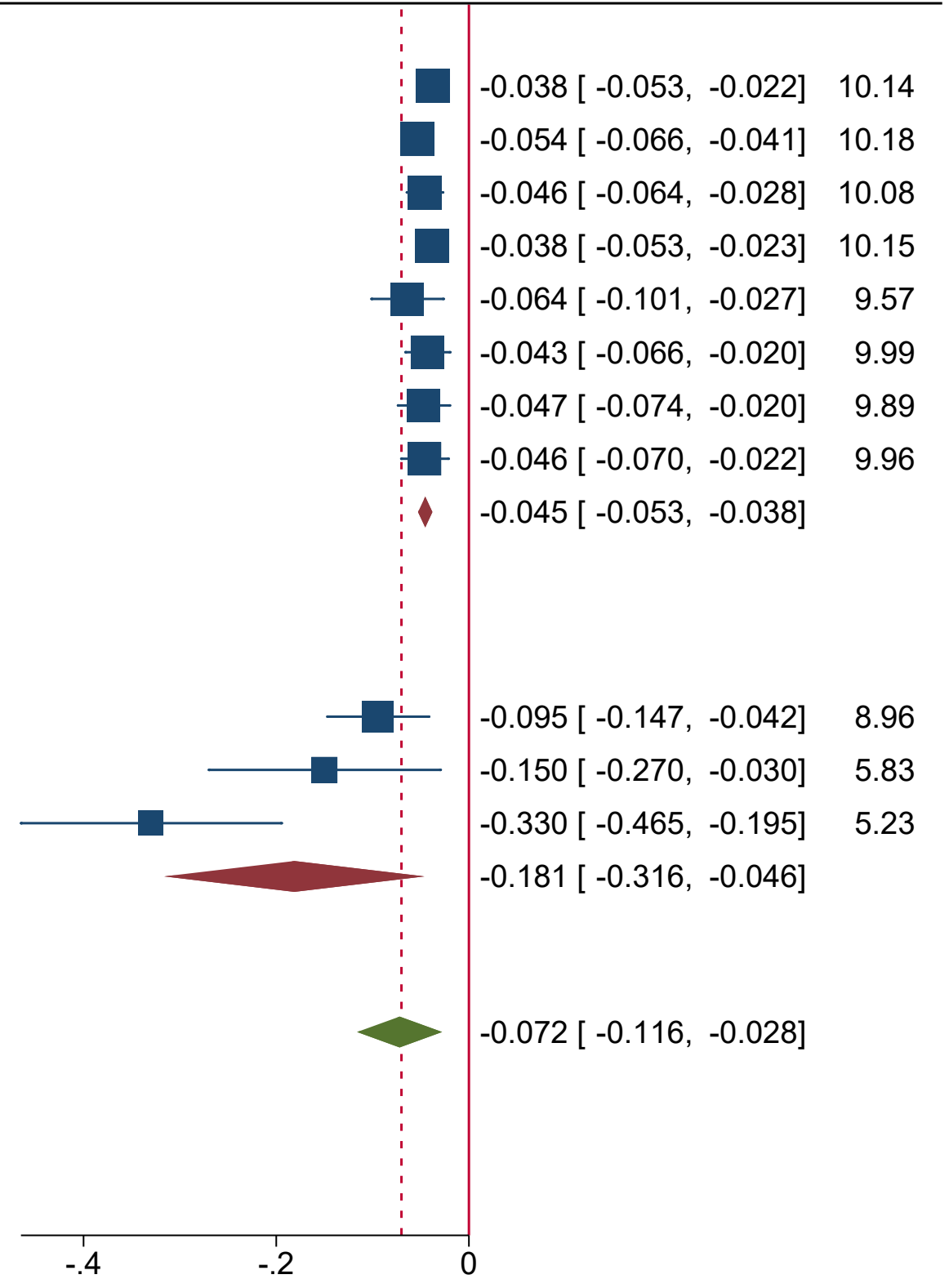




\begin{tabular}{lrl} 
Study & Sample size & Year \\
\hline 1. SF-6D & & \\
Kortt \& Clarke 2005 (33) &. & 1995 \\
&. & 1995 \\
Norman et al 2013 (35) & 85 & 2009 \\
& 163 & 2009 \\
Baxter et al 2015 (34) & 13 & 2010 \\
& 49 & 2010 \\
& 73 & 2010 \\
& 135 & 2010
\end{tabular}

Heterogeneity: $\tau^{2}=0.00, \mathrm{I}^{2}=58.29 \%, \mathrm{H}^{2}=2.40$

Test of $\theta_{\mathrm{i}}=\theta_{\mathrm{j}}: \mathrm{Q}(7)=8.94, \mathrm{p}=0.26$

\section{AQoL}

Khan et al 2012 (43)

1192009

Wang et al 2018 (44)

512005

$38 \quad 2007$

Heterogeneity: $\tau^{2}=0.01, \mathrm{I}^{2}=74.85 \%, \mathrm{H}^{2}=3.98$

Test of $\theta_{i}=\theta_{j}: Q(2)=7.11, p=0.03$

\section{Overall}

Heterogeneity: $\tau^{2}=0.00, I^{2}=94.80 \%, H^{2}=19.21$

Test of $\theta_{i}=\theta_{j}: Q(10)=27.86, p=0.00$

Test of group differences: $Q_{b}(1)=4.16, p=0.04$
$-0.050[-0.070,-0.029] 10.54$

$-0.071[-0.087,-0.054] 10.63$

$-0.078[-0.105,-0.051] 10.36$

$-0.080[-0.101,-0.059] 10.52$

$0.000[-0.070,0.070] \quad 8.57$

$-0.059[-0.101,-0.017] 9.86$

$-0.051[-0.108,0.006] \quad 9.17$

$-0.067[-0.101,-0.033] 10.16$

$-0.064[-0.080,-0.048]$

$-0.124[-0.194,-0.055]$

8.60

$-0.150[-0.270,-0.030]$

6.11

$-0.330[-0.465,-0.195]$

5.48

$-0.192[-0.315,-0.070]$

$-0.084[-0.130,-0.039]$

Random-effects Sidik-Jonkman model 
Table 1 Details of studies included in meta-analyses

\begin{tabular}{|c|c|c|c|c|c|c|c|}
\hline Study & Survey & $\begin{array}{l}\text { Utility } \\
\text { instrument }\end{array}$ & $\begin{array}{l}\text { Country of } \\
\text { preference } \\
\text { weights }\end{array}$ & Sample size & Mean age & $\begin{array}{l}\text { Proportion } \\
\text { of males }\end{array}$ & Published utility values \\
\hline $\begin{array}{l}\text { Kortt and } \\
\text { Clarke } 2005\end{array}$ & $\begin{array}{l}1995 \text { Australian } \\
\text { National Health } \\
\text { Survey (NHS) }\end{array}$ & SF-6D & UK & 12,661 & 41.5 years & $50.70 \%$ & $\begin{array}{l}\text { Mean utility decrement } \\
\text { per unit BMI } \\
\text { Male }=-0.0024 \\
\text { Female }=-0.0034\end{array}$ \\
\hline $\begin{array}{l}\text { Kortt and } \\
\text { Dollery } 2011\end{array}$ & $\begin{array}{l}\text { House-hold, Income } \\
\text { and Labour Dynamics } \\
\text { in Australia (HILDA) } \\
\text { Survey in } 2007 \text { and } \\
2009 \text { (combined } \\
\text { cohort) }\end{array}$ & SF-6D & UK & 16,488 & $\begin{array}{l}\text { Male: } \\
44.03 \text { years } \\
\text { Female: } \\
44.96 \text { years }\end{array}$ & $49.92 \%$ & $\begin{array}{l}\text { Mean utility change } \\
\text { Overweight: } \\
\text { Male }=0.0007 \\
\text { Female }=0.0022 \\
\text { All Obesity: } \\
\text { Male }=-0.0102 \\
\text { Female }=-0.0192\end{array}$ \\
\hline $\begin{array}{l}\text { Norman et } \\
\text { al } 2013\end{array}$ & $\begin{array}{l}\text { Wave } 9 \text { of HILDA } \\
\text { survey } 2009 / 10\end{array}$ & SF-6D & UK & 10,882 & 45.7 years & $46.7 \%$ & $\begin{array}{l}\text { Mean utility value for: } \\
\text { Healthy weight: } 0.782 \\
\text { Overweight: } 0.768 \\
\text { Obesity class 1: } 0.748 \\
\text { Obesity class } 2: 0.740 \\
\text { Obesity class 3: } 0.700\end{array}$ \\
\hline $\begin{array}{l}\text { Kanesarajah } \\
\text { et al } 2017\end{array}$ & $\begin{array}{l}7 \text { waves of data from } \\
3 \text { separate cohorts of } \\
\text { women in the } \\
\text { Australian } \\
\text { Longitudinal Study on } \\
\text { Womens Health }\end{array}$ & SF-6D & UK & $\begin{array}{l}\text { Young cohort } \\
\mathrm{n}=13772 \\
\text { Mid-age } \\
\text { cohort } \\
\mathrm{n}=12792 \\
\text { Older cohort } \\
\mathrm{n}=9972\end{array}$ & $\begin{array}{l}\text { Baseline: } \\
\text { Young cohort } \\
=20.7 \text { years } \\
\text { Mid-age } \\
\text { cohort } \\
=47.6 \text { years } \\
\text { Older cohort } \\
=72.6 \text { years }\end{array}$ & $\begin{array}{l}0 \% \text { (female } \\
\text { only study) }\end{array}$ & $\begin{array}{l}\text { Mean utility change } \\
\text { Overweight: } \\
\text { Young cohort }=-0.010 \\
\text { Mid age cohort }=-0.020 \\
\text { Older cohort= }-0.018 \\
\text { All Obesity: } \\
\text { Young cohort }=-0.038 \\
\text { Mid age cohort }=-0.057 \\
\text { Older cohort }=-0.059\end{array}$ \\
\hline
\end{tabular}




\begin{tabular}{|c|c|c|c|c|c|c|c|}
\hline $\begin{array}{l}\text { Baxter et al } \\
2015\end{array}$ & $\begin{array}{l}\text { Sample of randomly } \\
\text { selected public service } \\
\text { employees in } \\
\text { Australia, compared to } \\
\text { nationally } \\
\text { representative sample } \\
\text { (HILDA) in } 2010\end{array}$ & SF-6D & UK & $\begin{array}{l}\begin{array}{l}\text { Public } \\
\text { sample } \\
\mathrm{n}=3408\end{array} \\
\text { HILDA } \\
\text { survey } \\
\mathrm{n}=11234\end{array}$ & $\begin{array}{l}\text { Public } \\
\text { sample: } \\
\text { males } \\
=45.7 \text { years } \\
\text { females } \\
=44.5 \text { years } \\
\text { HILDA: not } \\
\text { reported }\end{array}$ & $\begin{array}{l}\text { Public } \\
\text { service } \\
\text { employees: } \\
28.29 \% \\
\text { HILDA: } \\
52.19 \%\end{array}$ & $\begin{array}{l}\text { Mean utility values for: } \\
\text { Female Public sample } \\
\text { Healthy weight: } 0.782 \\
\text { Overweight: } 0.776 \\
\text { Obesity class 1: } 0.753 \\
\text { Obesity class } 2: 0.739 \\
\text { Obesity class 3: } 0.723 \\
\text { Female HILDA sample } \\
\text { Healthy weight: } 0.786 \\
\text { Overweight: } 0.774 \\
\text { Obesity class 1: } 0.764 \\
\text { Obesity class 2: } 0.740 \\
\text { Obesity class 3: } 0.719 \\
\text { Male Public sample } \\
\text { Healthy weight:0.806 } \\
\text { Overweight: } 0.792 \\
\text { Obesity class 1: } 0.769 \\
\text { Obesity class } 2: 0.742 \\
\text { Obesity class 3: } 0.806 \\
\text { Male HILDA sample } \\
\text { Healthy weight: } 0.797 \\
\text { Overweight: } 0.797 \\
\text { Obesity class 1: } 0.785 \\
\text { Obesity Class } 2: 0.750 \\
\text { Obesity class 3: } 0.746\end{array}$ \\
\hline Le et al 2019 & $\begin{array}{l}2015+2016 \text { South } \\
\text { Australian Health } \\
\text { Omnibus survey }\end{array}$ & SF-6D & UK & 5609 & 48.8 years & $39.95 \%$ & $\begin{array}{l}\text { Mean utility decrement } \\
\text { Overweight/Obesity: } \\
-0.02\end{array}$ \\
\hline $\begin{array}{l}\text { Clemens et } \\
\text { al } 2014\end{array}$ & $\begin{array}{l}2011 \text { Queensland } \\
\text { Health status survey }\end{array}$ & EQ-5D-3L & Australia & 5555 & Not reported & $42.1 \%$ & $\begin{array}{l}\text { Mean utility values for: } \\
\text { Healthy weight: } 0.89 \\
\text { Overweight: } 0.87 \\
\text { All obesity: } 0.83\end{array}$ \\
\hline
\end{tabular}




\begin{tabular}{|c|c|c|c|c|c|c|c|}
\hline $\begin{array}{l}\text { Hawthorne } \\
2009\end{array}$ & $\begin{array}{l}\text { 2004 South Australian } \\
\text { Health Omnibus } \\
\text { survey }\end{array}$ & AQOL-8 & Australia & 3015 & 45 years & $\begin{array}{l}\text { Not } \\
\text { reported }\end{array}$ & $\begin{array}{l}\text { Mean utility values per } \\
\text { weight category } \\
\text { Healthy/overweight: } \\
0.83 \\
\text { All Obesity: } 0.78\end{array}$ \\
\hline $\begin{array}{l}\text { Hawthorne } \\
\text { et al } 2013\end{array}$ & $\begin{array}{l}2007 \text { Australian } \\
\text { National survey for } \\
\text { Mental Health and } \\
\text { wellbeing }\end{array}$ & AQOL & Australia & 8659 & 46.4 years & $45.8 \%$ & $\begin{array}{l}\text { Mean utility values per } \\
\text { weight category } \\
\text { Healthy weight: } 0.84 \\
\text { Overweight: } 0.82 \\
\text { All obesity: } 0.77\end{array}$ \\
\hline $\begin{array}{l}\text { Heard et al } \\
2017\end{array}$ & $\begin{array}{l}\text { Sample from } \\
\text { Queensland and South } \\
\text { Australia participating } \\
\text { in an online survey } \\
\text { from study looking } \\
\text { into publics priority } \\
\text { setting preferences }\end{array}$ & AQOL & Australia & 1994 & 46.6 years & $48.35 \%$ & $\begin{array}{l}\text { Mean utility decrement } \\
\text { per weight category } \\
\text { Overweight: } \\
\text { Female: }-0.05 \\
\text { Male: }-0.06 \\
\text { All obesity: } \\
\text { Female: }-0.14 \\
\text { Male: }-0.15\end{array}$ \\
\hline $\begin{array}{l}\text { Wang et al } \\
2018\end{array}$ & $\begin{array}{l}\text { Sydney Memory and } \\
\text { Ageing study }\end{array}$ & AQOL-6D & Australia & $\begin{array}{l}\text { Baseline } \\
\text { sample 926 } \\
\text { (wave 1) and } \\
\text { a 2-year } \\
\text { follow up } \\
\text { sample of } \\
751 \text { (wave 2) }\end{array}$ & $\begin{array}{l}\text { Wave 1: } 78.7 \\
\text { years } \\
\text { Wave 2: } 80.1 \\
\text { years }\end{array}$ & $\begin{array}{l}\text { Wave } 1 \\
44.5 \% \\
\text { Wave } 2 \\
44.3 \%\end{array}$ & $\begin{array}{l}\text { Mean utility decrement } \\
\text { per unit BMI } \\
\text { Wave 1: - } 0.04 \\
\text { Wave 2: }-0.05\end{array}$ \\
\hline
\end{tabular}


Table 2 Results of random effects meta-regression of factors potentially influencing utility decrements for each weight category

\begin{tabular}{|c|c|c|c|}
\hline $\begin{array}{l}\text { Weight } \\
\text { category }\end{array}$ & Variable & Coefficient (95\% CI) & $p$ value \\
\hline \multirow[t]{6}{*}{ Overweight } & Constant & $-0.48(-3.81,2.86)$ & 0.78 \\
\hline & MAUI & & \\
\hline & SF-6D & Referent & \\
\hline & AQoL & $-0.032(-0.052,-0.012)$ & 0.001 \\
\hline & EQ-5D-3L & $-0.011(-0.059), 0.036$ & 0.64 \\
\hline & $\begin{array}{l}\text { Year of data } \\
\text { collection }\end{array}$ & $\begin{array}{l}0.00023(-0.0014 \\
0.0019)\end{array}$ & 0.78 \\
\hline \multirow[t]{6}{*}{ All Obesity } & Constant & $0.4118233(-7.55,8.37)$ & 0.919 \\
\hline & MAUI & & \\
\hline & SF-6D & Referent & \\
\hline & AQoL & $-0.061(-0.11,-0.0088)$ & 0.022 \\
\hline & EQ-5D-3L & $-0.032(-0.13,0.063)$ & 0.503 \\
\hline & $\begin{array}{l}\text { Year of data } \\
\text { collection }\end{array}$ & $\begin{array}{l}-0.00022(-0.0042, \\
0.0038)\end{array}$ & 0.914 \\
\hline \multirow{5}{*}{$\begin{array}{l}\text { Obesity class } \\
1\end{array}$} & Constant & $-0.85(-8.47,6.77)$ & 0.83 \\
\hline & MAUI & & \\
\hline & SF-6D & Referent & \\
\hline & AQoL & $-0.081(-0.14,-0.021)$ & 0.008 \\
\hline & $\begin{array}{l}\text { Year of data } \\
\text { collection }\end{array}$ & $\begin{array}{l}0.00041(-0.0034 \\
0.0042)\end{array}$ & 0.83 \\
\hline \multirow{5}{*}{$\begin{array}{l}\text { Obesity class } \\
2\end{array}$} & Constant & $-0.41(-11.71,10.88)$ & 0.94 \\
\hline & MAUI & & \\
\hline & SF-6D & Referent & \\
\hline & AQoL & $-0.12(-0.21,-0.028)$ & 0.010 \\
\hline & $\begin{array}{l}\text { Year of data } \\
\text { collection }\end{array}$ & $\begin{array}{l}0.00018(-0.0055 \\
0.0058)\end{array}$ & 0.95 \\
\hline \multirow{5}{*}{$\begin{array}{l}\text { Obesity class } \\
3\end{array}$} & Constant & $-0.83(-12.16,10.50)$ & 0.89 \\
\hline & MAUI & & \\
\hline & SF-6D & Referent & \\
\hline & AQoL & $-0.12(-0.21,-0.032)$ & 0.008 \\
\hline & $\begin{array}{l}\text { Year of data } \\
\text { collection }\end{array}$ & $\begin{array}{l}0.00038(-0.0053 \\
0.0060)\end{array}$ & 0.90 \\
\hline
\end{tabular}

*Between-study variability $\operatorname{tau}^{2}$ estimate overweight $=0.00029$, all obesity $=0.0013$, obesity class $1=0.0012$, obesity class $2=0.00263$, obesity class $3=0.002525$ 
Table 3 Sensitivity Analysis results- Meta-analyses repeated with exclusion of Wang et al 2018 study

\begin{tabular}{|c|c|c|c|c|}
\hline $\begin{array}{l}\text { Weight } \\
\text { category }\end{array}$ & $\begin{array}{l}\text { Synthesised } \\
\text { mean utility } \\
\text { decrements } \\
(95 \% \text { CI }) \\
\text { including } \\
\text { Wang et al } \\
2018\end{array}$ & $\begin{array}{l}\text { Synthesised mean } \\
\text { utility decrement } \\
\text { (95\% CI) } \\
\text { excluding Wang } \\
\text { et al } 2018\end{array}$ & $\begin{array}{l}\text { Heterogeneity } \\
\left(\mathbf{I}^{2}\right) \text { including } \\
\text { Wang et al } \\
2018\end{array}$ & $\begin{array}{l}\text { Heterogeneity } \\
\left(I^{2}\right) \text { excluding } \\
\text { Wang et al } \\
2018\end{array}$ \\
\hline Overweight & $\begin{array}{l}0.020 \\
(0.030,0.010)\end{array}$ & $0.015(0.021,0.009)$ & $94.43 \%$ & $86.09 \%$ \\
\hline Obesity class 1 & $\begin{array}{l}0.047(0.077 \\
0.017)\end{array}$ & $0.031(0.039,0.022)$ & $97.86 \%$ & $73.13 \%$ \\
\hline Obesity class 2 & $\begin{array}{l}0.072(0.116, \\
0.028)\end{array}$ & $0.047(0.057,0.037)$ & $97.49 \%$ & $53.46 \%$ \\
\hline Obesity class 3 & $\begin{array}{l}0.084(0.130, \\
0.039)\end{array}$ & $0.066(0.085,0.047)$ & $94.80 \%$ & $69.97 \%$ \\
\hline
\end{tabular}




\section{PRISMA 2009 Checklist}

\begin{tabular}{|c|c|c|c|}
\hline Section/topic & $\#$ & Checklist item & $\begin{array}{l}\text { Reported } \\
\text { on page \# }\end{array}$ \\
\hline \multicolumn{4}{|l|}{ TITLE } \\
\hline Title & 1 & Identify the report as a systematic review, meta-analysis, or both. & 1 \\
\hline \multicolumn{4}{|l|}{ ABSTRACT } \\
\hline Structured summary & 2 & $\begin{array}{l}\text { Provide a structured summary including, as applicable: background; objectives; data sources; study eligibility criteria, } \\
\text { participants, and interventions; study appraisal and synthesis methods; results; limitations; conclusions and } \\
\text { implications of key findings; systematic review registration number. }\end{array}$ & 3 \\
\hline \multicolumn{4}{|l|}{ INTRODUCTION } \\
\hline Rationale & 3 & Describe the rationale for the review in the context of what is already known. & $5-6$ \\
\hline Objectives & 4 & $\begin{array}{l}\text { Provide an explicit statement of questions being addressed with reference to participants, interventions, comparisons, } \\
\text { outcomes, and study design (PICOS). }\end{array}$ & 6,8 \\
\hline \multicolumn{4}{|l|}{ METHODS } \\
\hline Protocol and registration & 5 & $\begin{array}{l}\text { Indicate if a review protocol exists, if and where it can be accessed (e.g., Web address), and, if available, provide } \\
\text { registration information including registration number. }\end{array}$ & 7 \\
\hline Eligibility criteria & 6 & $\begin{array}{l}\text { Specify study characteristics (e.g., PICOS, length of follow-up) and report characteristics (e.g., years considered, } \\
\text { language, publication status) used as criteria for eligibility, giving rationale. }\end{array}$ & 8 \\
\hline Information sources & 7 & $\begin{array}{l}\text { Describe all information sources (e.g., databases with dates of coverage, contact with study authors to identify } \\
\text { additional studies) in the search and date last searched. }\end{array}$ & 7 \\
\hline Search & 8 & $\begin{array}{l}\text { Present full electronic search strategy for at least one database, including any limits used, such that it could be } \\
\text { repeated. }\end{array}$ & Appendix \\
\hline Study selection & 9 & $\begin{array}{l}\text { State the process for selecting studies (i.e., screening, eligibility, included in systematic review, and, if applicable, } \\
\text { included in the meta-analysis). }\end{array}$ & 8, Fig 1 \\
\hline Data collection process & 10 & $\begin{array}{l}\text { Describe method of data extraction from reports (e.g., piloted forms, independently, in duplicate) and any processes } \\
\text { for obtaining and confirming data from investigators. }\end{array}$ & $8-9$ \\
\hline Data items & 11 & $\begin{array}{l}\text { List and define all variables for which data were sought (e.g., PICOS, funding sources) and any assumptions and } \\
\text { simplifications made. }\end{array}$ & NA \\
\hline $\begin{array}{l}\text { Risk of bias in individual } \\
\text { studies }\end{array}$ & 12 & $\begin{array}{l}\text { Describe methods used for assessing risk of bias of individual studies (including specification of whether this was } \\
\text { done at the study or outcome level), and how this information is to be used in any data synthesis. }\end{array}$ & 9 \\
\hline Summary measures & 13 & State the principal summary measures (e.g., risk ratio, difference in means). & $9-10$ \\
\hline Synthesis of results & 14 & $\begin{array}{l}\text { Describe the methods of handling data and combining results of studies, if done, including measures of consistency } \\
\left(e . g ., I^{2}\right) \text { for each meta-analysis. }\end{array}$ & $9-10$ \\
\hline
\end{tabular}




\begin{tabular}{|c|c|c|c|}
\hline Section/topic & $\#$ & Checklist item & $\begin{array}{l}\text { Reported } \\
\text { on page \# }\end{array}$ \\
\hline Risk of bias across studies & 15 & $\begin{array}{l}\text { Specify any assessment of risk of bias that may affect the cumulative evidence (e.g., publication bias, selective } \\
\text { reporting within studies). }\end{array}$ & \\
\hline Additional analyses & 16 & $\begin{array}{l}\text { Describe methods of additional analyses (e.g., sensitivity or subgroup analyses, meta-regression), if done, indicating } \\
\text { which were pre-specified. }\end{array}$ & $10-11$ \\
\hline \multicolumn{4}{|l|}{ RESULTS } \\
\hline Study selection & 17 & $\begin{array}{l}\text { Give numbers of studies screened, assessed for eligibility, and included in the review, with reasons for exclusions at } \\
\text { each stage, ideally with a flow diagram. }\end{array}$ & 11, Fig 1 \\
\hline Study characteristics & 18 & $\begin{array}{l}\text { For each study, present characteristics for which data were extracted (e.g., study size, PICOS, follow-up period) and } \\
\text { provide the citations. }\end{array}$ & Table 1 \\
\hline Risk of bias within studies & 19 & Present data on risk of bias of each study and, if available, any outcome level assessment (see item 12). & 12 \\
\hline Results of individual studies & 20 & $\begin{array}{l}\text { For all outcomes considered (benefits or harms), present, for each study: (a) simple summary data for each } \\
\text { intervention group (b) effect estimates and confidence intervals, ideally with a forest plot. }\end{array}$ & $\begin{array}{l}12-13, \\
\text { Fig 2-6 }\end{array}$ \\
\hline Synthesis of results & 21 & Present results of each meta-analysis done, including confidence intervals and measures of consistency. & $\begin{array}{l}\text { 12-13, } \\
\text { Fig 2-6 }\end{array}$ \\
\hline Risk of bias across studies & 22 & Present results of any assessment of risk of bias across studies (see Item 15). & \\
\hline Additional analysis & 23 & Give results of additional analyses, if done (e.g., sensitivity or subgroup analyses, meta-regression [see Item 16]). & $\begin{array}{l}13-14, \\
\text { Tables } 2 \\
\text { and } 3\end{array}$ \\
\hline \multicolumn{4}{|l|}{ DISCUSSION } \\
\hline Summary of evidence & 24 & $\begin{array}{l}\text { Summarize the main findings including the strength of evidence for each main outcome; consider their relevance to } \\
\text { key groups (e.g., healthcare providers, users, and policy makers). }\end{array}$ & 14-16 \\
\hline Limitations & 25 & $\begin{array}{l}\text { Discuss limitations at study and outcome level (e.g., risk of bias), and at review-level (e.g., incomplete retrieval of } \\
\text { identified research, reporting bias). }\end{array}$ & 16 \\
\hline Conclusions & 26 & Provide a general interpretation of the results in the context of other evidence, and implications for future research. & 16 \\
\hline \multicolumn{4}{|l|}{ FUNDING } \\
\hline Funding & 27 & $\begin{array}{l}\text { Describe sources of funding for the systematic review and other support (e.g., supply of data); role of funders for the } \\
\text { systematic review. }\end{array}$ & 2 \\
\hline
\end{tabular}

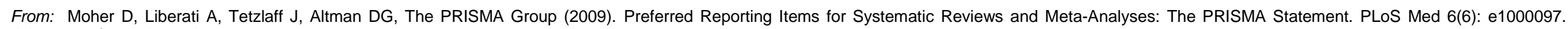
doi:10.1371/journal.pmed1000097 


\section{PRIShy 2009 Checklist}

Page 2 of 2 


\section{Appendix}

Supplementary Figure 1 Search terms for systematic review

1. "Health utilit*" OR "utilit*based" OR "utilit*-based" OR "utility* weight" OR "quality of life" OR QOL OR "health state valu*" OR "standard gamble" OR "Standard Gamble" OR "standard-gamble" OR "time tradeoff" OR "time trade off" OR "time trade-off" OR "multi-attribute utilit*" OR "discrete choice" OR "best worst scal*" OR "best-worst scal*" OR "multi attribute utilit*" OR "EQ-5D*" OR "EQ $5 D^{*}$ " OR "EQ5D" OR "Euroqol" OR "Euro qol" OR hui2 OR "HUI 2" OR hui3 OR "HUI 3" OR "short form survey-6D" OR "short form $6 D$ " OR "SF 6D" OR sf6d OR "assessment of quality of life" OR "AQOL" OR "AQOL-8D" OR "AQOL-6D" OR “AQOL-4D” OR "Quality of Well-Being Scale" OR "Quality of Well Being scale" AND

2. adult* AND

3. "weight status" OR "body mass index" OR obes* OR bmi OR overweight OR adipos* AND

4. Australia* 
Supplementary Figure 2 Sensitivity Analysis results- repeating meta-analysis for each weight category by sex

\section{(A) Overweight males}

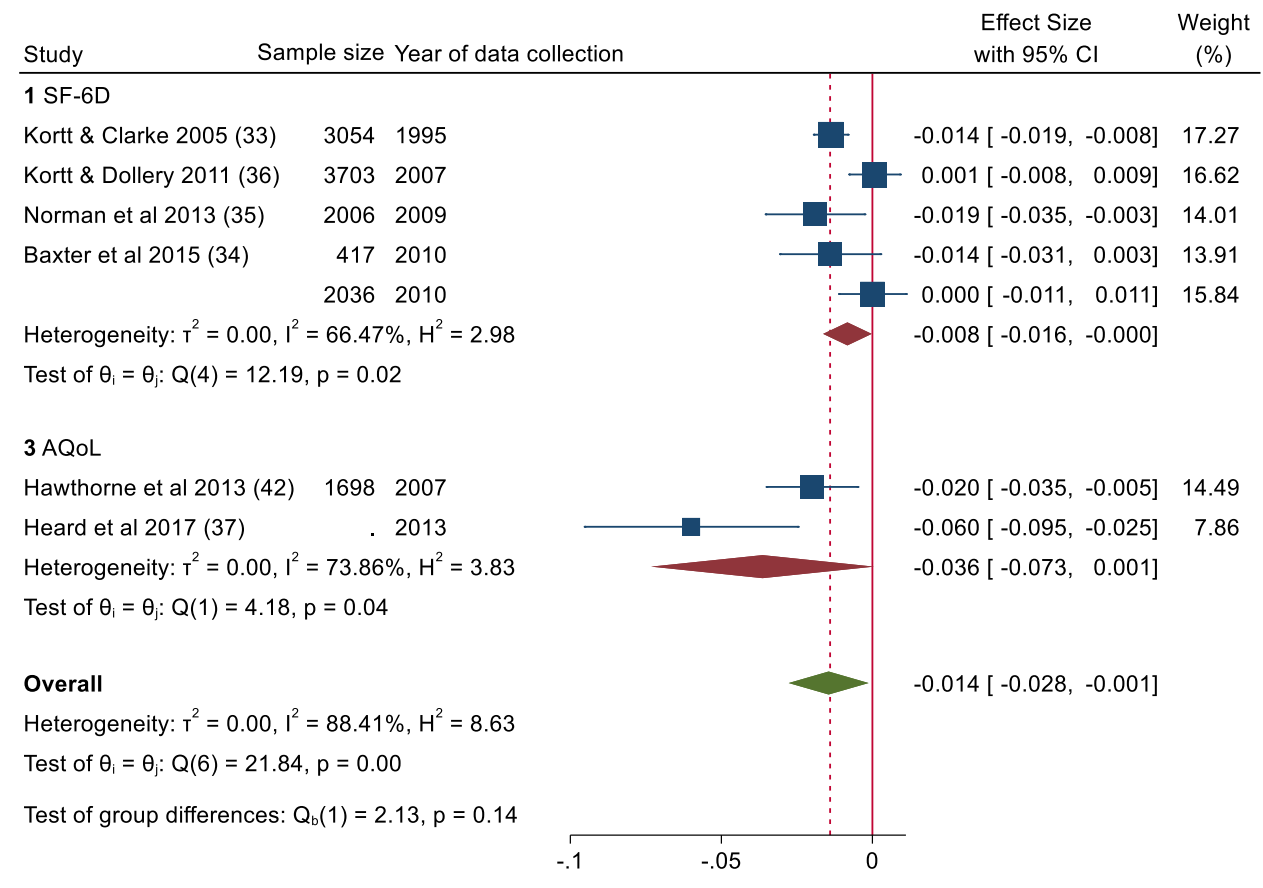

Random-effects Sidik-Jonkman model

\section{(B) Overweight females}

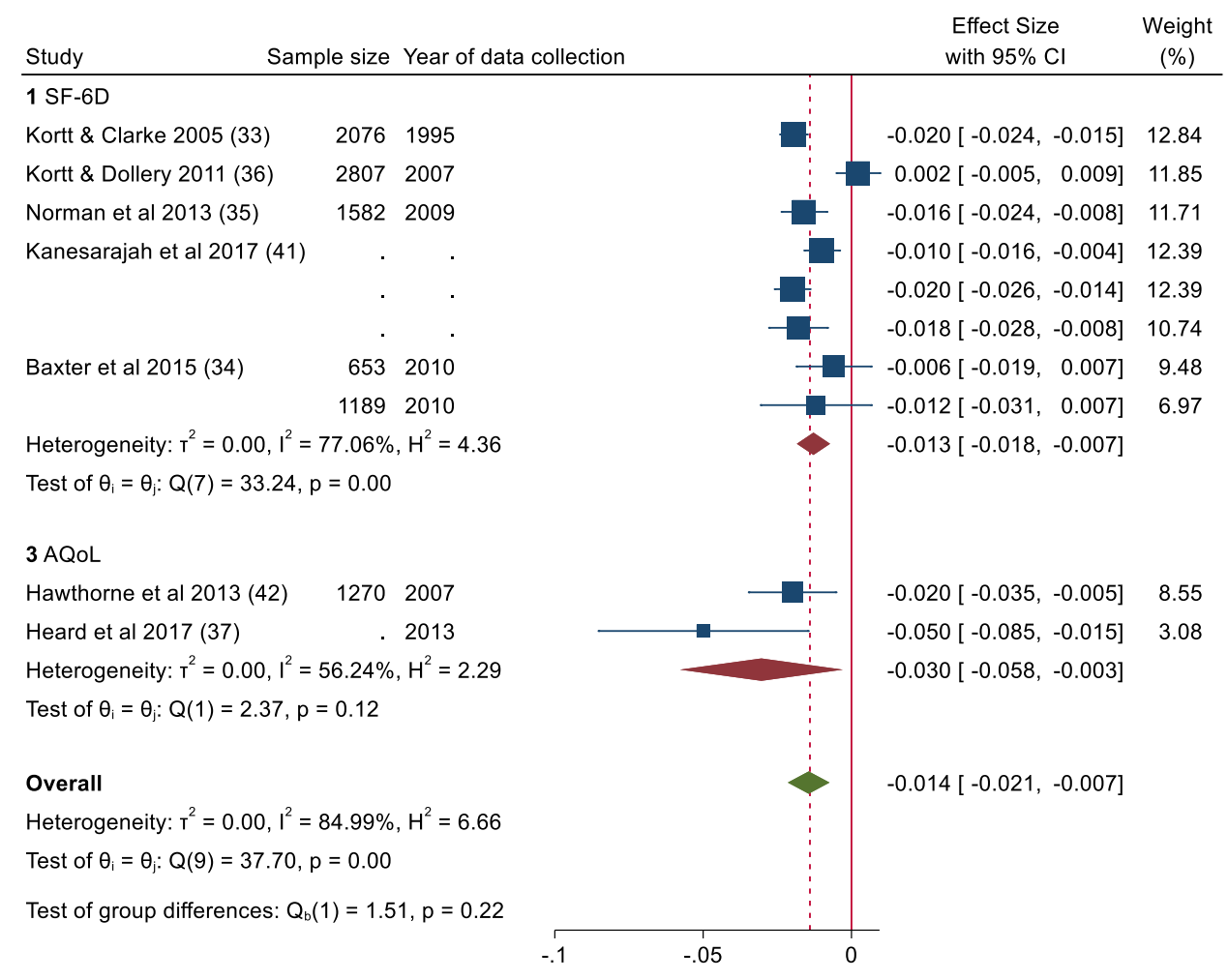

Random-effects Sidik-Jonkman model 


\section{(C) All Obesity male}

\begin{tabular}{|c|c|c|c|c|}
\hline Study & e size Year of data collection & & $\begin{array}{c}\text { Effect Size } \\
\text { with } 95 \% \mathrm{Cl}\end{array}$ & $\begin{array}{c}\text { Weight } \\
(\%)\end{array}$ \\
\hline \multicolumn{5}{|l|}{$1 S F-6 D$} \\
\hline Kortt \& Clarke 2005 (33) & 11861995 & & $-0.038[-0.053,-0.022]$ & 25.81 \\
\hline Kortt \& Dollery 2011 (36) & 24692007 & & $-0.010[-0.019,-0.001]$ & 26.14 \\
\hline \multicolumn{2}{|c|}{ Heterogeneity: $\mathrm{T}^{2}=0.00, \mathrm{I}^{2}=88.26 \%, \mathrm{H}^{2}=8.52$} & & $-0.023[-0.049,0.003]$ & \\
\hline \multicolumn{5}{|c|}{ Test of $\theta_{i}=\theta_{j}: Q(1)=9.16, p=0.00$} \\
\hline \multicolumn{5}{|l|}{$3 \mathrm{AQoL}$} \\
\hline Hawthorne et al 2013 (42) & 7652007 & & $-0.060[-0.081,-0.039]$ & 25.43 \\
\hline Heard et al $2017(37)$ & 2013 & $\square$ & $-0.150[-0.195,-0.105]$ & 22.62 \\
\hline \multicolumn{3}{|c|}{ Heterogeneity: $\mathrm{T}^{2}=0.00, \mathrm{I}^{2}=91.60 \%, \mathrm{H}^{2}=11.91$} & $-0.103[-0.188,-0.017]$ & \\
\hline \multicolumn{5}{|c|}{ Test of $\theta_{i}=\theta_{j}: Q(1)=12.63, p=0.00$} \\
\hline \multicolumn{3}{|l|}{ Overall } & $-0.062[-0.119,-0.004]$ & \\
\hline \multicolumn{5}{|c|}{ Heterogeneity: $\mathrm{T}^{2}=0.00, \mathrm{I}^{2}=97.71 \%, \mathrm{H}^{2}=43.67$} \\
\hline \multicolumn{5}{|c|}{ Test of $\theta_{i}=\theta_{j}: Q(3)=53.41, p=0.00$} \\
\hline \multicolumn{5}{|c|}{ Test of group differences: $Q_{b}(1)=3.03, p=0.08$} \\
\hline & -.2 & -.15 & 0 & \\
\hline
\end{tabular}

Random-effects Sidik-Jonkman model

\section{(D) All Obesity Female}

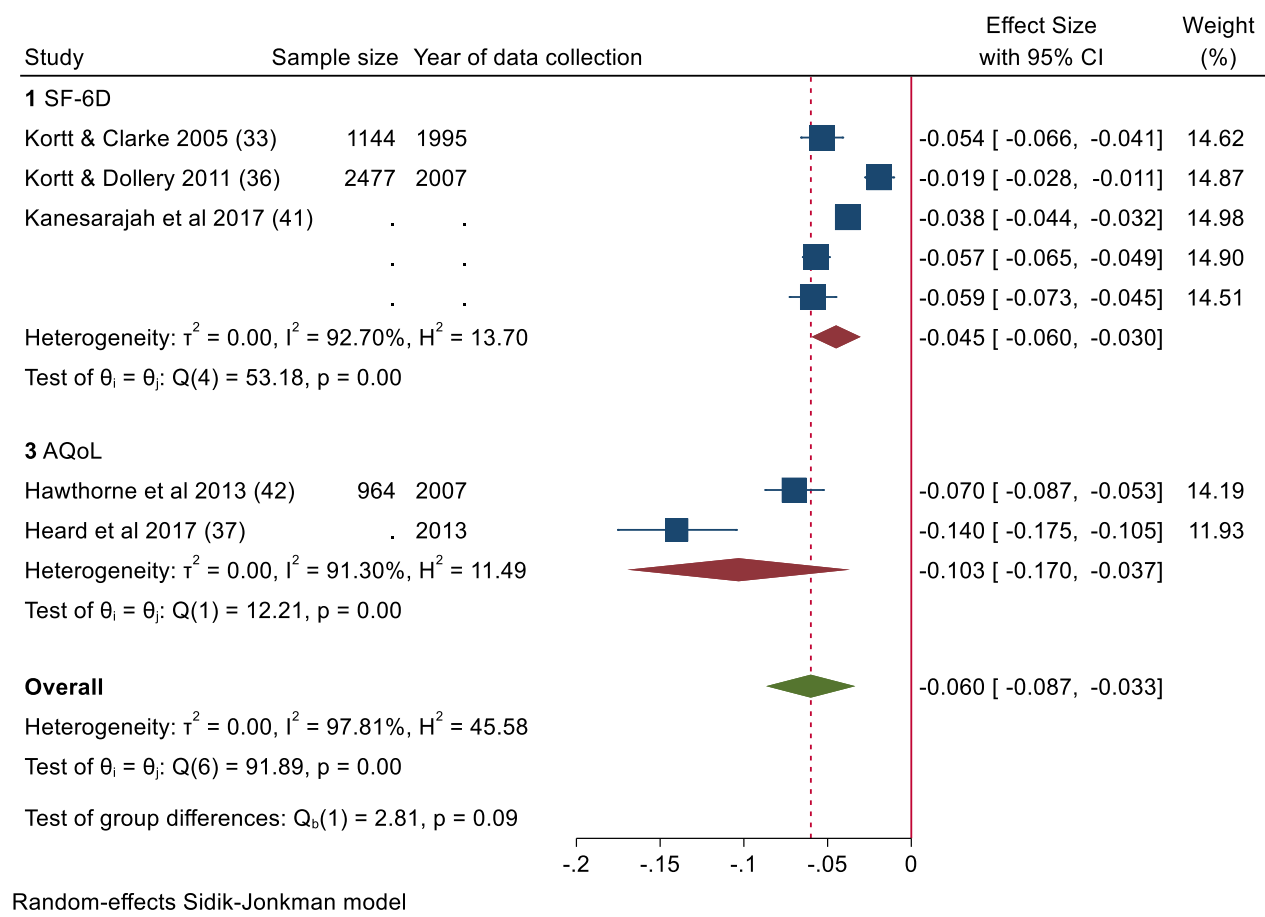


(E) Obesity Class 1 Male

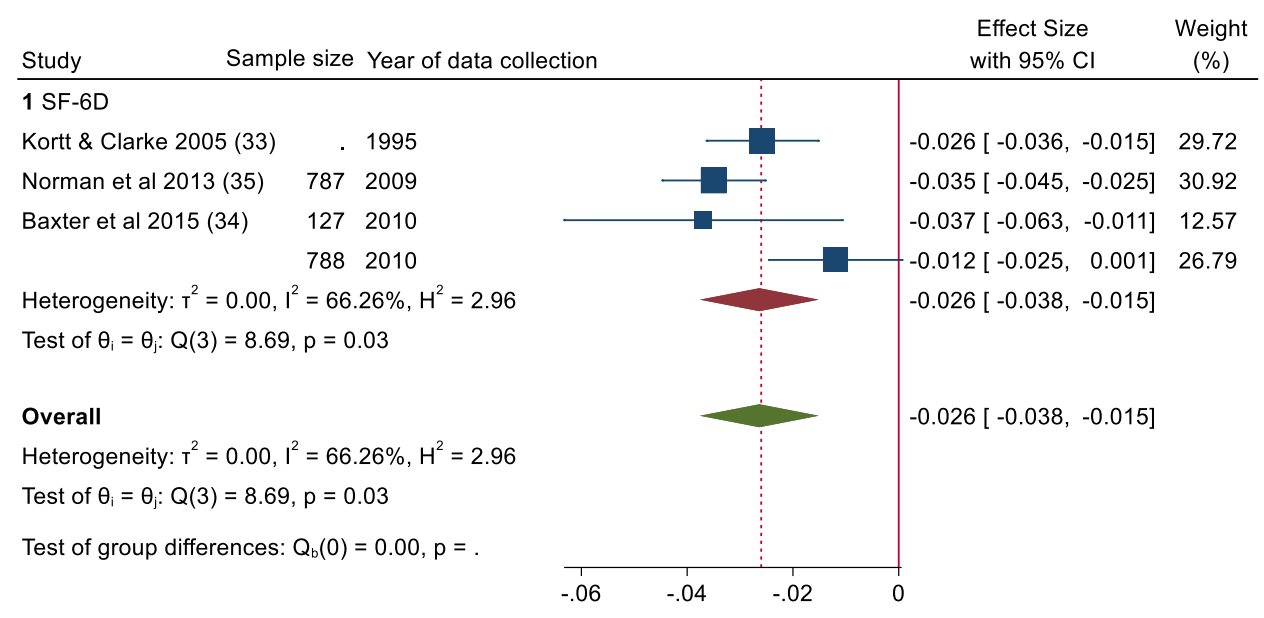

Random-effects Sidik-Jonkman model

(F) Obesity Class 1 Female

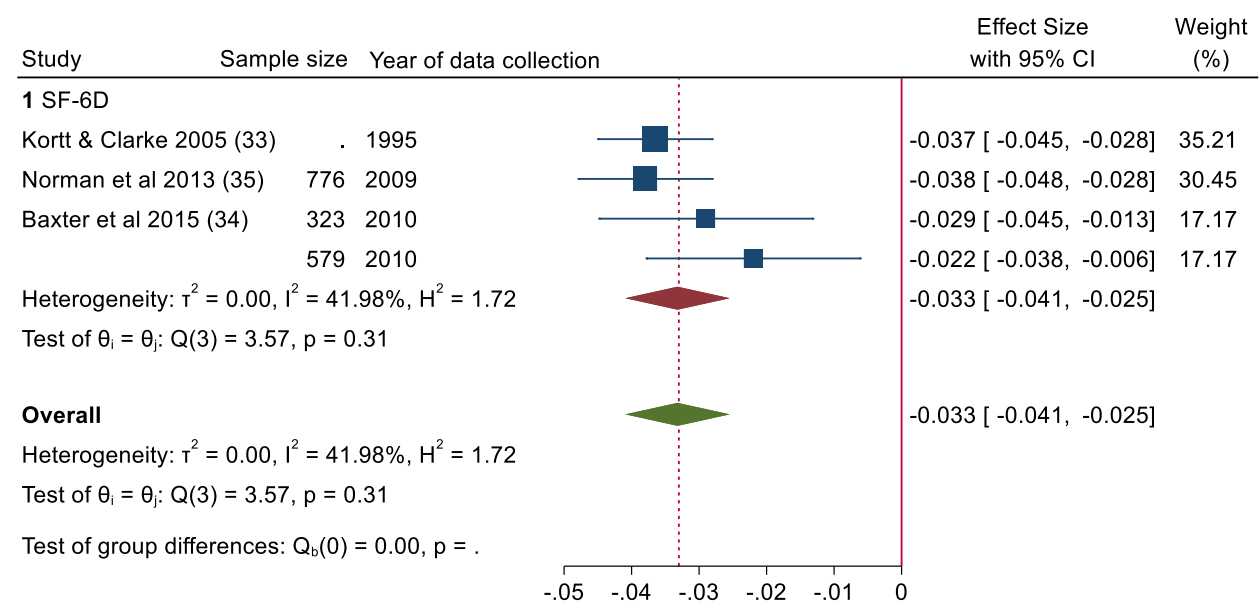

Random-effects Sidik-Jonkman model

(G) Obesity Class 2 Male

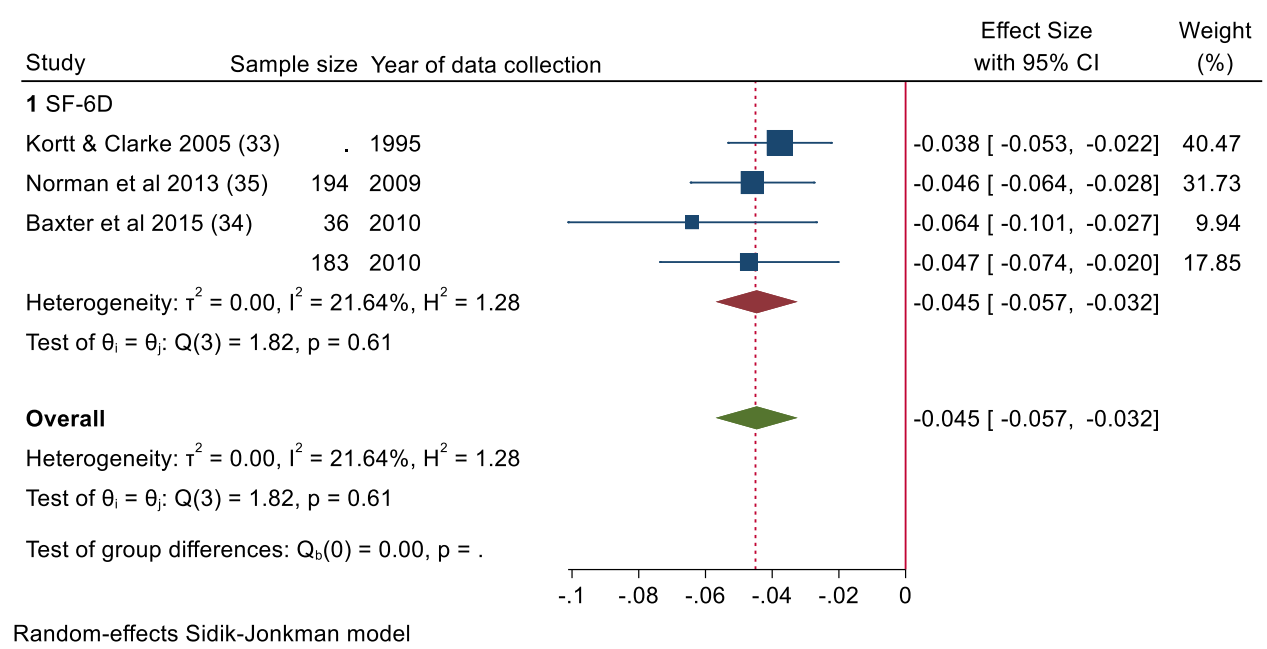


(H)Obesity Class 2 Female

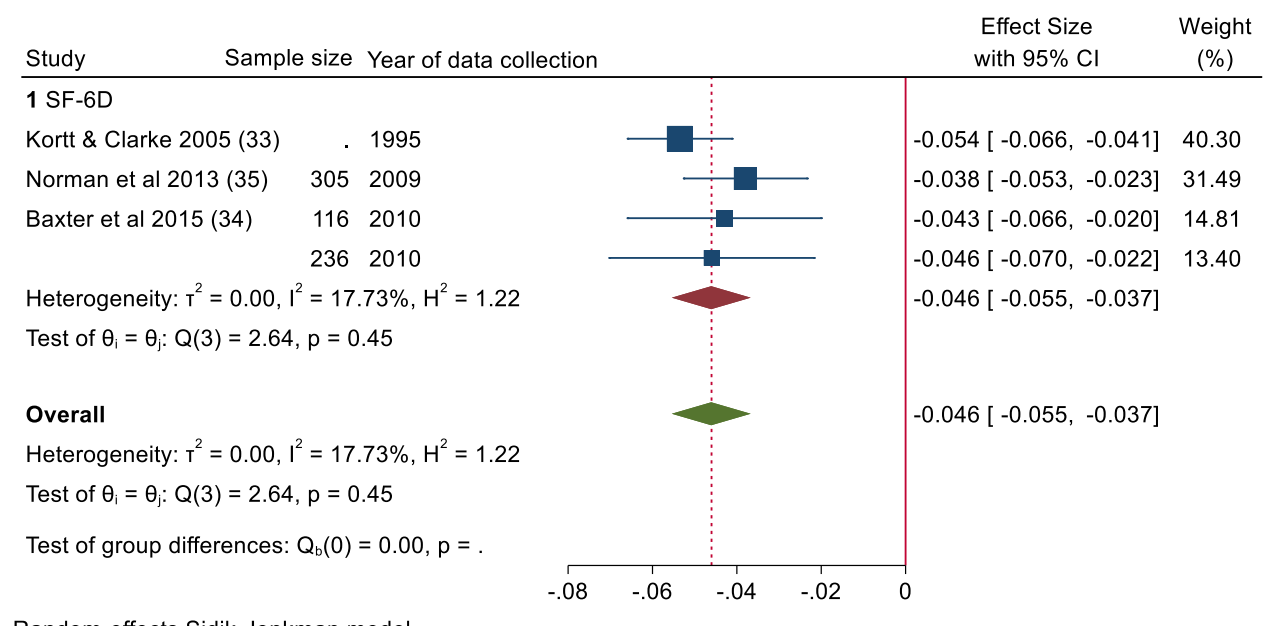

Random-effects Sidik-Jonkman model

\section{(I) Obesity Class 3 Male}

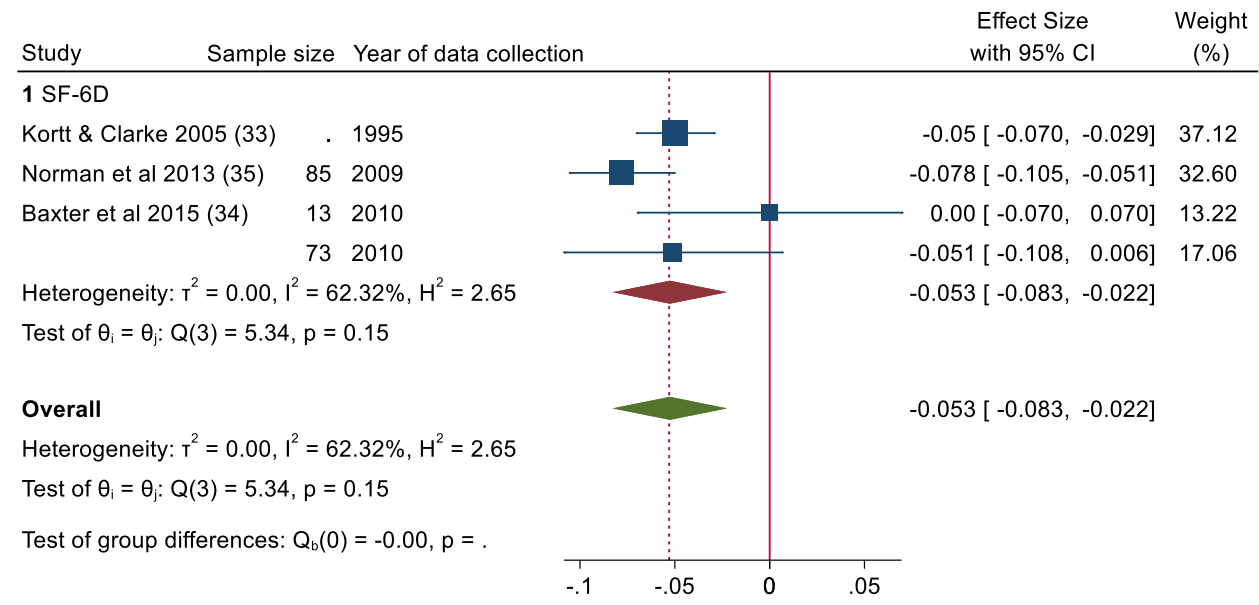

Random-effects Sidik-Jonkman model

\section{(J) Obesity Class 3 Female}

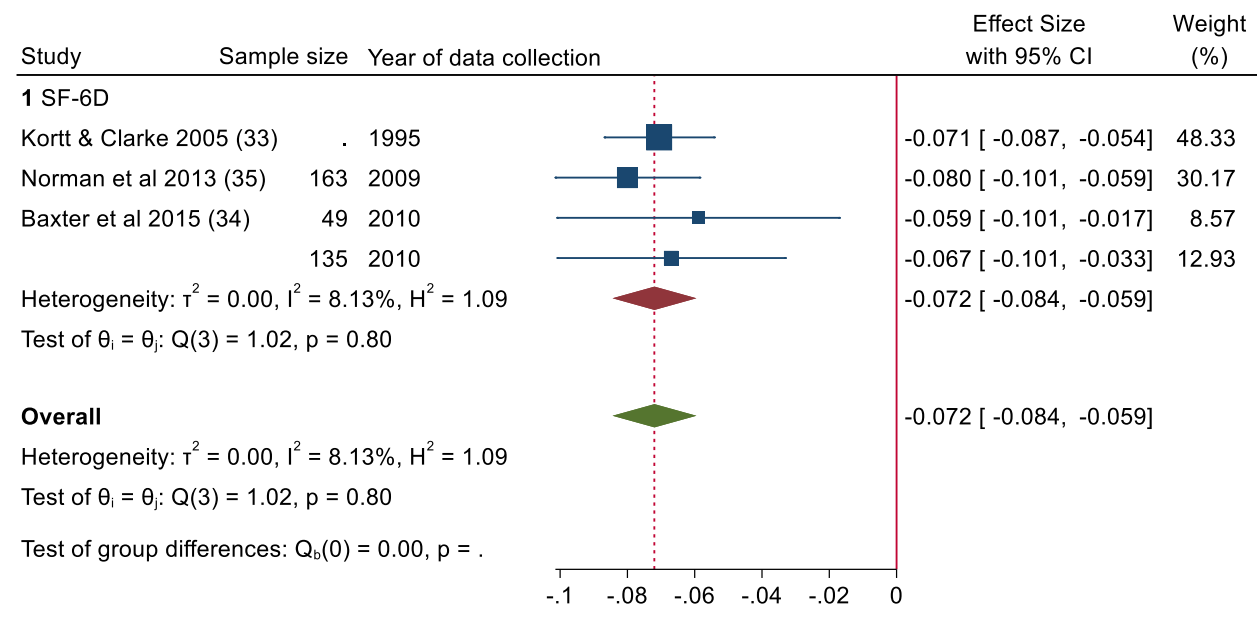

Random-effects Sidik-Jonkman model 